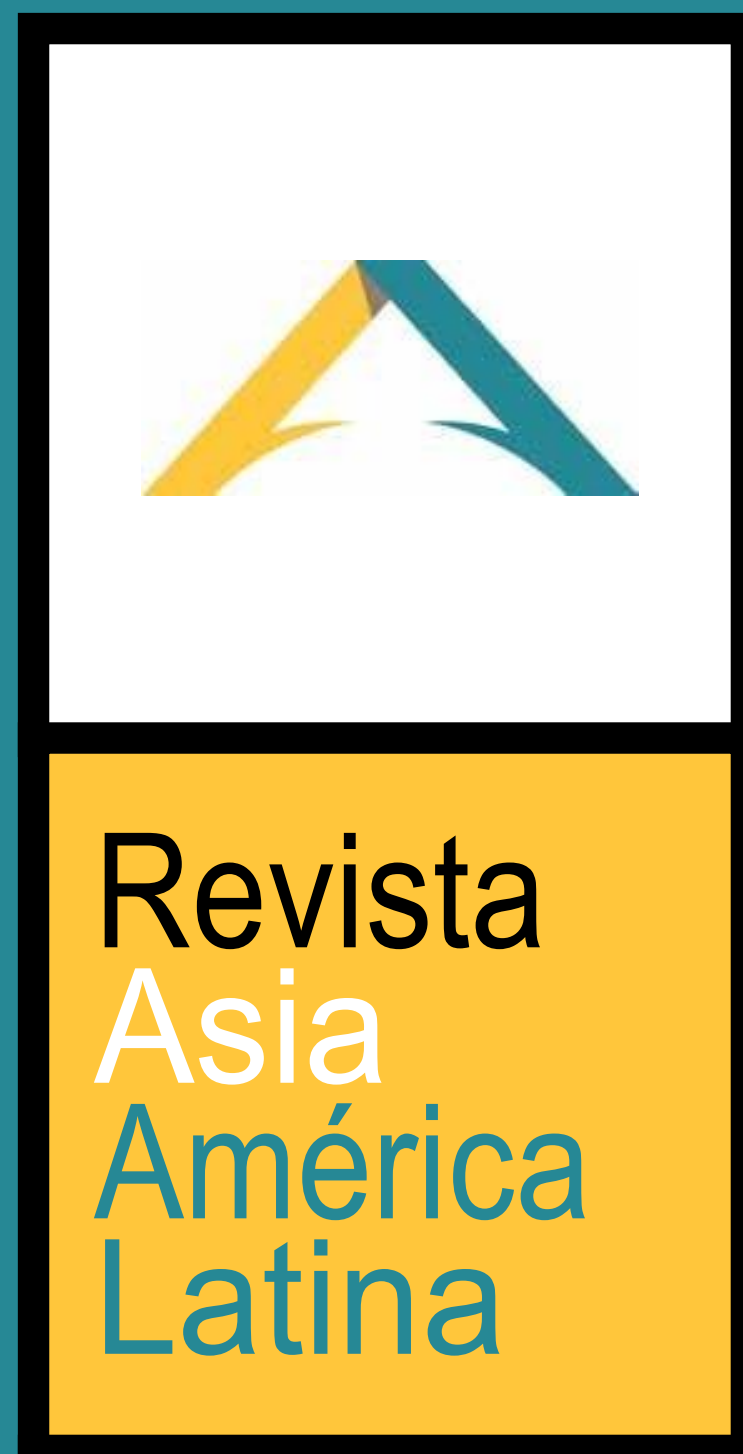

Año 6. Volumen 6. Número 11 OCTUBRE 2021. Argentina

ISSN 2524-9347

Grupo de Estudios sobre Asia y América Latina Instituto de Estudios de América Latina y el Caribe Universidad de Buenos Aires

\section{Contenido}

INTRODUCCIÓN. OTRO AÑO, EL MISMO MUNDO

Fernando Pedrosa y Max Povse

VARIA

REFUGIADOS CAMBOYANOS EN LONGCHAMPS: TRAYECTORIAS DESDE INDOCHINA HASTA ARGENTINA

Laura Puga

\section{TRADUCCIONES}

THE LIBERATIONIST THINKING IN OCEANIA: CARTOGRAPHY OF CIRCULATION OF LATIN AMERICAN IDEAS IN THE SOUTH PACIFIC

Eduardo Devés

\section{WORK IN PROGRESS}

ASEAN: ¿REGLA O EXCEPCIÓN?

Catalina Mas

\section{ENTREVISTAS}

LA DIFICIL TAREA DE LLEVAR LA

DEMOCRACIA A ASIA: UNA ENTREVISTA A ALBERTINA PITERBARG

ACOPIANDO FÓSILES EN MANTAS: UNA ENTREVISTA A PATRICIA EUSTAQUIO PÉREZ

RESEÑAS

GASQUET, AXEL AND GORICA MAJSTOROVIC ED. CULTURAL AND LITERARY DIALOGUES BETWEEN ASIA AND LATIN AMERICA

Chisu Teresa Ko

ÓSCAR HAHN. IMÁGENES NUCLEARES Y OTROS POEMAS

Rebeca Higuera Vidal

MATO, SHIGEKO. LAS VOCES QUE ENTRECRUZAN EL PERÚ Y JAPÓN.
EU
Alba de Diego Pérez de la Torre 


\section{Director}

Dr. Fernando Pedrosa (Universidad de Buenos Aires)

\section{Secretario de Redacción}

Lic. Max Povse (Universidad de Buenos Aires)

\section{Editora de Reseñas}

Dra. Araceli Tinajero (The City College of New York

\section{Equipo de edición}

Dr. Ariel Sribman (Universidad de Girona)

Lic. Alejandro Lamarque (Universidad de Buenos Aires)

Lic. Mariano Statello (Universidad de Buenos Aires)

Lic. Bárbara Turner (Facultad Latinoamericana de Ciencias Sociales)

\section{Comité Editorial}

Dr. Ignacio Bartesaghi (Universidad Católica de Uruguay)

Dr. Daniel Gomá (Universidad de Cantabria)

Dra. Nicole Jenne (Pontificia Universidad Católica de Chile)

Dr. Christopher Lundry (El Colegio de México)

Lic. Ezequiel Ramoneda (Universidad Nacional de La Plata)

\section{Consejo Académico}

Dr. David Doncel Abad (Universidad de Salamanca)

Dra. Mireya Sosa Abella (Universidad de Malasia)

Dra. Mercedes Botto (Facultad Latinoamericana de Ciencias

Sociales) Dr. Nicolás Comini (Universidad del Salvador)

Dra. Pasuree Luesakul (Universidad de Chulalongkorn)

Dr. Carlos Moneta (Universidad de Buenos Aires)

Dra. Zarina Othman (Universidad Nacional de Malasia)

Dra. Cristina Reigadas (Universidad de Buenos Aires)

Dra. Florencia Rubiolo (Universidad Nacional de Córdoba)

Dra. Leonor Seabra (Universidad de Macao)

Dr. Jaime Moreno Tejada (Universidad de Chulalongkorn)

Dr. Ignacio Tredici (Organización de las Naciones Unidas)

Dra. Wasana Wongsurawat (Universidad de Chulalongkorn)

Eudeba

Universidad de Buenos Aires

$1^{\circ}$ edición: junio 2016

() 2016

Editorial Universitaria de Buenos Aires

Sociedad de Economía Mixta

Av. Rivadavia 1571/73 (1033) Ciudad de Buenos Aires

Tel: 4383-8025 / Fax: 4383-2202

www.eudeba.com.ar 


\section{INTRODUCCIÓN. OTRO AÑO, EL MISMO MUNDO \\ INTRODUCTION. ANOTHER YEAR, SAME WORLD}

\section{Fernando Pedrosa}

Grupo de Estudios sobre Asia y América Latina, Universidad de Buenos Aires ferpedrosa@gmail.com

\section{Max Povse}

Grupo de Estudios sobre Asia y América Latina, Universidad de Buenos Aires ferpedrosa@gmail.com

\section{Noticias desde América}

Finaliza otro año agitado en la política global. El recambio presidencial en la Casa Blanca lejos estuvo de apaciguar las relaciones entre las potencias, y las relaciones entre Estados Unidos y la República Popular China siguieron el rumbo de la desconfianza. Los aprontes para los años venideros anuncian tiempos difíciles y no exentos de conflictos. En líneas generales, en la relación con China hubo más continuidades que cambios, lo que refleja también una decisión política norteamericana que trasciende los gobiernos de turno. Por su parte, la retirada norteamericana de Afganistán fue seguida de un reagrupamiento en la zona del Indopacífico, que tuvo en el affaire de los submarinos de propulsión nuclear y la alianza AUKUS un capítulo muy significativo.

Funcionarios importantes de la administración Biden recorrieron numerosas veces la zona, especialmente algunos de los países de la ASEAN y los tradicionales aliados occidentales, como Japón y Corea del Sur. Además de la vicepresidenta Kamala Harris y el secretario de Defensa Lloyd Austin, hace pocos días visitó nuevamente algunos países del Sudeste Asiático el secretario de Estado, Antony Blinken. El objetivo fue organizar reuniones en tres países claves: Indonesia, Malasia y Tailandia, aunque este último debió cancelarse por un caso de COVID-19 en la delegación.

Cuatro iniciativas de Estados Unidos deben mencionarse especialmente, porque representan un posible indicador del tipo de estrategias que se anuncian para hacer frente a este escenario de avance global chino. Primero, se debe mencionar la aprobación en el Senado de una ley que habilita un billonario fondo para inversiones en ciencia y tecnología. Este fondo estaría destinado a contrarrestar las estrategias chinas, sobre todo, apuntando al campo de la innovación tecnológica, y a la relación entre la producción industrial y el mundo de las universidades y la investigación científica. 
En segundo lugar, el boicot parcial a los Juegos Olímpicos de Invierno que se realizarán en China en 2022 puede recordar a un episodio similar en los juegos olímpicos de 1980, organizados entonces en la disuelta Unión de Repúblicas Socialistas Soviéticas. Aquella vez la medida fue mucho más severa que la actualmente propuesta, y se tomó en protesta por la invasión soviética a Afganistán, un momento clave en eso años de la Guerra Fría. Curiosamente, China ofreció un apoyo entusiasta a la propuesta de no concurrir a Moscú, e incluso fue parte de un evento paralelo y alternativo (Liberty Bell Classic) que se realizó en la ciudad de Filadelfia, Estados Unidos.

En esta ocasión, la medida se vincula con la condena a la violación de derechos humanos que, según el informe 2021 de Human Rights Watch, no se ha visto en una escala similar desde la masacre de la Plaza Tiananmén. A diferencia de momentos anteriores, la adhesión entre los gobiernos de países occidentales no parece ser tan estricta. Mientras Australia, Canadá y el Reino Unido adhirieron al boicot, Francia y Alemania se mostraron contrarias a la medida y tratan de arrastrar al resto de la Unión Europea en esa posición. Corea del Sur y Argentina se manifestaron en el mismo sentido que los europeos.

Una tercera medida para destacar en esta tarea de intentar predecir las formas de las futuras relaciones entre las potencias globales fue la sanción en el congreso estadounidense de la flamante Ley de Prevención del Trabajo Forzado Uigur. Esta legislación apunta a poner trabas a productos fabricados con ese tipo trabajo en la Región Autónoma Uigur de Xinjiang, donde abundan las denuncias por las serias violaciones a los derechos humanos que está cometiendo el gobierno chino contra la minoría musulmana.

Finalmente, uno de los hechos más importantes, y que con más atención debemos seguir en el futuro quienes trabajamos en el plano de las ideas y el mundo académico, fue la realización de la Cumbre por la Democracia. Este evento agrupó a políticos y gobernantes de más de 100 países en la búsqueda de estructurar algún tipo de respuesta al avance autoritario a lo largo del mundo. No es posible ahora definir si este espacio y discurso continuará desarrollándose, pero lo que es posible advertir es un inicio de conformación de mejores posiciones para ejercer el poder blando en lo que respecta a la promoción global de la democracia, para enfrentar el activo y vital discurso autoritario y soberanista.

\section{China también mira para adentro}

Mientras tanto, en China el Partido Comunista ha estado dedicado intensamente a consolidar su poder en el plano interno, sobre todo, con vistas al próximo Congreso y la rereelección de su líder, Xi Jinping. Los planes de Xi para perpetuarse en el poder siguen a pie firme, y esto ha venido acompañado por un aumento de la represión interna, haciendo oídos sordos a los reclamos por la 
situación de los derechos humanos en Xinjiang, acelerando la muerte de la democracia en Hong Kong, como también aplicando una mayor censura y persecución de artistas, youtuberos y disidentes.

La aplicación de una nueva ley de protección de datos destinada a empresas tecnológicas puso en jaque a varios gigantes como Didi (una empresa china similar a UBER), ya que apunta a aumentar la capacidad regulatoria del

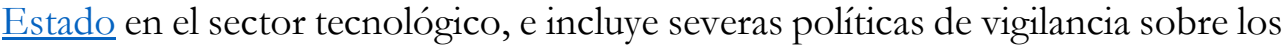
procesos de desarrollo y los softwares de las empresas. Por ejemplo, incluso las empresas y páginas web dedicadas a la educación a distancia ya no podrán recibir financiamiento extranjero.

Otro momento de desgaste para el gobierno chino tuvo lugar con la escandalosa desaparición -y reaparición posterior- de la tenista Peng Shuai, como había sucedido anteriormente con Jack Ma, el fundador del portal Alibaba, posiblemente el hombre más rico de China, y también con la desaparición y posterior condena del presidente de Interpol, Meng Hongwei, en claras demostraciones del modus operandi del régimen para silenciar las voces que le disgustan. Por otra parte, el clima de nacionalismo recargado imperante con motivo del centenario del Partido Comunista también tiene consecuencias hacia afuera, y la sombra de un conflicto definitivo con Taiwán comienza a aparecer con insistencia en la agenda de la política internacional y sus analistas.

\section{E1 mundo en medio de una nueva controla autoritaria}

El conflicto entre ambos gigantes globales se potencia en un mundo que muestra un pronunciado retroceso de los sistemas democráticos, no solamente por rupturas constitucionales, sino también por el deterioro de las instituciones en países que solían ser modelos del funcionamiento democrático. La estela de la pandemia de COVID-19 sigue siendo un telón de fondo para políticas de control y reducción de derechos que, sin embargo, no se mostraron tan eficientes en el Sudeste Asiático para mejorar ni la situación sanitaria ni la económica.

En Asia se puede destacar los casos de India, Malasia, Camboya, y en particular la dramática situación de Myanmar, a poco tiempo de cumplirse un año del golpe de Estado que terminó con el incipiente gobierno democrático asumido en 2016. Este caso es de especial interés para el Grupo de Estudios sobre Asia y América Latina de la Universidad de Buenos Aires. Por ello, hemos dedicado numerosas actividades y debates públicos sobre el fracaso del proceso de democratización y la llegada al poder de una nueva dictadura militar. Lo hemos hecho no solo porque es un caso de interés teórico, sino que al mismo tiempo es parte de muchas de las tendencias que muestra la región, tendencias hemos visto que luego se expanden al resto de los continentes.

Al mismo tiempo, la coyuntura de Myanmar es trascendente porque realza la importancia y la confusión reinante en la comunidad internacional, no 
solo entre los Estados nacionales, sino también en las organizaciones internacionales y trasnacionales de derechos humanos sobre cómo tratar diversos aspectos del retroceso democrático global y el concepto de los derechos humanos en el mundo asiático.

\section{Myanmar, ¿volver al futuro?}

El golpe de Estado del 1 de febrero de 2020 puso fin a una etapa de transición que comenzó a planificarse por los mismos militares en 2003, con la llamada "hoja de ruta para una democracia disciplinada". En 2015 ese proceso dio un paso trascendente con las elecciones generales que llevaron al gobierno a la Liga Nacional para la Democracia, el partido que lideraba (y posiblemente aun lo siga haciendo, aunque en forma limitada por su encarcelamiento) la premio Nobel de la Paz de 1991, Aung San Suu Kyi.

Sin embargo, esta llegada al gobierno no significó un acceso al poder que, en gran medida, se mantuvo en las autoritarias manos del Tatmadaw, palabra con la que se conoce a las poderosas fuerzas armadas birmanas. Por una reforma constitucional previa a la elección, los militares mantuvieron el control de tres ministerios clave (fronteras, interior y guerra), de cuerpos armados y empresas públicas, entre otras instituciones claves del país. Además, continuaban con el control directo del $25 \%$ de los parlamentarios, asignados por la constitución de 2008 a las fuerzas armadas, sin pasar por ningún proceso electoral. Los militares también mantuvieron el control de negocios informales vinculados a la explotación de recursos naturales, como el preciado jade, y el comercio de drogas, particularmente, opioides.

De hecho, es tal el poder de los uniformados, que bloquearon la llegada de Suu Kyi a la presidencia con una artimaña legal, y la líder debió ocupar un cargo creado especialmente a su medida para ocupar la cabeza del gobierno. Así, Suu Kyi se convirtió en la consejera de Estado, la número uno en la práctica, pero sin ser la presidenta, cargo que ocupó nominalmente un dirigente de su partido. La apuesta de Suu Kyi entonces fue por una transición paciente, buscando consolidar la democracia a largo plazo, en una suerte de juego constante de posiciones con los militares. Posiblemente, cierto espíritu budista haya influido en el plan de la informal jefa de Estado, que al mismo tiempo se revelaba como un proyecto pragmático, ya que su endeble posición no le permitía abrigar esperanzas de cambios más profundos, mucho menos a corto plazo.

Lo que quedó claro rápidamente es que los militares no pensaban volver a los cuarteles y la situación de caos étnico que vive el país, con guerrillas y grupos irregulares poblando la larga geografía birmana, dieron argumentos a los uniformados para seguir manteniendo sus espacios de poder, reclamando un estatus especial como los garantes de la integración territorial de Myanmar. De 
aquí se desprenden los ataques del Tatmadaw a los rohinyás -miembros de una minoría musulmana apátrida en Myanmar-, que llevaron el conflicto interno a un terreno que fue catalogado como limpieza étnica por diferentes organizaciones de derechos humanos como Human Rights Watch en su Informe Mundial 2018. Los militares también fueron condenados por espacios de la ONU vinculados a los derechos humanos.

En las estrategias del Tatmadaw para arrasar con las poblaciones rohinyá no solo aparecía un nacionalismo budista extremo y una intención de erosionar el prestigio internacional de Suu Kyi, sino también la apuesta a conectar con una amplia demanda popular de no ceder en esa cuestión, sobre todo, entre los ciudadanos perteneciente a la etnia mayoritaria, los bamar. Suu Kyi pagó un alto costo por las masacres y las persecuciones del Tatmadaw en el estado Rakáin, donde se ubicaban los rohinyá-, más aún, cuando casi un millón de ellos debió abandonar el país y radicarse forzadamente en precarios campos de refugiados en la vecina Bangladesh.

Dos momentos claves erosionaron el poder y la capacidad de operación de Suu Kyi. El primero fue el asesinato de su principal asesor legal y hombre de confianza, el abogado musulmán $\mathrm{Ko} \mathrm{Ni}$ a plena luz del día en el aeropuerto de Yangon, cuando volvía de una cumbre en Indonesia sobre el asunto rohinyá. Nunca se conocieron los verdaderos responsables del hecho, que terminó con la vida de un brillante asesor, el único en ese nivel que no era miembro de la mayoría bamar. El otro momento clave -que determinó el fin de la estrella internacional de Suu Kyi- fue su comparecencia ante el Tribunal Internacional de Justicia de Naciones Unidas en La Haya para defender a su país frente a la acusación de genocidio realizada por Gambia.

\section{Las opciones de Aung San Suu Kyi}

Al mismo tiempo que la crisis rohinyá consumía su crédito internacional, internamente Suu Kyi intentó consolidar el poder de las autoridades democráticas y ganarle, de a poco, terreno a los militares. Apostó, para ello, a reformar la constitución que actuaba como un cerrojo sobre el poder militar. Aunque fracasó en el intento (necesitaba un 75\% del congreso donde el 25\% son legisladores militares designados), la concreción de la iniciativa alertó a los líderes del Tatmadaw. Por ello, el abrumador triunfo electoral del 2020 abrió la puerta para avanzar aún más en esa dirección, y los militares acabaron por derrocarla el mismo día en que iba a asumir su segundo mandato.

En el período de tiempo de su primer gobierno, Suu Kyi no solo debió enfrentar el pode militar. Además, debió también hacerse cargo de las consecuencias del radical cambio de posición de la diplomacia norteamericana con Donald Trump, el abandono de la política activa de Estados Unidos en el país, la creciente intromisión de la vecina China, y la falta de una burocracia 
eficiente para lidiar con la crisis económica, con la pandemia y con la organización de las elecciones generales del año pasado.

Así, Suu Kyi se aferró a la idea de que la democracia era capaz de sobrevivir a cualquier costo, y la tomó como su única estrategia, aunque fuera en las condiciones precarias que el Tatmadaw le imponía. ¿Qué opciones tenía la líder birmana frente a la debilidad de su gobierno? ¿Renunciar e irse a vivir a Londres? ¿Olvidar los trece años de luchas y encierros para quedar bien con la el ala izquierda del Partido Demócrata y la prensa progresista? Las exigencias de las organizaciones internacionales de derechos humanos y la prensa norteamericana y europea sobre Suu Kyi fueron desmedidas, erradas estratégicamente, poco realistas, y la debilitaron fatalmente al ignorar que su posición no le permitía tomar decisiones como las que le reclamaban.

Solo su permanencia en el poder y una sucesión democrática por varios mandatos le hubiera dado a Myanmar chances de recorrer con algún poco optimismo un camino democrático en el largo plazo, un camino que los regímenes políticos predominantes en los países vecinos no permitían esperar con optimismo. El error de diagnóstico de la comunidad internacional le costó muy caro a la transición. Hoy, Myanmar tiene miles de muertos y una represión salvaje que convive con el silencio y la falta de interés de la comunidad internacional por el país y por el destino de la población civil, ahora que la líder ha sido derrocada.

Finalmente, es llamativa la falta de interés por la suerte de los miembros del gobierno derrocado, que han sido juzgados sin ninguna garantía, y abandonados por las organizaciones gubernamentales internacionales y las trasnacionales de derechos humanos, ahora embarcadas en una ingenua revancha sobre la líder birmana por no haberse convertido en Juana de Arco en el altar de la corrección política.

\section{El undécimo número de Asia/AméricaLatina}

En este número, el segundo de nuestro sexto volumen, presentamos una variada compilación de artículos, por lo que recomendamos la lectura a partir de las cinco secciones que publicamos. En primer lugar, en Varia, presentamos el artículo de la geógrafa Laura Puga, el artículo de la geógrafa Laura Puga, quien hizo un análisis de la vida personal y social de los refugiados camboyanos arribados en la Argentina en 1980, con una perspectiva etnográfica que permite comprender los desafíos de la integración de comunidades migrantes que, por un lado, huyen de regímenes genocidas (en este caso, el de los Jemeres Rojos), y por otro, transitan desde el Sudeste Asiático hasta América Latina.

En la sección de Traducciones, publicamos en inglés el artículo del filósofo latinoamericanista chileno Eduardo Devés "El liberacionismo en Oceanía: Una cartografía de circulación de ideas suramericanas en el Pacífico Sur", 
originalmente publicado en la revista Izquierdas. El espacio de traducciones es fundamental para la labor de Asia/AméricaLatina, en la medida en que las traducciones hacia el español abren las puertas a valiosas fuentes para nuestra academia, mientras que las traducciones al idioma inglés permiten proyectar los originales artículos de autores latinoamericanos en la academia global. En este caso, el artículo tiene una relevancia particular, en la medida en que se inscribe en una escueta biblioteca de análisis comparado de las ideas entre Asia y América Latina.

Por su parte, en la sección Work in Progress, tenemos el artículo de la politóloga internacionalista Catalina Mas, que analiza las teorías detrás de las características del funcionamiento -formal e informal- de la ASEAN. La autora testea enfoques comunes a las relaciones internacionales para demostrar la particularidad del proceso de integración del Sudeste Asiático, aportando a una nutrida biblioteca sobre el tema en términos globales, pero que en español es lamentablemente aún muy escueta.

En este número inauguramos la sección Entrevistas, con dos artículos publicados por la redacción de la Revista. En esta ocasión, entrevistamos a Albertina Piterbarg, especialista en materia electoral y funcionaria de las Naciones Unidas, sobre su experiencia como parte de la misión internacional para organizar las primeras elecciones libres de Timor Oriental, en 2008 y 2012. La entrevistada nos cuenta no solo sobre las características institucionales del incipiente país, sino también sobre la vida cotidiana en un país tan poco estudiado desde nuestra región. También dialogamos con Patricia Eustaquio Pérez, una artista plástica filipina que presentó una muestra de tapices tejidos digitalmente en 2020. La artesana nos cuenta sobre las implicancias culturales de su obra, y también sobre la situación de los artistas filipinos en la actualidad.

Por último, en nuestra sección Reseñas, publicamos tres artículos: el primero, un análisis del libro Cultural and Literary Dialogues Between Asia and Latin America, de Axel Gasquet y Gorica Majstorovic, hecho por la lingüista Chisu Teresa Ko, que resalta los importantes debates que se abren en esta compilación. A continuación, la filóloga Rebeca Higuera Vidal analiza el clásico de Óscar Hahn, Imágenes nucleares y otros poemas, mostrando los aspectos universalistas de la poesía latinoamericana, que muchas veces mira al mundo para inspirarse. Finalmente, la hispanista Alba de Diego Pérez de la Torre comparte con nosotros desde la Universidad de Waseda una reseña sobre el libro Las voces que entrecruzan el Perú y Japón, de Shigeko Mato, en la que señala la riqueza de la literatura nikekei en nuestra región. 
VARIA 


\section{REFUGIADOS CAMBOYANOS EN LONGCHAMPS: TRAYECTORIAS DESDE INDOCHINA HASTA ARGENTINA}

\section{CAMBODIAN REFUGEES IN LONGCHAMPS: JOURNEYS FROM INDOCHINA TO ARGENTINA}

\section{Laura Puga \\ Universidad de Buenos Aires \\ lauramapuga@yahoo.com.ar}

Fecha de recepción: 30/04/2021

Fecha de aceptación: 06/07/2021

RESUMEN: Este analiza las trayectorias a un pequeño número de familias de origen camboyano, quienes formaron una comunidad tras asentarse en un barrio del Área Metropolitana de Buenos Aires, en la década de 1980. Procedentes de una zona de conflictos sucesivos y extremadamente violentos, en el norte de Camboya, se convirtieron en refugiados de Naciones Unidas, con acogida en Argentina. Se interpretan algunas violencias de aquel entorno y se pone en diálogo la bibliografía histórica, política y geográfica, con el trabajo de campo etnográfico. También se analiza el contexto particular de recepción, marcado por la última dictadura militar de Argentina.

PALABRAS CLAVE: refugiados camboyanos, trayectorias, comunalización, violencia, dictadura.

ABSTRACT: This paper analyses the journeys of a small number of Cambodian families that formed a community after settling in a neighbourhood of Buenos Aires Metropolitan Area (or AMBA) in the 1980s. Coming from a region of continuous and extremely violent conflicts in northern Cambodia, they became refugees under the United Nations with refuge in Argentina. Some of the violence from that context is interpreted and discussed with historical, political, and geographical literature as well as the ethnographic field research. The context of reception, marked by the last military dictatorship in Argentina, is also analysed.

KEY WORDS: Cambodian refugees, journeys, communalization, violence, dictatorship 
Refugiados camboyanos en Longchamps: trayectorias desde Indochina hasta Argentina LAURA PUGA

\section{Introducción}

Camboya es un país lejano en términos territoriales, pero también en sus aspectos culturales. Es sumamente infrecuente encontrar algún residente en Argentina que tenga ese origen, pero más aún lo es hallar un colectivo constituido por más de cien personas residentes en el barrio Rayo de Sol de Longchamps, en la localidad de Almirante Brown. Tal es el caso del colectivo al que se referirá este escrito.

Cuando inicié mi trabajo en la escuela de aquel barrio, en el año 2003, estaba vigente la Ley Federal de Educación 24.195 y existía un vínculo administrativo entre la escuela primaria y el Tercer Ciclo de la Enseñanza General Básica. Por este vínculo, los docentes de ambas instituciones compartíamos reuniones periódicas de personal. Fue en ese espacio que escuché por primera vez los relatos referidos a "los camboyanos", por parte de maestros primarios. Especialmente interesantes eran las narraciones del vicedirector de la escuela primaria, quien mantenía cotidiana comunicación con las madres de la comunidad educativa. Por entonces, aquellas "mamás camboyanas" apenas hablaban el idioma español.

Desde el lugar que ocupé como docente en el Secundario del barrio, se me facilitó la observación participante y el acceso a las entrevistas. Tuve estudiantes en la escuela, nietos de los refugiados llegados a Argentina desde Camboya y Laos. Llegaron al país matrimonios jóvenes con hijos muy pequeños, otros niños nacieron en Argentina y algunos de mis alumnos eran nietos de aquellos. Tres generaciones coexistentes desde la llegada; quienes se constituyeron como refugiados, con aproximadamente sesenta y cinco años, sus hijos de entre 35 y 45 años y los nietos. Durante la labor investigativa tomé contacto con las tres generaciones.

En la escuela aprendí a distinguirlos entre mis estudiantes de entonces, aún si no llevaban el apellido de origen camboyano, ni poseían un claro fenotipo indochino. ${ }^{1}$ Lo hacía observando su comportamiento social, lo que me llevó a pensar en ellos como comunidad. Haberlos reconocido entre su grupo de compañeros, puede estar vinculado a las modalidades en que los jóvenes transitan el proceso de comunalización y la manera en que lo actúan en la escuela; tal como interpreta Brow (1990) estos procesos. ${ }^{2}$

\footnotetext{
${ }^{1}$ El conjunto de caracteres visibles que los individuos de este grupo presentan, se identifica con facilidad entre los adultos de mayor edad, no así en individuos más jóvenes, aun cuando estos tengan el total de su genotipo (de padre y madre) camboyanos. La tercera generación, ya mestizada es de difícil reconocimiento. La característica más notoria que he notado es la baja altura.

2 A lo largo de la investigación se desarrolló el concepto de comunidad otorgado por distintos autores, tales como Brow, Anderson, Golluscio, Briones.
} 
A lo largo de la investigación se generaron fuertes vínculos de respeto y afecto entre los miembros de la comunidad y la investigadora. En algunas instancias de este escrito se puede leer el resultado del trabajo etnográfico en primera persona, producto del compromiso personal que se generó y del fuerte impacto que tuvieron y tienen los relatos de aquellos horrores. La investigación tuvo un enfoque histórico-etnográfico en el que se combinó el trabajo de campo con material estadístico, histórico y con otras fuentes. Ese enfoque permitió privilegiar el conocimiento que los involucrados tienen de los fenómenos sociales y reconstruir las lógicas que guían sus vidas cotidianas.

Este colectivo de personas a las que los vecinos del barrio y los docentes de la escuela reconocen como "camboyanos", está constituido por una mayoría de esa nacionalidad. Sin embargo, no todos lo son. Su estadía en un campo de refugiados de Tailandia duró por lo menos dos años. Durante ese tiempo se conformaron nuevas parejas, algunas de ellas con un integrante de otra nacionalidad, y nacieron niños en ese campo de refugiados, hechos que determinaron su posibilidad de acceder a la acogida en Argentina. ${ }^{3}$ Además de ello, a lo largo de los cuarenta años transcurridos desde su llegada, se integraron a las familias nuevos miembros de origen étnico diferente.

Las trayectorias de las familias "camboyanas" a las que se refiere este trabajo se iniciaron con la huida por tierra desde la provincia de Oddar Mean Chey, al norte de Camboya. Los integrantes de este grupo fueron, en su mayoría, de poblados muy cercanos al límite con Tailandia e iniciaron el escape entre 1977 y 1979. Lo hicieron en pequeños grupos o individualmente y de manera desesperada. Aquel contexto expulsor no solo determinó la huida, sino que impactó a lo largo de sus vidas, tanto en las representaciones que construyen sobre sí mismos como en las que construyen quienes los rodean y quien investiga (Debandi, 2013). Las vivencias por ellos narradas durante la investigación han sido resignificadas en un ejercicio de "recuerdos y olvidos singulares" (Jelin, 2002 , p. 3), que involucran una reconstrucción en la que se omite aquello que no encuentra lugar o sentido en el relato.

La investigación más amplia a la que se refiere este trabajo se centra en analizar las trayectorias de los refugiados camboyanos asentados en el Barrio Rayo de Sol de Longchamps, su devenir y constitución como comunidad articulada a partir de su llegada en 1980. En este artículo se espera describir el contexto histórico que motiva el éxodo y poner en diálogo el trabajo etnográfico realizado con la bibliografía académica acerca del tema, interpretando algunas maneras en que aquellos refugiados recién llegados a Longchamps han

\footnotetext{
${ }^{3}$ Para acceder a la condición de refugio y ser recibidos en Argentina, se requería que las parejas tuvieran por lo menos dos hijos, motivo por el cual varias de estas parejas tuvieron hijos allí o incluso adoptaron. Tal el caso de una de las entrevistadas quien adoptó un segundo hijo en Tailandia.
} 
Refugiados camboyanos en Longchamps: trayectorias desde Indochina hasta Argentina LAURA PUGA

rediseñado y extendido sus vínculos sociales, así como interpretar sus comportamientos y narrativas actuales en función de aquellos sucesos.

\section{El objeto de estudio: refugiados, comunalización e integración}

Los camboyanos llegados al país en 1980 lo hicieron en condición de refugiados. Este concepto tiene múltiples significados y está ampliamente desarrollado, aunque su descripción excede el propósito de este trabajo. Se han tomado ideas de Cicogna (2006), quien contribuye en ese desarrollo, ampliando la idea de que esta categoría de análisis está profundamente atravesada por la violencia. Para ella, el refugio puede estar originado también en "una violación de los derechos humanos de un colectivo de personas y [que esta situación] represente un temor fundado" (p. 104).

El pequeño grupo al que se aboca el estudio llegó al país durante el gobierno de la dictadura cívico-militar, en el año 1980. Este hecho es poco característico de tales gobiernos. Como dice Cicogna, “(...) el Estado argentino, en algunos momentos de su historia coincidentes con la asunción de gobiernos de facto o por fraude electoral, (...) cerró las puertas a los extranjeros". En el mismo párrafo agrega: "a partir de la reapertura democrática adoptó una posición favorable al ingreso de solicitantes de refugio y ha actuado para efectivizar su protección" (pp. 106). Esta interpretación ofrece un marco de cierta "rareza" en el análisis de la llegada de estas personas.

Una característica de la categoría "refugiados" especialmente tratada por Cicogna (2006) y que resulta de interés rescatar, es su vínculo con la violencia. La autora afirma que "Una persona refugiada puede ser violenta porque es producto de la violencia" (pp. 109). En este escrito se retomarán relatos de informantes que se ponen en diálogo con el contexto histórico, y otorgan sentido a la violencia transitada en el pasado.

En relación con el concepto de comunidad, se incorporan múltiples aportes. Entre ellos, los de Anderson (1993) fueron utilizados para recuperar los componentes imaginarios y simbólicos que se ejercen entre los miembros. En este trabajo se consideró integrantes del colectivo a quienes se reconocen como pertenecientes a la comunidad, aunque no necesariamente como "camboyanos". Las desigualdades existentes entre ellos no impiden que se formen lazos de profundo compañerismo y un sentido fraterno basado en la idea de horizontalidad y de profunda hermandad que caracterizó a las relaciones entre los refugiados camboyanos.

Por su parte, Golluscio y otros (1996) dicen que una comunidad se construye de modo procesual, en conflicto y diversificación de sus miembros. Brow (1990) desarrolla el concepto de comunalización a partir de los aportes que Weber (1994) formuló en torno a los tipos de relaciones que en ellas se 
producen. ${ }^{4}$ Para Brow, este proceso de comunalización se lleva adelante a partir de una manera de narrar el pasado que opera bajo condiciones económicas y políticas determinadas y modelan la conciencia de quienes integran una comunidad. En ambos trabajos, la comunidad se construye como un "sentido de pertenencia" que define algunos patrones de acción cultural históricamente determinada. Dicha idea de pertenencia involucra además versiones dominantes que circulan con relación a su propio pasado y que gozan de un mayor consenso al interior de las familias. Durante el trabajo de campo se observaron versiones y relatos del pasado que algunos entrevistados desarrollaron y todas ellas parecen ser compartidas o legitimadas por sus compañeros de grupo. Aquellos relatos que se nos ofrecían fueron emitidos por las voces genuinas, "con las que se debe hablar" denotando su legitimidad y traspasando las fronteras del recuerdo individual para convertirse en relatos colectivos.

Las conexiones existentes en este conjunto de personas tienen su expresión a través de la historia compartida. En el interior del grupo bajo estudio se conocen entre sí, se reúnen periódicamente, conocen los nombres de todos y/o el tipo de relación que los conecta. Se trata de una sociedad que alimenta sus relaciones en el "cara a cara" y aún constituidas en estos términos todas las comunidades tienen un componente imaginario (Brow, 1990) que en cierto modo traspasa la materialidad de los vínculos. Aun cuando la presencia de los integrantes de la comunidad haya variado a lo largo del tiempo y su convivencia no sea de contacto constante, cualquier miembro del grupo puede acceder a información disponible acerca de algún integrante, como un fondo común construido por "reputaciones". La reputación de algunos de los integrantes de este grupo usualmente se expresa en los relatos de los jóvenes que son nietos de los refugiados llegados en 1980 .

Brow (1990) advierte que el proceso de comunalización continuo puede tener lugar sobre diferentes bases. En esta pluralidad particular de personas, el pasado vivenciado en la nación camboyana, o lo sucedido posteriormente en Tailandia, así como el tránsito realizado por las diferentes familias hasta llegar al barrio Rayo de Sol, pudieron formar parte de un cúmulo complejo de experiencias a partir de las cuales se versionan recuerdos e identidades que varían según el período histórico, contexto o situación en el que son evocadas.

El pequeño grupo de refugiados asentado en Longchamps ha transitado muchas vivencias y nuevos miembros se han integrado a este colectivo; es por eso por lo que los lazos entre ellos se rediseñan constantemente. La vivencia de estos vínculos se ha podido advertir durante el trabajo de campo. En numerosas ocasiones fueron narrados y actuados en un lenguaje relativo al de las relaciones

\footnotetext{
${ }^{4}$ Weber realiza una distinción fundamental entre relaciones comunales, basadas en un sentido subjetivo de pertenencia y relaciones asociativas basadas en ajuste o acuerdos de intereses.
} 
familiares, poniendo en juego una definición parental que demuestra el grado de cercanía y afinidad entre las personas. Así lo evidencian los apodos con los que se tratan: "mi cuñada/mi cuñado", "primos" y demás, aunque no posean vínculo parental. Los jóvenes nietos de refugiados, todos ellos nacidos en la Argentina, se refieren a cualquier integrante de la primera generación como "abuelos", aun cuando sólo dos de ellos lo sean. En muchos casos los jóvenes desconocen el nombre de pila de los "abuelos" y se refieren a ellos por "abuelo-apellido". Naturalizan las relaciones a través del recurso a denominarlas en términos parentales y/o manifestaciones de cercanía afectiva.

Eduardo Page Poma (2015) estudia la manera en que se desarrolló un pequeño grupo de laosianos llegados a Argentina, procedentes de campos de refugio ubicados también en Tailandia. Estos laosianos fueron distribuidos por el territorio del país en base a las solicitudes de mano de obra recibidas desde las autoridades de distintas provincias. La intención que advierte Page Poma por parte de las autoridades estatales es generar un proceso de "integración" rápido, para luego ser enviados a explotaciones agrícolas al interior del país. En su trabajo se atiende especialmente a la "integración" de este grupo en el contexto de la última dictadura cívico militar.

\section{El contexto expulsor: guerra y violencia en Indochina}

Las condiciones históricas que dieron origen a la migración en cuestión deben interpretarse en el marco de la realidad regional del Asia comunista durante la posguerra, y esta situación obliga a realizar una lectura histórica que brinde sentido a los hechos. Se cuenta con escasa bibliografía disponible acerca del contexto de origen. Entre ellos se encuentra el texto de Ben Kiernan "El régimen de Pol Pot: raza, poder y genocidio en Camboya bajo el régimen de los Jémeres Rojos, 1975-1979”. Este texto específico del contexto de origen es citado por otros trabajos en casos similares de refugio de la ACNUR y también en relación con los laosianos asentados en la provincia de Misiones. Los aspectos históricos descriptos en ese texto caracterizan a la década del 60 y 70 en Indochina en torno al ascenso al poder del régimen de los Jemeres Rojos a través de la figura de Pol Pot. Este régimen tuvo dos naciones enemigas: Estados Unidos y Vietnam. Se mantuvo contrario a ambas a costa de la administración de una particular forma de terror que constituyó uno de los regímenes más opresivos y sanguinarios del siglo Xx, que resultó del desenlace de un golpe de Estado perpetrado en marzo de 1970 contra el gobierno monárquico de Sihanouk por parte del general Lon Nol.

\footnotetext{
5 Esta situación de estadía “de adaptación” que contempla Paga Poma (2015) fue mencionada por una entrevistada camboyana, se refirió a ella como de un mes de duración y localizada en Ezeiza.
} 
Kiernan (2010) afirma que en los años de guerra y dictadura en Camboya se rediseñan elementos de identidad nacional en oposición a la nacionalidad vietnamita. Todos esos episodios no pueden ser reducidos a la Guerra Fría debido a que, aunque esta incluye confrontación entre el mundo capitalista y el mundo comunista, aquellos exaltan la nacionalidad como elemento constitutivo en la Camboya comunista. Esto da origen a una "nacionalidad camboyana comunista" fundada sobre los principios de la Revolución Francesa y con la influencia ideológica del capitalismo central. Esta idea es compatible con las expresadas por Anderson cuando afirma que la invasión de Camboya realizada por los vietnamitas entre diciembre de 1978 y enero de 1979 era la primera guerra convencional en gran escala librada entre regímenes marxistas revolucionarios, "el ataque perpetrado por China contra Vietnam en febrero confirmó rápidamente el precedente" (1993, p. 17). Agrega: "Tales consideraciones ponen de relieve el hecho de que, desde la segunda Guerra Mundial, toda revolución triunfante se ha definido en términos nacionales: la República Popular de China, la República Socialista de Vietnam, etc.” (p. 18). Estas afirmaciones sustentan la necesidad de comprender los sucesos de Camboya en la década de 1970, no solo en el marco de la Guerra Fría, sino en el de enfrentamientos nacionales, entendidos como parte de la conformación de los Estados-nación en Indochina.

En relación con el golpe de Estado en Camboya llevado a cabo por los Jemeres Rojos, se debe mencionar la publicación de "Diario 90. Defendiendo la verdad desde La Habana. Cuba", con fecha 7 de marzo de 2012. Esta publicación de Jorge Wejebe Cobo ${ }^{6}$ realiza un análisis acerca de los sucesos de los años 70 con el título de "El año cero de Pol Pot". En este análisis se adjudica una gran relevancia al rol que Estados Unidos tuvo en las luchas de liberación de Vietnam y en la intervención de Camboya después, fundamentando el argumento en que hacia 1970 la neutralidad de Camboya era un estorbo para los Estados Unidos, pues pretendía evitar la circulación del ejército vietnamita comunista a través de tierras camboyanas. Por ello, la publicación arriba mencionada afirma que la Agencia Central de Inteligencia (CIA) organizó un golpe de estado contra el príncipe Norodom Sihanouk.

Las investigaciones o trabajos realizadas sobre los hechos políticos sucedidos en Indochina durante 1970 y 1980 no parecen contener grandes contradicciones entre sí, sino más bien centrar la atención del proceso en diferentes aspectos. Anderson centra el conflicto en la conformación de una nacionalidad moderna de acuerdo con las características regionales, que resultan tardías respecto a Latinoamérica y Europa. Además, sostiene que la cohesión se logra con herramientas diferentes a las utilizadas en otras regiones del mundo. Para Kiernan, el conflicto se centra en el carácter sanguinario y de extremo armamentismo, visto como un proceso particular y único, cuyos conflictos

${ }^{6}$ Disponible en versión digital en: https://eladversariocubano.net/ 
Refugiados camboyanos en Longchamps: trayectorias desde Indochina hasta Argentina LAURA PUGA

surgen del posicionamiento que Estados Unidos tuvo en el Sudeste Asiático y las características nativas de la resistencia.

En tanto, el periódico cubano arriba mencionado coloca el centro del conflicto en la intervención de Estados Unidos, su voluntad política de extender su dominio en el Sudeste Asiático y los "artilugios" que utilizó el ejército norteamericano para sortear las limitaciones que se sancionaron en su propio Congreso. Pone además el foco en los comportamientos autónomos de las fuerzas armadas imperialistas, cuyo principal interés fue/es el de fortalecer el negocio armamentista y consolidar su poder.

Se carece de análisis nativos del proceso. Esta carencia podría estar originada en la falta de traducciones a cualquier lengua occidental, en la tradición oral del Reino de Camboya y en la ausencia de un revisionismo acerca de este proceso por parte de las ciencias sociales en la sociedad camboyana. Es posible que todos los aspectos que enfatizan estos autores contribuyan a la complejidad del proceso histórico y político que afectó a los refugiados camboyanos en Argentina. Existen documentales y películas, a los que se alude en este escrito, pero ninguno de las cuales agrega nuevos análisis a los recién mencionados.

Para otorgar significado a la violencia de la que proceden los refugiados, es necesario conocer el trayecto de huida por tierra y las vivencias que los movilizaron a tal hazaña. A pesar de que los camboyanos refugiados en nuestro país fueron pocos, son numerosos los que huyeron de su tierra a través de Tailandia, especialmente durante la segunda mitad de la década de 1970. Según los datos publicados por ACNUR en La situación de los Refugiados en el mundo (2000), ingresaron por tierra desde Camboya hacia Tailandia 171.933 personas en condición de asilo. Son de especial interés las características históricas, territoriales y políticas llevadas a cabo en Camboya a partir de la década de 1960, cuyos orígenes son anteriores, como generadores de expulsión de personas. Pocos de ellos ingresaron a la Argentina en varios contingentes durante el año 1980. Aquel contexto expulsor impactó en las trayectorias de vida de los refugiados. Sus experiencias de procedencia fueron muy variadas, algunos de los entrevistados habitaban y trabajaban en sus pueblos de origen, en tanto otros yacían en campos de trabajo forzados.

La llegada de estos refugiados es poco común para los alrededores de la Ciudad de Buenos Aires, en términos de Pacecca (2013). Se la suele incluir entre la "inmigración reciente" procedente del Este Asiático. En Argentina, como en todos los países receptores de migración, la agenda política y periodística los tiene siempre presentes. Pacecca (2013) dice que esta y otras colectividades han sufrido el recrudecimiento de prejuicios étnicos y raciales, durante la década de 1990, especialmente por los duros embates periodísticos e institucionales. Estos prejuicios se reflejan, entre otras cosas, en la generación de noticias prejuiciosas, reduccionistas, estandarizadas y negativas acerca de estos inmigrantes. Esos prejuicios no salieron fácilmente a la luz en las entrevistas, en ningún caso se 
expresaron abiertamente con términos alusivos al fenotipo, que podrían considerarse prejuiciosos.

Durante la observación participante tuve múltiples charlas con vecinos del barrio. Especialmente AB fue muy cuidadoso en sus expresiones acerca del colectivo; buscaba las palabras adecuadas minuciosamente. Parecía esforzarse por no emitir ningún comentario que pudiera sonar como prejuicioso. Es posible que tal como Martino (2015) advierte para otra comunidad, existan mecanismos de invisibilización del racismo. Esto, según la misma Martino explica, puede estar originado en la idea de una Argentina de "brazos abiertos", un país de inmigrantes en el que el prejuicio racial está mal visto. Solo en algunos casos, las entrevistas dejaron ver argumentos prejuiciosos tales como la realizada a $\mathrm{DE}^{7}$, vecina del barrio, cuando dijo: "no eran capaces de afrontar con éxito la escolaridad" y también "cuando llegaron eran muy oscuros y con el tiempo se blanquearon". Otra vecina del barrio dijo: "No sé por qué ----- se casó con un camboyano, si es una linda chica, él es muy petiso, ella le lleva una cabeza de altura". Estas frases hacen referencia al color de piel y la baja estatura, características predominantes en este colectivo camboyano. Es posible que el racismo contra los camboyanos haya sido silenciado por ellos mismos también, por la vergüenza que les implica. Otro informante, SK, manifestó cierta incomodidad por expresarse en relación con sus vecinos. Ante la pregunta respecto a cómo fueron recibidos en el barrio, evadió la respuesta y siguió hablando de lo mal que fueron tratados en Camboya.

\section{El país de origen: el “año cero” de los Jemeres Rojos}

El Reino de Camboya es un pequeño Estado en la península de Indochina, que limita con Vietnam, Laos y Tailandia y posee costas sobre el golfo de Tailandia. Según Strahler (1982), su clima es tropical con estación seca en el invierno y tiene áreas de pluviselva, la estación seca es lo que diferencia este clima del ecuatorial y permite ciertas actividades de cultivo. Las costas de Indochina están bañadas por los vientos húmedos y tropicales que generan lluvias abundantes coincidentes con los momentos en que el sol está alto en el cielo, lo que otorga al ambiente temporadas de altas temperaturas y abundantes precipitaciones. Sus tierras están atravesadas de norte a sur por el río Mekong,

\footnotetext{
${ }^{7} \mathrm{DE}$ es la sigla con la que se refiere a una mujer que en el momento de la entrevista tenía aproximadamente 60 años y vivía en el mismo barrio. Ella había sido maestra en 4to grado durante la década del 1980 y recibió estudiantes camboyanos. Recordó muchas historias y nombres de quienes ahora tendrían 35 años aproximadamente. Fue llamativo el desconocimiento acerca de su condición de refugiados y los motivos que los llevaron a huir de su país. Esa escuela era y sigue siendo la más cerca al lugar en que originalmente se asentaron los refugiados, era inevitable que pasaran por allí.
} 
Refugiados camboyanos en Longchamps: trayectorias desde Indochina hasta Argentina LAURA PUGA

que nace en el Himalaya chino, recorre más de $4.200 \mathrm{~km}$ y desemboca en forma de delta en las aguas del Mar de China, en Vietnam.

Esta cuenca es fuente principal de recursos pesqueros. Se trata de un río navegable desde el mar por pequeñas embarcaciones hasta Phnom Penh, la capital de Camboya. Solo los barcos de poca profundidad pueden avanzar río arriba. El suelo fértil de la llanura deltaica y la abundancia de agua estacional son propicios para el cultivo de arroz. Recursos ambos (arroz y pescado) que determinaron la importancia que tuvo el país en el aprovisionamiento de comida para los soldados de uno y otro bando durante la guerra de Vietnam.

Hoy Camboya tiene algo más de quince millones de habitantes y transita por un recientemente iniciado proceso de democratización, en el que hubo pocos juicios contra los crímenes cometidos durante el régimen de los Jemeres Rojos. El 30 de enero de 2009, después de treinta años de la caída de aquel régimen, se inició el proceso judicial ${ }^{8}$, en un contexto de numerosas irregularidades políticas, crisis económica y el recrudecimiento de un conflicto fronterizo con Tailandia.

El régimen de los Jemeres Rojos tuvo dos naciones enemigas: Estados Unidos y Vietnam. Pol Pot se mantuvo contrario a ambas a costa de reprimir minorías étnicas, prohibir el islam, asesinar posibles aliados políticos y varios otros crímenes; todo en el marco de uno de los regímenes más opresivos y sanguinarios del siglo $\mathrm{Xx}$, y que resultó del desenlace de un golpe de Estado perpetrado en marzo de 1970 contra el gobierno de Sihanouk. Esto dio lugar al régimen de Pol Pot que, como dijo Anderson, contenía políticas de crueldad, paranoia, delirios de grandeza, despotismo y nacionalismo tendiente a conservar los intereses dinásticos imperiales?.

China y Vietnam competían por el liderazgo político en Indochina. En ese marco, la dictadura de los Jemeres Rojos que se inicia en Camboya a partir del golpe de Estado de abril de 1975 y perdura hasta 1979, se manifiesta antivietnamita. La rivalidad nacional con Vietnam parece pesar más que su similar tinte político, la procedencia étnica de la mayoría de su población o la

${ }^{8}$ En AAVV (s/f) bajo el título Primer proceso de una antigua autoridad jemer roja, se contextualiza el primer proceso judicial contra un autor de crímenes durante el régimen jemer rojo, se trató de "Duch", acusado por sus acciones como director del centro de detención S-21. Su nombre era Kiang Guek Eav. Durante el juicio que lo condenó tuvo la diabólica sinceridad de relatar sus torturas detalladamente. Fue condenado a cadena perpetua y murió en la cárcel el 2 de septiembre de 2020.

${ }^{9}$ Esta afirmación de Anderson, se replica también en otra bibliografía con relación a quienes estaban desconformes con el golpe de estado de Lon Nol, que derrocó al príncipe Sihanouk generando desconformidad por sectores monárquicos y tradicionales de la sociedad. Si bien la tendencia política de Pol Pot era comunista, prometió restituir en el gobierno al príncipe. Esta promesa y ciertos gestos propios de su formación lo ayudaron a obtener la connivencia de sectores conservadores de la sociedad. 
religión; pues la dictadura camboyana aceptó el patrocinio chino y se manifestó antivietnamita, al punto de fusilar aliados políticos de su misma etnia solo por tratarse de vietnamitas (Kiernan, 2010).

En el mismo texto se afirma que China de alguna forma patrocinó a la dictadura de Camboya de los Jemeres Rojos. Mao Tse-Tung contribuyó con armamento, alimentos y otros aportes al ejército de Pol Pot. Esto habla de un acercamiento entre el nacionalismo camboyano y el chino, alineados contra Vietnam. Por este motivo se considera que estos enfrentamientos no se explican exclusivamente por la Guerra Fría, entre los ejes comunista y capitalista, sino por rivalidades nacionales. Tal como afirma Anderson (1993), las revoluciones se definieron como "nacionales", la Revolución china y la vietnamita atan el proceso revolucionario a un pasado nacional heredado al que el autor define como "el valor más universalmente legítimo en la vida política de nuestro tiempo" (p. 19)

Los hechos violentos acontecidos en Indochina tienen una larga trayectoria. En 1867 el rey de Camboya solicita el ingreso al protectorado francés, con el objetivo de que sea Francia quien proteja al reino de otros posibles invasores. Entre los temidos invasores se encontraba el reino de Siam, actualmente Tailandia y Cochinchina. Ante la formación del protectorado francés y la inclusión de Camboya, Siam renunció a la soberanía sobre esas tierras y dio su reconocimiento oficial al nuevo protectorado. De esta manera lo relata el Diccionario Enciclopédico Hispanoamericano de Literatura, Ciencias y Artes:

No hay historia escrita de Camboya, pero la tradición asegura que hubo un tiempo en que este país fue el estado más rico y poderoso de Indochina oriental [...] Según los anales del Celeste Imperio, las primeras relaciones entre China y el Reino de Camboya datan del 616 d C. [...] entonces era un gran reino. Hacia 1670, comenzó a decaer. Combatido a su vez por Siam y Cochinchina que, poco a poco le fueron arrebatando territorios. [...] Cuando los franceses con la ayuda de los españoles lograron triunfar en Cochinchina y se establecieron en ella, el Rey de Camboya no vaciló en aceptar su protectorado que le había de poner al cubierto de los seculares enemigos de su

pueblo. (AA.VV., p. 326)

Durante la Segunda Guerra Mundial, Indochina fue ocupada por los japoneses, y es en ese contexto cuando Sihanouk es coronado rey en 1941. Tras la derrota de Japón, los franceses retoman el poder de su protectorado con gran debilidad política. En 1953 se firmó el Acuerdo de Ginebra, por el cual Francia reconocía como estados independientes a Camboya, Laos y los dos Vietnam. Esos largos años de influencia cultural francesa, especialmente entre las élites camboyanas, fueron y son aún muy importantes.

Para otorgar sentido a la dictadura ejercida por los Jemeres Rojos en Camboya es necesario mencionar algunas características y coyunturas. En primer 
lugar, su cercanía territorial al conflicto de Vietnam y el tránsito que los bandos del enfrentamiento tuvieron a través del territorio camboyano. Por otro lado, fue importante el desgaste político heredado de invasiones y ocupaciones anteriores, así como el ascenso al poder político de un sector social muy complejo, que fuera liderado por el conocido déspota Pol Pot o "Angkar", como él mismo se hizo llamar ${ }^{10}$.

Pol Pot nació el 19 de mayo de 1925, su nombre era Saloth Sar y sus padres eran propietarios de nueve hectáreas de arrozales, tres huertas y seis búfalos. Pertenecía a la etnia jemer, profesaba el budismo y mantenía contacto con la realeza. Tuvo una educación muy estricta y podríamos decir de privilegio entre sus coetáneos. Obtuvo una beca para estudiar en París en 1949, que perdió años más tarde. Sin embargo, durante su estadía en Francia conoció a quien después fue su esposa, se convirtió en miembro de la sección camboyana del Partido Comunista Francés y consolidó amistades. Ya de vuelta en Camboya, surge como líder político viable, cuando su fracción toma la conducción del Partido Comunista en 1963. Casi inmediatamente esta conducción pasa a una clandestinidad que le ofrece numerosas ventajas, tales como evitar cualquier debate político abierto, preparar la rebelión contra Sihanouk y formar alianzas con los enemigos de sus enemigos (Kiernan 2010). En 1967 ya estaba a la cabeza de la insurgencia comunista que generó un giro en la conducción del partido, conformando a partir de ese entonces una dirigencia de clase urbana, educada en Francia, radicalizada y antivietnamita.

El ascenso al poder de Pol Pot tuvo algunos antecedentes que debemos mencionar, dentro de los cuales es importante destacar la intervención del ejército norteamericano en la región. Su objetivo político era aislar a China, consolidando la hegemonía norteamericana en los países que la rodean, para limitar su poder, según lo expresa Kiernan (2010). A medida que el conflicto en Vietnam se intensificaba por la intromisión del ejército norteamericano, los soldados comunistas buscaban refugio en campos camboyanos, cuyo gobierno se mantenía neutral. Esperaban evitar los bombardeos del ejército estadounidense y obtener comida, especialmente arroz procedente de los campos del noroeste. Un poco más tarde, en 1966 se iniciaron incursiones norteamericanas de aviones bombarderos B-52 en el campo camboyano cercano al límite con Vietnam. Y aunque Kiernan dice que el objetivo era llevar a los soldados comunistas nuevamente al campo de batalla, otras versiones hablan de bombardeos anteriores y con intenciones confusas. Estas incursiones del ejército norteamericano, cada vez más frecuentes, y la crisis económica que generó el aumento del contrabando de arroz, desgastaron fuertemente al gobierno de Sihanouk y disminuyeron los recursos económicos disponibles de la nación.

\footnotetext{
${ }^{10}$ Angkar podría ser traducido como "la organización".
} 
Con el apoyo de Estados Unidos (y el silencio complaciente de la oposición política de Pol Pot), el 18 de marzo de 1970 el general Lon Nol derrocó al príncipe Sihanouk y se instaló en el poder, usurpando el gobierno camboyano. A pesar de la manifiesta colaboración de Estados Unidos con el nuevo gobierno de Lon Nol, el ejército estadounidense intensificó los ataques de B-52, sembró minas personales en campos camboyanos, en el marco de las misiones "Salem House" primero y "Daniel Boom" después. Las operaciones militares realizadas fueron ochocientas solo en el año 1967 (Kiernan, 2010); causaron terror y confusión en la población.

En la entrevista realizada por Miguel Riera el 3 de noviembre de 2009 a Mark Aguirre, autor del libro Camboya. El legado de los Jemeres Rojos, este último dijo:

El caso camboyano es una vergüenza más de tantas para nosotros los occidentales, los supuestos civilizadores que rompemos las leyes cuando queremos y exigimos cumplirlas a nuestros supuestos enemigos. Por los últimos documentos desclasificados por el Pentágono se sabe que Camboya tiene la desgracia de ser el país más bombardeado de la historia. Más que Japón, incluyendo las bombas atómicas, y más que Alemania, durante la segunda guerra mundial. No olvides que Camboya es un pequeño país, un poco más grande que las dos Castillas juntas. Es difícil saber los muertos que hubo, pero la cifra generalmente aceptada por los historiadores alcanza el medio millón. Tanta destrucción arrasó la sociedad rural. La ciudad, que apoyaba a los norteamericanos, se libró de las bombas, facilitando el camino a los jemeres rojos. Pero lo patético es que Johnson primero y después Nixon nunca lo hicieron público para no alimentar al movimiento contra la guerra de Vietnam, que veían como una amenaza interna. Cuando Martin Luther King fue asesinado en 1968 estaba en el proceso de unir el movimiento por los derechos civiles al movimiento contra la guerra de Vietnam, una alianza explosiva. El mismo Congreso estaba contra la expansión de la guerra. Es en este contexto que decidieron actuar contra la legalidad; según la Constitución los Estados Unidos de América no pueden atacar a un país sin declararle la guerra, actuando como rufianes protegidos por la oscuridad. Al final la guerra ilegal de Camboya fue un elemento más de los que afortunadamente hicieron caer al presidente Nixon. ${ }^{11}$

La descripción anterior es una de las tantas referidas a la violencia padecida en Camboya. El letrado español Miguel Ángel Rodríguez Arias, impulsor de la causa judicial que espera recuperar cuerpos de asesinados por el franquismo español entre 1936 y 1974, afirma que "España es el segundo país del mundo en fosas comunes tras la Camboya de Pol Pot". Esta afirmación fue

\footnotetext{
${ }^{11}$ Nota disponible en: http://www.rebelion.org/noticia.php?id=94488
} 
Refugiados camboyanos en Longchamps: trayectorias desde Indochina hasta Argentina LAURA PUGA

tomada como propia por el movimiento memorista español, sintetizando con ella a dos grandes genocidios y sus secuelas enterradas en fosas comunes y aún impunes.

Respecto a la confusión generada por las operaciones norteamericanas acerca de quien o quienes eran responsables de los ataques a poblados en Camboya, se han encontrado en esta investigación múltiples fuentes. $\mathrm{SK}^{12} \mathrm{y}$ $\mathrm{ChS}^{13}$, informantes de la comunidad de Longchamps, se manifestaron en este mismo sentido. Ambas afirmaron no entender del todo la situación política que las obligó a huir, tampoco conocer la identidad de los batallones que ingresaban a los pueblos vecinos, y que cuando llegaban mataban a todos los que encontraban. Es posible que esta confusión esté basada en que algunas veces los soldados americanos o sus aliados vietnamitas que intervenían en estos operativos "vestían uniformes de Viet Chong", es decir, del ejército contrario (Kiernan, 2010, p. 65). Con Lon Nol en el poder, y sin indicadores previos que pudieran anticiparlo, el ejército de Estados Unidos invadió Camboya generando "en 1971, 130.000 refugiados jemeres", ante las Naciones Unidas.

Según Kiernan, los ataques cada vez más frecuentes originaban tal malestar que los sobrevivientes eran fácilmente captados por el Partido Comunista de Kampuchea, liderado por Pol Pot. Las operaciones de inteligencia norteamericanas, las plantaciones de minas y los bombardeos facilitaban el reclutamiento. A este respecto, múltiples artículos de The New York. Times hacen referencia a esta situación y los entiende como factores de presión para la elaboración de la ley del Congreso de Estados Unidos, del 15 de agosto de 1973, en la que se ordena el cese del fuego y el retiro de las tropas norteamericanas de Camboya.

Acerca del rol que Estados Unidos tuvo en Camboya, hay dos películas de ficción que evocan la situación de violencia vivida en Camboya y son de interés para el tema, la más antigua titulada Los gritos del silencio (1984), enfocado en la repercusión mediática que generó el golpe de estado de Pol Pot. La segunda y más reciente es First they killed my father (2017), muy bien documentada y con

\footnotetext{
${ }^{12} \mathrm{Sk}$ es la sigla con la que se designa a una mujer refugiada de entre 62 y 65 años. Es abuela de varios de mis alumnos, se anunció en la escuela cuando se enteró por la directora que yo estaba haciendo trabajo etnográfico con miembros de la comunidad camboyana. Fue mi primera entrevista a un miembro de la primera generación de esta comunidad, sus dificultades para expresarse en español son moderadas, en relación con otras mujeres de la primera generación de esta comunidad que entrevisté más tarde.

${ }^{13} \mathrm{ChS}$ es la sigla con la que se refiere a una mujer de la primera generación de la comunidad, también tiene entre 62 y 65 años, ella asistió a la escuela a mi pedido, realizado a través de su nieta. Vino acompañada de otra mujer de la misma edad, a quien se refiere en este trabajo como Lam. Ambas fueron acompañadas por la hija de ChS, presentada como S, madre de una de mis alumnas.
} 
una tibia mirada crítica respecto de la intromisión de Estados Unidos en la región. Son pocas las manifestaciones artísticas que llegaron al mundo occidental de aquel genocidio. Es pertinente recordar que las intervenciones americanas en Camboya durante las décadas de 1960 y 1970 son aún causales de acusaciones judiciales dirigidas al entonces embajador ${ }^{14}$ de Estados Unidos, según se puede leer en The New York Times ${ }^{15}$.

Durante 1966 se había producido un bloqueo marino de los Estados Unidos sobre la costa de Vietnam, que impedía la conexión por barco entre los vietnamitas comunistas del norte y del sur. Es entonces cuando construye la ruta terrestre de Ho Chi Minh, también llamada por los norvietnamitas la "599". Se trata de una red de caminos trenzados de aproximadamente 20.000 kilómetros de extensión total, que unen la ciudad de Hanoi con Saigón. La circulación de tropas comunistas por esta red de caminos sobre territorio laosiano y camboyano fue extremadamente difícil de atacar por parte de norteamericanos que bombardeaban de forma constante. Este bombardeo creciente que los aviones americanos realizaban vulneraba el acuerdo de neutralidad de Laos y Camboya. La intromisión americana por este camino causó tal descontento entre los camboyanos y laosianos, que favoreció el reclutamiento de comunistas en ambos países y la creciente fuerza política comunista que sería fundamental más adelante $^{16}$.

La zona norte del país fue reiteradamente bombardeada. Una mañana de febrero de 1973 los B-52 atacaron la aldea de Stung Kambot (también denominada Pnum Kambot) al sur de la región de Oddar Men Chey. Allí asesinaron a cincuenta aldeanos e hirieron de gravedad a treinta. Más tarde, en marzo, los B-52 y los F 111 bombardearon una caravana de carros de bueyes en el mismo distrito, momento en el que mataron a diez aldeanos más: "un joven campesino recordaba como los B-52 bombardeaban su aldea entre tres y seis veces por día durante tres meses" (Kiernan, 2010, p. 72). El norte del país fue una región especialmente perjudicada por los ataques aéreos, la confusión y el terror. La provincia de Oddar Mean Chey es el lugar de residencia de origen de algunos refugiados, hoy residentes en Longchamps, según los registros de campo realizados. Aquellos sobrevivientes que no se convirtieron en partidarios del

\footnotetext{
${ }^{14}$ Bajo las órdenes del entonces secretario de Estado Henry Kissinger, Thomas Enders fue jefe de la misión norteamericana en Camboya entre 1971 y 1973, años en que Estados Unidos bombardeó en secreto zonas ocupadas por fuerzas de Vietnam del Norte. Después fue acusado en el Congreso de haber hecho todo lo posible por obstaculizar las investigaciones sobre tales bombardeos. El País, 19/3/1996.

15 The New York Times (1 de marzo de 1982) Columna de opinión editorial, "American Embassy's Role in the 1973. Bombing in Cambodia”.

${ }^{16}$ Kiernan dice: "el 60\% de los encuestados en Ciudades de Camboya daba como causa principal de su desplazamiento el bombardeo de los Estados Unidos” (2010, p. 67).
} 
Partido Comunista de Kampuchea de Pol Pot, fueron captados como mano de obra en los campos de trabajo, exiliados o asesinados. Durante los años de su gobierno ejecutaron a camboyanos no jemeres, incluso a quienes tenían alguna experiencia revolucionaria, como una "limpieza étnica".

Durante una entrevista le pregunté a SK acerca de su adscripción étnica. Respondió inmediatamente con actitud defensiva: "¡Yo no soy jemer!". Al responder cambió el tono de voz y me hizo notar su disgusto por la pregunta. También dejó claro que serlo constituye algún tipo de deshonra entre el grupo. Esta comunidad es un heterogéneo étnico, social y económico, que se define hacia el barrio por su nacionalidad y no por su origen étnico o religioso, ni por su condición de "refugiados". Posiblemente su rápido distanciamiento de la adscripción a la etnia jemer tenga lugar en la asociación generalizada que existe entre la dictadura de los jemeres rojos y la extrema violencia de la que la comunidad fue producto.

En Camboya, los jemeres mantenían los privilegios y quienes no lo eran fueron perseguidos. "No se trataba ni de una revolución proletaria comunista que privilegiaba a la clase trabajadora, ni de una revolución campesina que favorecía a todos los granjeros. Los favores en Kampuchea Democrática, tal como se daban, estaban reservados para los jemeres aprobados" (Kiernan, 2010, p. 77). Nunca se explicitó el significado de "aprobados", pero con seguridad los refugiados de este estudio no lo eran.

Con la toma del gobierno por parte de Pol Pot y el ingreso de los soldados a las ciudades, obligaron a la población urbana a abandonar sus casas a la fuerza, sin un destino claro, solo debían alejarse tres $\mathrm{km}$ de la ciudad. Los extranjeros que residían en Phnom Penh fueron reunidos en la embajada francesa y expulsados días más tarde. Para realizar estas difíciles maniobras utilizaron el pretexto de posibles bombardeos norteamericanos, y así evacuar en pocos días a la población de dos millones de habitantes que poseía la ciudad capital Phnom Penh en ese momento. La evacuación fue caótica y, de acuerdo con el cálculo realizado por Kiernan la tasa de mortalidad del viaje fue muy alta, equivalente en números absolutos a 10.600 personas muertas o ejecutadas durante el éxodo. Algunos de los habitantes expulsados de las ciudades fueron enviados a zonas menos pobladas del norte, con cuyo trabajo esperaban producir y exportar dos millones de toneladas de arroz en 1977.

Para Aníbal Quijano (2000), la colonialidad es un elemento constitutivo del patrón mundial de poder capitalista y Camboya durante el gobierno de Pol Pot fue comunista. Sin embargo, para este autor, la colonialidad se funda en la imposición de una clasificación racial o étnica de la población que se mundializa a partir de la conquista de América. A pesar de la aparente imposibilidad de aplicar la idea a este caso, se intentará dar sentido a las narraciones de los refugiados a la luz del concepto de colonialidad. En primer lugar, porque la supremacía de los jemeres rojos educados en Francia fue parte fundamental en 
la estructura de dominación durante los años de dictadura de Pol Pot (por lo menos). La expulsión de extranjeros, los discursos acerca de la nueva Camboya que la situaban distanciada del mundo occidental, pero también del mundo comunista podría interpretarse como una imposición de superioridad étnica. Los camboyanos no jemeres y campesinos fueron relegados, fusilados, expulsados u obligados a trabajar en situaciones de subordinación extrema. Recordemos que todas las escuelas del país fueron cerradas, las expresiones de arte prohibidas, los disidentes asesinados, los extranjeros expulsados. Las pertenencias privadas con algún valor económico o artístico fueron inmediatamente apropiadas por el régimen de los jemeres rojos.

Es posible interpretar que la racionalidad eurocéntrica reinante en el poder de Camboya ${ }^{17}$ durante fines de la década de 1970, fue un elemento de dominación utilizado por Pol Pot y su círculo de poder. En tanto la población del país se vio privada de finalizar su escolaridad, dando así legitimidad a la "superioridad intelectual" de la clase dirigente, los campesinos no disponían de escuelas para sus hijos y la dirigencia política educada en Francia marcaba el rumbo a seguir.

El eurocentrismo en la dirigencia camboyana se manifiesta, además, en el fortalecimiento de la identidad nacional, que se rediseña en contraposición a la vietnamita. Esta idea, que se convierte en emblema del gobierno de los jemeres rojos, se sustenta en una rivalidad con Vietnam que con algunos antecedentes históricos se fortaleció como producto del alineamiento con China a partir del golpe de Estado de Pol Pot.

Durante mis observaciones de campo tuve la oportunidad de escuchar relatos de la huida. SK me transmitió con el suyo angustia, hambre y desorientación. Ella estaba abandonando a sus dos hijos pequeños en el pueblo que dejaba, aunque más tarde logró recuperarlos y su recuerdo está cargado de aquella sensación. El relato de ChS ponía énfasis en el miedo, el hambre y el dolor físico. En todos los casos, el tiempo transcurrido durante el relato de la huida me transportó al lugar y al momento en presente. Estos relatos estaban marcados por la desposesión, la subordinación y el terror creciente, todo ello cobra sentido ante la decisión de cruzar a Tailandia.

Cuando inicié el trabajo de campo me preguntaba: ¿por qué esta minoría sigue definiéndose "no jemer" en un contexto que desconoce todo significado de esa identidad? El primer sentido que le di fue que, en el barrio nadie lo preguntó. También pensé que su adscripción era una muestra política que los excluye de cualquier asociación con los jemeres rojos. Así, encontré sentido a su expulsión, en la desposesión de bienes, propiedades, bienestar, paz, y hasta

17 Según Kiernan (2010), la admiración de Pol Pot por la Revolución Francesa lo llevó a elegir el día de la Toma de la Bastilla para su boda con una camboyana que conoció en Francia. 
incluso de la pertenencia a la etnia jemer. Por otro lado, su adscripción a la nacionalidad camboyana en Argentina al igual que en cualquier lugar del mundo es indiscutible y universalmente admitida. Puede ser que todo lo dicho sea motivo de cierta aceptación de la comunidad a ser denominados "camboyanos", en vez de refugiados, indochinos, jemeres u otra denominación.

Posiblemente la entidad histórica de esta etnia los haya vinculado, tanto allá como acá, con la clase oprimida. Definirse no jemer puede ser una forma más de evidenciar la desposesión padecida, aun cuando entre sus vecinos del barrio no se le diera tal significado. Durante el trascurso de las observaciones participantes escuché comentarios acerca de los miembros de la comunidad y nunca se refirieron a ellos por su etnia, siempre lo hicieron por su nacionalidad.

Así, su identidad étnica continúa refiriéndose a su situación allá, reafirmando la nacionalidad camboyana "no jemer"; reafirman que son sobrevivientes de crímenes perpetrados contra "su" gente y que no participaron de ninguna ventaja durante los años de Pol Pot. Esta identidad tan marcada entre la generación de los refugiados ${ }^{18}$, parece estar ausente entre las siguientes generaciones. No se trata de una "mezcla" étnica que los hizo desaparecer, sino de una identificación propia de la generación que padeció la condición persecutoria y que compone la otredad, en notable diferencia con sus hijos y nietos. Díaz Polanco hace referencia a esto y dice: "puede observarse que ciertos grupos mantienen constante una identidad contrastable con respecto a otros conjuntos sociales, pero eso no significa necesariamente que la identidad que establece el contraste es siempre la misma" (1988, p. 66). Lo que puede ser constante es la existencia de una identidad que funda la diferencia, pero la naturaleza de esa identidad en cada momento histórico es impactada por las transformaciones que sufre la estructura social.

\section{La llegada: un nuevo "año cero"}

Cuando SK aceptó darme una entrevista desconocía su experiencia en Camboya en la década de 1970. Ese fue mi primer contacto con una persona que transitó la huida. Me ocupé de dejarle claro que sus nietas, que eran entonces alumnas mías, no tenían nada que ver con mi voluntad de hablar con ella. Eso que yo sentí una obligación decirle, resultó en un lazo afectivo que facilitó el diálogo y generó de allí en adelante un vínculo de confianza. Una de las primeras advertencias que hizo SK me pareció exagerada: no quería hablar de lo sucedido en Camboya. Para ella la vida empezó el 13 de enero de 1980, el día que llegaron

${ }^{18}$ Me refiero a la generación de quienes hoy tienen entre 60 y 65 años y eran adultos jóvenes al momento de la huida, por tanto, conscientes de lo que sucedía, tomaron su propia decisión. Respecto a esto parece ser distinta la mirada de quienes huyeron con muy corta edad o nacieron en Argentina. 
al aeropuerto de Ezeiza (Buenos Aires) y no quería hablar de lo sucedido antes de ese día.

Hablamos más de una hora. Fue agotador, porque la barrera del idioma fue grande: a veces ella no encontraba las palabras y utilizaba miradas y gestos para enfatizar aquello que no podía verbalizar. Yo me anticipaba con intención de facilitar las palabras, sintiéndome muy torpe e incómoda ya que pocas de mis propuestas resultaron útiles. Todas esas herramientas fueron utilizadas por SK, para dar fuerza a aquella frase: tres o cuatro veces a lo largo de la entrevista repitió que su vida se inició el 13 de enero de 1980. Su insistencia, el énfasis en el tono de voz y la mirada, me dio indicios de que no se trataba de una afirmación como las otras y traté de buscarle sentido.

Pensé que podía tratarse de un agradecimiento a la Argentina por darle paz a su vida, que los sucesos vividos por ella en Camboya habían sido extremadamente dolorosos o vergonzosos y/o humillantes y no hablaría de ellos conmigo. También pensé que ese 13 de enero había sido crucial para su familia, pues había reunido a sus hijos y a partir de ese momento podría pensar en un futuro para ellos. Muchas cosas pasaron por mi mente cuando trataba de dar sentido a aquella insistente frase de SK. Lo llamativo fue que sí hablo de lo sucedido en su pueblo, de lo mucho que lamenta no haber vuelto a ver a su padre. Respecto a eso dijo: "Hablo por teléfono todos los meses con mi hermano, mi padre murió, pero mi hermano sigue viviendo en Kumon”. Relató algunos detalles de los familiares que se quedaron, de su madre que murió cuando ella era niña. Además, describió minuciosamente la huida. También habló sobre su vida de niña, sus juegos y su relación con el hermano: "Era una vida sencilla, pero éramos felices".

Meses más tarde, volví a pensar en sus palabras y encontré un nuevo sentido. Con la llegada de Pol Pot al poder, se exterminaron aldeas completas, asesinaron simpatizantes de Vietnam, Estados Unidos, la URSS o de casi todos los países del mundo. Las ciudades fueron evacuadas y los habitantes fueron enviados a campos de concentración donde eran obligados a trabajar. Se prohibió la moneda, el comercio, el mercado, las escuelas, la literatura, toda forma de arte, cultura y religión. El país se llenó de centros de torturas y ejecuciones, instalados en escuelas. La política oficial decía que solo la vida en el campo, lejos de la comodidad de la vida moderna occidental, era posible en la nueva Camboya, enfatizando sus aspiraciones fundacionales. Incluso cambió el nombre de la nación por el de Kampuchea Democrática y designó el inicio de su gobierno como el año cero.

Todo lo sucedido antes de la llegada del régimen de los jemeres rojos, quedaba anulado. Esta categoría instalada como estrategia de poder, atravesó a los sobrevivientes de tal manera que SK adoptó su propio año cero. "Le otorgo un nuevo sentido al 13 de enero de 1980”. Ella reemplazó el año cero de Pol Pot por un nuevo año cero en el que ella y su familia comenzaron una nueva 
trayectoria de vida. Este descubrimiento me enojó conmigo por no haber advertido algo tan obvio desde el mismo momento en que lo dijo, más tarde me alegré porque pude advertirlo y finalmente me emocionó la posibilidad de cambio que SK estaba realizando en su vida, pues el concepto de año cero que la acompañó en su trayectoria de vida en Camboya había sido resignificado perdiendo la carga de terror y amenaza que contenía en la política de Pol Pot para adoptar una apuesta por la vida.

\section{Dictaduras: expulsión y recepción}

El 9 de octubre de 1975 la Comisión Permanente de Camboya le otorga poder absoluto a Pol Pot sobre el ejército y la economía. Comienza un período de crímenes conocido como el genocidio camboyano, durante el cual se produce la muerte de aproximadamente una cuarta parte de la población total del país y el éxodo de miles de personas entre quienes se encuentran las familias residentes en Longchamps. Según Capote, en el Diario 90, de La Habana, del 7 de marzo de 2012: "La mayoría de la comunidad internacional guardó silencio alrededor del holocausto en Kampuchea, mientras que en el contexto de la Guerra Fría se jugaba un complejo ajedrez, sobre un tablero ensangrentado por millones de víctimas en el país".

El 24 de marzo de 1976, a partir del golpe de Estado que quiebra el orden institucional argentino, se instala en este país una dictadura cívico militar. Durante ese período, el país se caracterizaba por constituirse en emigrante (Pacecca y Courtis, 2008), lo que contrastó con la llegada de esta comunidad. Además, a partir de la década de 1960, el Área Metropolitana de Buenos Aires (AMBA) recibió principalmente migrantes de países limítrofes de varias provincias del país, junto a algunas minorías de otras nacionalidades. Entre ellos, refugiados procedentes de Laos y Camboya, pequeñas y aisladas comunidades con suertes diferenciadas de acuerdo con la zona y el carácter de sus trayectorias laborales. La Dirección Nacional de Población (2012), contextúa la llegada de estos refugiados en el marco del arribo de la Comisión Interamericana de Derechos Humanos.

El contexto de llegada de la comunidad constituye una particular contradicción: mientras Argentina se convertía en un país expulsor de población por causas políticas y económicas bajo una dictadura, recibía refugiados políticos de Indochina. Comprendiendo o no la situación política local, los refugiados debieron desenvolverse (los primeros tiempos por lo menos) con la exclusiva ayuda de la ONU y del Estado argentino, pues carecían de recursos propios y/o de la capacidad de generarlos (según lo que algunos informantes narraron, la barrera del idioma les parecía en aquel momento, infranqueable). Esta contradicción su suma a un doble gesto del Estado, quien se muestra solidario 
ante la ONU, Estados Unidos y Europa y ante los refugiados/damnificados comete desatención.

A partir de la observación participante que se llevó a cabo por casi cuatro años, en un contexto de confianza, los nietos y amigos de los nietos de refugiados narraron la tarde en que el abuelo $\mathrm{H}$ mostró sus heridas de guerra. Fascinados por la supervivencia de aquel que, según ellos, tenía el cuerpo cubierto de balas: "una bala le atravesó el cuerpo, una herida de cuchillo le rodeaba el pecho, está lleno de heridas", era indudable para ellos que se trataba de un héroe, guerrero y superviviente. Poco después mantuve una charla con su esposa y ella me dijo lo que los nietos y sus amigos me habían relatado con fascinación. El abuelo había sido soldado del rey Sihanouk. Este abuelo/soldado/héroe de mis alumnos fue quien lideraba las excursiones a las oficinas de la ONU, cuando la comunidad no se encontraba conforme. El liderazgo que este soldado tenía era muy bien descripto por mis alumnos, quienes fueran miembros o no de la comunidad aceptaban aquella reputación de liderazgo y la reproducían. Todo indicaba que yo debía hablar con él para obtener información interesante. La insistencia de mis alumnos y de los miembros de la comunidad me indicaba que "el abuelo H" o "el soldado del Rey" poseía la supremacía en la mirada acerca del pasado, es decir, la versión dominante. Poco después de haber concertado una entrevista con él, murió de un infarto. Nunca pude entrevistarlo, pero más tarde, entrevisté a su esposa quien parece haber heredado tal supremacía respecto al relato de aquel pasado en Camboya. Él era conocido en el barrio y en el centro de Longchamps, pues vendía muñecas de lana, tejidas por las mujeres de la comunidad.

Al llegar a la Argentina, la comunidad recorrió una larga trayectoria por diversos pueblos de la provincia de Buenos Aires: Tres Arroyos, Necochea, Pilar, Las Heras, Pehuajó, de todos ellos se retiraron a pedido de la comunidad en conjunto. Una persona de la comunidad se constituyó en vocero para solicitar y lograr el cambio de localización: el soldado del rey. Él encabezaba las negociaciones y oficiaba de interlocutor ante las autoridades. Los reiterados pedidos de cambio, así como la incomodidad por el lugar asignado, fue una constante en los grupos de refugiados laosianos y camboyanos, tal como expresa Page Poma en su tesis para el caso de los laosianos de Posadas.

\section{Violencia}

Se han rescatado algunas características históricas y territoriales en Camboya a partir de la década de 1960, especialmente aquellas que se vinculan a la expulsión y trayectorias de la comunidad de refugiados, haciendo visible la trasposición de vivencias de allá hacia acá. Algunas de ellas cargadas de violencia. El uso de la fuerza para derrocar el gobierno camboyano, dominar a los seguidores de Lon Nol y por tanto a los norteamericanos, constituyó tanto al 
Refugiados camboyanos en Longchamps: trayectorias desde Indochina hasta Argentina LAURA PUGA

golpe de estado como al gobierno de Pol Pot. La violencia relatada tanto en la bibliografía histórica como en el trabajo de campo se puede reflejar en actitudes que no pueden ser entendidas sin conocer aquel pasado. Esta violencia reflejada en el cuerpo de algunos de los sobrevivientes, componen e incluso han determinado algunas entrevistas.

Durante dos años los mediodías de los miércoles salían a buscar algo de comer y yo hacía trabajo de campo. Me instalaba en la plaza Rayo de Sol, frente a la escuela primaria $n^{\circ} 60$. Allí, uno de esos mediodías, entablé conversación con una mujer que integra este colectivo camboyano, a quien llamaré $\mathrm{S}^{19}$. Aquel mediodía, hablaba con ella de su parecer respecto a las creencias religiosas hinduistas de sus padres, yo la escuchaba entretanto tenía la intención de obtener alguna entrevista con otro camboyano de la primera generación.

Mientras S hablaba del budismo de sus padres, aumentaba mi ansiedad por encontrar el momento adecuado para pedirle que me ayude a conseguir tal entrevista. Esa ansiedad me hizo perder el registro de lo que sucedía a mi alrededor. Llevada por esa inquietud, le pregunté. No dudó ni un instante y señalando con un gesto de su cabeza (sus brazos estaban sosteniendo al bebé que no tenía aún dos meses) respondió: "mirá, ahí tenés a uno". Apenas giré la cabeza hacia la derecha, vi una escena a pocos metros de donde estábamos paradas. Se trataba de un varón de unos 60 años aproximadamente, bajo, de un metro cincuenta y cinco centímetros de altura, vestido con una remera sin mangas, musculosa de un cuadro de futbol. Él estaba de pie en la calle y hablaba con tres muchachos jóvenes que se recostaban sobre el muro de la escuela.

Ellos eran entre 20 y 30 centímetros más altos y su diferencia de estatura se acentuaba, pues los tres jóvenes estaban sobre la vereda, considerablemente más alta. Ninguno de los tres parecía tener intensión de emitir palabra respecto de lo que el más bajo decía. Los tres tenían una actitud corporal similar, manos en los bolsillos o tras de su propio cuerpo, hombros caídos y dos de ellos apoyaban sus espaldas sobre el muro. Mendoza Reyes (2012) dice que "La proxémica es el estudio de la forma en que las personas utilizan el espacio (personal y/o social) para comunicarse". En su interpretación acerca de las formas de "ocupar" lugar, se entiende que la distancia entre los tres jóvenes y el adulto camboyano era una distancia social. Esta distancia social es de uno a dos metros y medio, y marca el límite a partir del cual la otra persona no se siente

19 "S" es la mamá de una de mis alumnas, tiene entre 32 y 35 años, nació en Argentina de padre y madre camboyanos recién llegados. Sus dos hijas tienen papá criollo y hablan en perfecto "argentino". Comprende lo que sus padres le dicen, es capaz de hablar no muy fluidamente la lengua camboyana, pero les responde en español. La conocí el día que acompaño y presentó a ChS, quien es su madre. S tiene dos hijas, una es alumna en la escuela secundaria $n^{\circ} 64$ y tiene 14 años, la otra era recién nacida en el momento de conocerla. 
afectada por nuestra presencia. Estos tres jóvenes, a pesar de superar esa distancia, sí parecían estar afectados por la presencia del mayor.

Desconociendo en aquel momento lo expresado por Mendoza Reyes, no dudé en comprender que se trataba de una situación totalmente dominada por el bajo, mayor. Él hablaba con voz firme y gesticulaba con los brazos, parecía ocupar más lugar que los otros tres. Tenía los hombros erguidos, sacaba el pecho en una actitud amenazante. Nada de lo que decía podía parecer una amenaza, se trataba de una charla superficial, vinculada al futbol. Sin embargo, la escena era claramente de subordinación de los jóvenes hacia él. No me animé a interrumpir, ni a esperar a que termine el monólogo, me intimidó su actitud. El varón bajo se impuso más allá de sus oyentes.

Me paralicé. No puedo decir que su actitud fuera amenazadora, pero me sentí sorprendida y acorralada ante la propuesta de $\mathrm{S}$; aquella situación era evidentemente intimidante para mí. En ese momento, sentí que S había disfrutado mi sorpresa y la notoria negativa a abordar a aquel potencial informante. Tiempo más tarde me acordé de que cuando salieron de Camboya, llevaron consigo ciertas marcas de violencia. Aquella escena pudo ser otra forma de actuar lo que ya había sido actuado desde su llegada al barrio, ciertas posturas corporales de defensa, que pueden percibirse como agresivas. Tal como expresó $\mathrm{SMa}^{20}$, cuando los definía como amenazantes, ella dijo: "era difícil relacionarse con ellos al principio, metían miedo".

Ya se ha mencionado que el Estado argentino tuvo un doble gesto con relación a los refugiados. Este grupo fue mostrado internacionalmente como grupo vulnerado, explotado y perseguido por los ejércitos comunistas en uno de los más violentos regímenes del siglo Xx. Por otro lado, abandonados en un contexto en el cual nadie conocía su condición de refugiados por ACNUR. Esta situación vivida por los vecinos y por los mismos refugiados a su llegada, pudo determinar ciertas formas de relacionarse que no fueran "amables", ni de bienvenida.

Es posible también que esto facilitara el control de su trabajo y perpetuara la condición de sometimiento en el barrio receptor, pues difícilmente los ayudaran a conseguir trabajo, a ubicarse en el barrio o a otra colaboración que cualquier vecino podría estar dispuesto a realizar. Sin embargo, los vecinos generaron imaginarios adjudicados a la comunidad. Esos imaginarios no son más que la transferencia hacia el "otro" de prácticas que son propias y no necesariamente de aquel "otro" al que se las conferimos. Esta idea que Trinchero (2000) aplica a los americanos nativos, puede otorgar sentido a algunos de los

\footnotetext{
${ }^{20} \mathrm{SMa}$ es una mujer que tiene algo menos de 60 años, en el momento de realizar el trabajo de campo. Mantuve contacto con ella y tuve la posibilidad de entrevistar pues está vinculada a la comunidad educativa de la escuela primaria $\mathrm{n}^{\circ} 60$, vivía en el barrio desde su infancia en la década de 1960.
} 
Refugiados camboyanos en Longchamps: trayectorias desde Indochina hasta Argentina LAURA PUGA

imaginarios que el barrio adjudica a la comunidad. Pues en este caso, al igual que a los "indios", a los desconocidos "orientales", es decir, a los integrantes de la comunidad en estudio, también se los asocia con estigmas.

\section{Conclusiones}

A manera de conclusión podríamos decir que la violencia vivida por quienes fueran refugiados y la padecieran en Camboya, así como la larga historia de ocupaciones, guerras y gobiernos despóticos, puede reflejarse tanto en la bibliografía académica como en el trabajo etnográfico. Es por ello por lo que se hace posible otorgar sentido a frases, gestos, comportamientos corporales, en los que pueden expresar la crueldad padecida. Es posible advertir también que los lazos comunitarios han tenido un importante rol en este conflicto. Y que aquellas formas de violencia afectaron a esta comunidad de tal manera que sus potencialidades presentes o futuras se ven afectadas y con seguridad representadas en sus narraciones. Concluyendo que la violencia permanece en la vida de los refugiados tomando formas muy varias y representadas de muy diversas maneras.

Tanto durante la investigación, como durante la elaboración de este trabajo se encuentran muy escasos trabajos académicos relacionados con esta minoría étnica. Se han incluido antecedentes de trabajos antropológicos, geográficos e históricos realizados acerca de otras minorías étnicas residentes en el país, para entender y/o dar sentido a las trayectorias de vida del grupo en estudio. Sin embargo, todo parece indicar que está en aumento la inclusión de estas minorías en la investigación académica.

En 1980, cuando Argentina recibió a refugiados de Camboya y Laos, se encontraba bajo el gobierno de la dictadura cívico-militar vigente entre 1976 y 1983. Sus características represivas y su uso del terrorismo de Estado suponen que recibir refugiados no fue una prioridad. Aquella dictadura tuvo razones para acordar la llegada de estos refugiados. En este hecho fue fundamental la búsqueda de legitimidad internacional. Entonces, Argentina se convertía en un país expulsor de población por causas políticas y económicas, al tiempo que recibía refugiados de Indochina.

Por otro lado, las comunidades laosianas y camboyanas alojadas en Misiones se han consolidado como mano de obra barata y marginada en explotaciones agrarias. Esto es funcional como herramienta disciplinaria del Estado, pero también como mecanismo de enriquecimiento de élites locales y conniventes con la dictadura cívico-militar. La responsabilidad que el Estado nacional tuvo con los refugiados lo convierte en partícipe de la explotación económica $\mathrm{y} / \mathrm{o}$ segregación social padecida por ellos. Las maneras de contratación o en que estas personas fueron forzadas a incluirse como mano de 
obra en propiedades preestablecidas por los gobiernos locales podría ser una responsabilidad más del Estado dictatorial que nunca fue juzgada.

\section{Referencias bibliográficas}

AA.VV. (s/f). Diccionario enciclopédico hispanoamericano de literatura, ciencias, artes, tomo IV. Barcelona: Montaner y Simón.

Alto Comisionado de las NACIONES UnidAs PARA los REFUGIAdOS (2000). La situación de los Refugiados en el mundo 2000. Cincuenta años de acción Humanitaria. www.acnur.org/publicaciones-SRM/cap43.php

ANDERSON, B. (1993). Comunidades Imaginadas. Reflexiones sobre el origen y la difusión del nacionalismo. Buenos Aires: FCE.

Brow, J. (1990). Notes on community, hegemony, and the uses of the past. Antropological Quarterly, 63(1), 1-6.

CicognA, M.P. (2006). Exiliados, solicitantes de refugio y refugiados en Argentina Una cronología del siglo XX. VII Jornadas de Sociología. Facultad de Ciencias Sociales, Universidad de Buenos Aires.

CONVENIO Almirante BROWN - FADU/UBA - FUndACión Metropolitana (2010). Programa para el fortalecimiento institucional del Municipio de Almirante Brown. Diagnóstico urbano de Almirante Brown, etapa I.

DeBAnDi, N. (2013). La expulsión de inmigrantes en Francia. ¿Interrupción o parte de las carreras migratorias? Argumentos, 15.

Díaz Polanco, H. (1988). La cuestión étnico-nacional. Fontamara. México.

Golluscio, L.; Briones, C.; Lenton, D.; Ramos, A. y SPOliansky, V. (1996). El discurso en los procesos de formación de comunidad. Lengua y Literatura Mapuche, 7, 87-102. Universidad de la Frontera. Temuco, Chile.

JELIN, E. (2002). Los trabajos de la memoria. Madrid: Siglo XXI.

KIERNAN, B. (2010). El régimen de Pol Pot: raza, poder y genocidio en Camboya bajo el régimen de los Jémeres Rojos, 1975-1979. Buenos Aires: Prometeo Libros.

MARTinO, M.C. (2015). Hacia una contextualización de las migraciones de caboverdeanos en el Gran Buenos Aires a partir de sus diferencias generacionales. Universitas Humanistica, 80, 107-131.

MENDOZA REYES, L. (2012). Lenguaje corporal como medio de comunicación. Lingüistica aplicada. Universidad Autónoma Metropolitana. México.

PACECCA, M.I. Y COURTIS, C. (2008). Inmigración contemporánea en Argentina: dinámicas y politicas. Santiago de Chile: Centro Latinoamericano y Caribeño de Demografía (CELADE). División de Población. CEPAL

PACECCA, M.I. (2013). El trabajo adolescente y la migración desde Bolivia a Argentina: entre la adultez y la explotación. Antropología y Proceso Migratorios, 7. 
Refugiados camboyanos en Longchamps: trayectorias desde Indochina hasta Argentina LAURA PUGA

Page Poma, E. (2015). La integración de los refugiados laosianos de Posadas. Tesis de Licenciatura en Ciencias Antropológicas. Departamento de Antropología. Facultad de Filosofía y Letras, UBA.

Quijano, A. (2000). Colonialidad del poder y clasificación social. Journal of World Systems Research, 6(2), 342-386.

Ministerio Del InTERIOR (2012). Refugiados del Sudeste Asiático en la Argentina. 30 años de Historia. Serie de documentos de la Dirección Nacional de

Población. http://www.mininterior.gov.ar/poblacion/pdf/Documento07.pdf

Strahler, A. (1982) Geografía física. Editorial Omega.

Trinchero, H. (2007) Aromas de lo exótico (retornos del objeto) para una crítica del objeto antropológico y sus modos de reproducción. Colección complejidad humana. Buenos Aires.

Weber, M. (1944) Economía y sociedad. Esbozo de sociología comprensiva. Fondo de Cultura Económico. México.

Wejebe Cobo, J. 7 de marzo de 2012). El año cero de Pol Pot. Diario 90. Defendiendo la verdad desde La Habana. Cuba. https://eladversariocubano.net 
TRADUCCIONES 
The liberationist thinking in Oceania: cartography of circulation of Latin American ideas in the South Pacific

EDUARDO DEVÉS

Devés, Eduardo. "El liberacionismo en Oceanía: Una cartografía de circulación de ideas suramericanas en el Pacífico Sur”. Irquierdas, 49 (2020), 209-221.

\section{THE LIBERATIONIST THINKING IN OCEANIA: CARTOGRAPHY OF CIRCULATION OF LATIN AMERICAN IDEAS IN THE SOUTH PACIFIC ${ }^{1}$}

\section{Eduardo Devés}

Universidad de Santiago de Chile

eduardo.deves@usach.cl

ABSTRACT: The research consists of detecting the presence from the 1970s until the beginning of the 21st century, of two expressions of South American liberationist thinking (Paulo Freire's pedagogy and theology of liberation) in Oceania. Intellectual reception ecosystems and processes of circulation and re-elaboration are indicated in 4 intellectual spaces: higher education institutions (universities and religious seminaries), liberation movements, adult literacy, and indigenous peoples' organizations. Cases are detected in states and territories such as Australia, Fiji, New Caledonia, New Zealand, Papua New Guinea, Timor East, and Vanuatu. Finally, this research concludes with the characterization of the ways in which the South American ideas were received and re-elaborated and the channels through which they arrived in the region and through which they circulated within it.

KEYWORDS: Circulation of ideas, Liberationist thinking, Latin American thought, Paulo Freire, Oceania

RESUMEN: La investigación consiste en detectar la presencia desde los años 1970s hasta inicios del siglo XXI, de dos expresiones del pensamiento liberacionista suramericano (la pedagogía de Paulo Freire y la teología de la liberación) en Oceanía. Se indican los ecosistemas intelectuales de recepción y algunas de las formas de circulación y procesos de reelaboración. Ello se estudia en 4 espacios: las instituciones de formación superior (universidades y seminarios religiosos), los movimientos de liberación, la educación de adultos y las organizaciones de pueblos indígenas. Se estudian casos en Estados y territorios como

\footnotetext{
${ }^{1}$ Traducción al inglés hecha por Alejandro Lamarque y editada por Max Povse.
} 
The liberationist thinking in Oceania: cartography of circulation of Latin American ideas in the South Pacific

EDUARDO DEVÉS

Australia, Fiyi, Nueva Caledonia, Nueva Zelanda, Papúa Nueva Guinea, Timor Oriental y Vanuatu. Se concluye caracterizando las formas en que las ideas suramericanas fueron recepcionadas-reelaboradas y los canales a través de los cuales llegaron a la región y por los cuales circularon dentro de la misma.

Palabras Clave: Circulación de las ideas, Liberacionismo, Pensamiento latinoamericano, Paulo Freire, Oceanía

\section{Introduction}

Studies about ideas have barely ventured towards the Pacific, understood as the whole of the basin while disregarding the interior. Practically, the South Pacific region has not been a unit of analysis, notwithstanding few exceptions (Gardner, 2013; Vervoorn, 2005). Moreover, the Pacific is completely irrelevant among South American thought and its studies when compared to the importance of the Atlantic. Studies concerning South American thought have recently focused on studying connections with other regions of the world besides conventional relations with Western Europe (Bayle, 2015; Beigel, 2013; Devés, 2017). Nevertheless, spatial, and regional coverage remains scarce. Within this, the Pacific continues to be almost entirely absent, except for a few exceptions (Connelly, 1983; Devés, 2016; Rothwell, 2012; Zea, 1988). A first glance would insinuate that practically no circulation of ideas has existed, and that would lead to a major error since new approaches suggest numerous pointers. Moving forward in the task of studying the connections of comings and goings between the basin shorelines seems like an urgent necessity, especially for those willing to highlight non-Eurocentric dimensions in the circulation of ideas. The objectives of this research are, first and primarily, to determine in which intellectual milieus, of what nature, and in which States or territories, aspects of the south American liberationist ${ }^{2}$ thinking were received and cultivated; secondly, to determine where did such ideas came from, through which channels and if these were later exported and where to. In view of these objectives, this paper tries to offer a first cartography of circulation-settlement of ideas coming from South America between 1970, that is, since the liberationists (Paulo Freire and the theologists) published their first volumes, until a little over the 2000 s.

${ }^{2}$ Understanding liberationist thinking as the set of South American expressions inspired by the notion of liberation expressed in education, theology, philosophy, psychology, and sociology among others. Those interested in this thinking can see Cerruti, 2007; Silva, 2009; McKeever, 2004; Richard, 2002; Dussel, 1999; Gadotti, 1996; Libanio, 1992.

Asia/ América Latina, vol. 6, no 11, (2021), pp. 38-56. DOI: 10.33177/11.3 
The liberationist thinking in Oceania: cartography of circulation of Latin American ideas in the South Pacific

EDUARDO DEVÉS

This paper presents some cases, bearing in mind the different ambits of reception. It could not be exhaustive given the required length, but it aims to be merely indicative of what is happening with a South American eidetic tendency in the region, providing work criteria rather than a finished revision. It should be added that the earliest information has been prioritized given its greater interest.

The paper will follow a historical exposition bearing in mind grosso modo the order in which this presence is detected. Each case will be studied considering the following issues: persons, institutions, cities, most relevant years and connections with other figures and institutions to understand this eidetic circulation, giving voice to the protagonists in the reception and circulation of the ideas.

The hypothesis that organized this investigation was the existence of numerous intellectual niches in Oceania, where some ideas of South American origin had been received through a process of eidetic circulation energized by the World Council of Churches (WCC). As the conclusion of a more exhaustive investigation, this hypothesis is confirmed in good measure, although other cases are presented with diverse profiles, other networks, and "energizers", that is, instances that provided human and economic resources so that the circulations would be carried out. From this point forward, the surveyed cases are classified depending on the intellectual ecosystems receiving them: academic, university and seminary ambits, national liberation movements, indigenous movements, and educators in adult teaching. Such ambits and niches should be considered as interconnected because people belong to not just one of these, and, above all, because ideas circulate among them ${ }^{3}$.

\section{Universities and theological seminars}

A first ambit of reception can be identified in the theological seminars of diverse Christian denominations and various Oceanic universities. A very early case is revealed through the Vanuatuan John Sethy Regenvanu, member of a presbyterian denomination. In his biography Regenvanu, who was born in 1945 and held important positions in the politics of his country before and after the independence, tells how during his studies in Suva, Fiji, he shared the experience with teachers and students from varied educational institutions, such as the University of the South Pacific, where a small group of vanuatuans and people from the Christian Student Movement studied. He lived in Fiji in the 70s

\footnotetext{
${ }^{3}$ On this conceptualization and some of its developments, see Devés and Kozel (2018).
} 
The liberationist thinking in Oceania: cartography of circulation of Latin American ideas in the South Pacific

EDUARDO DEVÉS

as a student at Pacific Theological College ${ }^{4}$, where he had the chance to listen to Ivan Illich during his visit to Suva in 1972 (Gardner, 2013, p.135). Regenvanu writes:

Through these contacts and exchanges of ideas, I became increasingly interested in the problems affecting our society and eager to become actively involved in the changes. I began to learn about Father Walter Lini and his newspaper, New Hebrides Viewpoint, and on one occasion I even met him in Suva alongside Kalpokor Lasakau. These young men inspired me, and I saw them as leaders to work with for the good of the country. (2004, p.87)

Regenvanu narrates what happened on his return to Port Vila, Vanuatu, in 1974 and how he involved himself in the tasks of the Secretariat of Education at the presbyterian church where the missionaries William and Roxianne Coop worked. Ragenvanu highlights that working with them was particularly important for his development: "They motivated me to read extensively: editorials produced by colleagues from the Pacific islands, books about Third World countries, such as those texts by Julius Nyerere in Tanzania or the Liberation Theology in Latin America" (2004, p.88). Expounding on this, Regenvanu recalls he was shocked by the proposal of:

Self-reliance from President Julius Nyerere of Tanzania. I was equally impressed by the concepts of education for liberation and liberation theology developed by the Roman Catholics of Latin America, especially Doctor Paulo Freire. Freire, whose method and style of work with the politically and socially oppressed masses of Brazil, had particular significance for me. (2004, p.92-93)

The aforementioned indicates numerous hints leading to the WCC, which we know contributed to the motivation, organization, and financing of a set of initiatives in the region and its ecumenic activities in the different Christian denominations would manifest in the shipping of agents for the diffusion of Christianity, teachers for institutions, travel financing, publications, and scholarships, among others (Gardner, 2013). In addition, during those years Paulo Freire worked at the headquarters of the WCC in Bern. This becomes clearer with the fact that WCC sponsored Freire's trip to Oceania very early on,

4 "The Pacific Theological College is an ecumenical theological college located in Suva, Fiji. Established in 1965, it opened for training in 1966 and was originally designed as the only regional institution to offer degree-level education in theology, available primarily to students from Pacific Island churches". Taken from: www.http://ptc.ac.fj/. 
The liberationist thinking in Oceania: cartography of circulation of Latin American ideas in the South Pacific

EDUARDO DEVÉS

an occasion in which he would have participated in the conference on "Education for Liberation and Community" at Pacific Theological College in Suva (Gardner, 2013, p.135; Hassan, 1991, p.9), in activities in Australia and the Waigani Seminar at Papua NG in 1973. Places where his Pedagogy of the Oppressed, published in English in 1970, was already known.

The Vanuatuan John S. Regenvanu barely mentions the networks spreading South American ideas, rebuilding institutions and publications in the region. Nevertheless, a publication such as Melanesian Journal of Theology embodies these more thoroughly. This journal was edited in the city of Goroka, Papua New Guinea, within the activities of the Melanesian Institute and the Melanesian Association of Theological Schools. The Australian John D'Arcy May was the editor of this journal during its first era. Affiliated to the WCC, D'Arcy lived in Papua NG between 1983 and 1987, after having obtained a PhD in Theology at the University of Münster and another one in History of Religions in Frankfurt. In the presentation to the first issue of the journal, he underlined that the Melanesian Association of Theological Schools had decided to create "a journal with the specific purpose of developing an indigenous theology in Melanesia" (1985, p.2). Clearly, the journal "implies the use of English, which is both a barrier and an intermediary: it interferes due to its foreignness, just as it facilitates due to its universality. This dilemma is faced by all theologists of Third World" (1985a, p.3). Furthermore, he insisted on this orientation: "we aim to publish regularly literary reviews with special relevance to Melanesia, particularly in theological issues of the Third World" (1985b, p.4). Some of these ideas were further reinforced in a review written by D'Arcy himself commenting Walbert Buehlmann's book, The Coming of the Third Church. He states that:

a fascinating thing is that those different emphases and apparent contradictions have been addressed in a South/South discussion between theologists from each side, for instance, at the Ecumenical Association of Third World Theologians (EATWOT) forum and its journal $V$ oices of the Third World. We can look forward to the day in which Melanesians can make their own contributions to these discussions. (1985b, p.67)

In this context he repeatedly cites Hugo Assman, Juan Luis Segundo, and Leonardo Boff, as well as the Sri Lankan Aloysius Pieris, who published Asia Theology of Liberation and participated early on in the EATWOT meetings, and he also met him personally. It must be noted that EATWOT is the primary network that connected South American theological liberationism with the world. 
The liberationist thinking in Oceania: cartography of circulation of Latin American ideas in the South Pacific

EDUARDO DEVÉS

In parallel, by analysing the first issues of the Melanesian Journal of Theology it is possible to tell how the perspective, subjects, authors, and networks of south American liberationist thinking were recurrent among its editor and readers. Even more so, that there already was certain non-South American processing of the liberationist thinking, like considering subjects in terms of theologies of the Third World, theologies of the South and the issue of context, which do not properly pertain to the first stage of South American liberationist thinking. This, on the other hand, exposes the networks through which liberationist ideas would circulate, in some cases as a matter of activism in favour of these ideas, in other cases as a state of the art on theology. For example, Paul Richardson, a British resident in Popondetta, Papua, referred to Gustavo Gutiérrez:

who argues that liberation theology offers a new way to theology? This theology is much more self-conscious about its relationship to everyday struggles of Western theology. Even though European theology can be seen as a response to the pressures of society. (1985, p.62)

Laurenti Magesa's article, on the other hand, mentions the subject of liberation theology, as well as Gutiérrez and Leonardo Boff in reference to social sin and class struggle (1985, p.176-177). For his part, the Belgian Albert Bundervort, catholic bishop of Rabaul, Papua NG, argues that for evangelization to be effective "it must never go without the social and cultural context or life situation of those addressed by it. Therefore, liberation theology, just as it was elaborated in Latin America, is not and cannot be an article for export" (1958, p.183-183). Conversely, the journal is not without authors taking responsibility for the trajectory of oceanic figures that either knew South American liberationist thinking or had similar views such as John Momis, Walter Lini, Fred Timakata and Leslie Boseto. Esau Tuza writes:

On a social and religious level, John Momis and Leslie Boseto have spoken loud and clear. Momis, a religious catholic, considers involving himself with matters relative to social justice as part of his role as a priest. For him, it is in Papua NG's political arena where people's liberation must be considered. The church-state relationship has always been a hot topic of dialogue for Momis, for Walter Lini (Anglican) as well and Reverend Fred Timakata (Presbyterian) from Vanuatu, who fought to lead their peoples towards independence in 1980. (1985, p.52)

In this vein of studying expressions of liberationist thinking and its networks in Oceania's academic milieu, another figure that must be mentioned is the theologist Philip Gibbs, who exhibits a host of receptions, networks and reworks of South American liberationist thinking in those academic ambits. Born in 1947 in New Zealand, Gibbs obtained his doctorate in theology at 
The liberationist thinking in Oceania: cartography of circulation of Latin American ideas in the South Pacific

EDUARDO DEVÉS

Rome's Gregorian University, with a thesis revolving around The Word in the Third World. Divine Revelation in the Theology of Jean-Marc Éla, Aloysius Pieris and Gustavo Gutierre: Gibbs has dedicated numerous works to South American liberation theology as well as its derivations towards other places in the world and the resulting specific modulations $(1998 ; 2005 ; 2007)$, addressing the derivations from South America to Oceania on theological work. He argued in 1998 that "liberation theology is a recent attempt trying to integrate salvation and human effort, since it addresses salvation as an intra-historical reality where the political is grafted to the eternal" (1998, p.42). What Gibbs called "ferocious debate on liberation theology" is indicative, "of the diversity of opinions within the Catholic church". The underlines that:

In the past, conservative Evangelical and Pentecostal churches tended to considerer politics as a sinful world and kept distance. Nevertheless, there has been a significant change in Papua NG. Christians have accepted they must be a part in the answer to their prayers. This means they must become involved in political and social realities. (1998, p.42)

Following this he would quote dean Sherman who writes: "We are called upon to build and repair the damages to the walls of society through struggle, prayer and involvement". His call for involvement does not differ from the demand of commitment within liberation theology (1998, p.42). The New Zealander stressed in 2005 that "there are contextual theologies coming from many Third World countries that may stimulate ideas among the people of Papua NG. Theologists from Papua NG must make a significant contribution to EATWOT's work" (2005, p.51). Referring to Aloysius Pieris, creator of the "Asian liberation theology", he remarks that when talking about contextual theology "it is useful wondering just how much theological thought finds in the experience of faith among grassroot communities, what Pieris calls third magisterium" (2005, p.52). In 2007, Gibbs returned to this topics remarking that "over the last 30 years, there have been numerous attempts in various places around the world to include circumstance in theological thought", emphasizing that this circumstance is specific since "in Latin America, attention to political and social struggle against dependence and poverty has resulted in a form of theology in which 'liberation' has become the fundamental hermeneutical key to understanding the Christian message", whereas "in the Asia context, religious pluralism remains a constant challenge to contextual theology" and, "in Africa, theologies have focused on the ethnic and cultural dimensions of life in that continent. In the Pacific, there has been renewed attention develop a genuine contextual theology" (2007, p.4). 
The liberationist thinking in Oceania: cartography of circulation of Latin American ideas in the South Pacific

EDUARDO DEVÉS

\section{Popular and adult education}

A second space of reception-rework for South American liberationist thinking in Oceania was composed of those responsible for popular and adult education. Popular education is a privileged ambit and the most specific in terms of reception of Paulo Freire's ideas. In relation to this, various expressions may arise and three in particular: a first one, the most conventional, understood as the pedagogical work of professional educators; a second one, as indigenous education and overlapped with aboriginal people's organizations; and a third formula found in liberation movements, as will be observed in Timor. In this section, only the first one will be addressed, with the other two appropriately expounded on in the following parts.

The figure of Gwayeweng Kiki and his investigations, as part of his doctoral thesis under the guidance of Edmund Parker at Australia's Charles Sturt University, enables linking the presence of liberationist thinking in seminars and universities closely with adult education. Kiki, coming from Papua NG, has dedicated to the way of teaching theology to "non-Western" people. During a long residence at Suva's Pacific Theological College, he conducted research he characterized as oriented towards "a better and more efficient way of teaching theology to students in Papua NG within the Lutheran Evangelical Church" (Parker and Kiki, 2014, p.108). To frame and conduct his research, he systematically consulted Paulo Freire's work, just as he leaves written record of his work ${ }^{5}$. He has stressed that "an analysis of current teaching and learning methodologies used in the formation of Papua NG's Lutheran ministers was of particular importance", and it was supplemented with "praxis and transcultural learning, which shows ways of knowing and learning as they are used by people with non-Western orientations. In this vein, writers such as Paulo Freire were considered" as well as others. Thirdly, they highlight the "wokabaut-kaikulum notion, a 'concept' coming from tokpisin (a pidgin from Papua NG). In this view, non-aboriginal theorists of education, pedagogy and curricula were considered alongside aboriginal Melanesian specialists on culture, religion, and theology"

\footnotetext{
${ }^{5}$ For instance: Paulo Freire, Cultural Action for Freedom, preface by Joao da Veiga Coutinho (Middlesex: Penguin Education, 1974), and Pedagogy of the Oppressed, new rev. 20th-ann. ed. Translation by Myra Bergman (Ramos, New York: Continuum, 1997).
} 
The liberationist thinking in Oceania: cartography of circulation of Latin American ideas in the South Pacific

EDUARDO DEVÉS

(Parker and Kiki, 2014, p.109-110). His idea, aiming towards Melanesian epistemological systems, were innovative by trying to articulate Freire's thought with the Melanesian cultural trajectory, based on the wokabaut-karikulum which is defined as:

a shared relational approach to learning that emphasizes the relationship between learning and being, in the sense that mind and body are bound. But, on the other hand, knowledge obliges the individual in their relationship with the community, where the existence of knowledge is socially distributed. (Parker and Kiki, 2014, p.115)

The aforementioned research on theological education for adults is very recent, but Paulo Freire's impact on Oceania's adult education can be noticed since the early 70s. The South American visited Melbourne in 1972, invited as a speaker by the WCC. The argument has been made (Osmond, 2016) that his visit motivated a commitment among popular educators in the state of Victoria to adult education as a labour of social change, resulting in the permanence of concepts such as "emancipation" and "liberation" in this educator sector's discourse. This led to a set of pedagogical approaches such as: co-participation in learning, the notion of the teacher's task as a facilitator instead of an expert, the need of taking cues from the students' lives and experiences, student's involvement in the elaboration of learning goals and contents, and the presence of concepts such as emancipation and liberation in the discourse of those working as popular educators (Medlin, 2017; Osmond, 2016).

Precisely as an expression of the extensive legacy left by Freire in Australia, groups such as "Popular Education Network of Australia" and "Twenty First Century Critical Education" must be mentioned. The latter, composed of Tracey Ollis, Jo Williams, Rob Townsend, Anne Harris, Jorge Jorquera and Lea Campbell, states in its declaration of principles that:

Drawing on the philosophies and writings of Paulo Freire regarding education as activism, the network, founded in 2009, involves educators, academics, and community workers working together on issues relating to critical pedagogy and social change in schools, communities, and adult education contexts. (Ollis et al, 2010, p.175)

Afterwards, they remarked that the first symposium on Teaching and Learning for Social Justice and Action they organized "was held at Victoria University in October 2013 and focused on the ways in which popular education upholds a social justice agenda and functions within community development" (p.178) and that the fundamental address of the symposium "was done by 
The liberationist thinking in Oceania: cartography of circulation of Latin American ideas in the South Pacific

EDUARDO DEVÉS

Professor Antonia Darder and titled Reinventing Paulo Freire: A Critical Pedagogy of Love" (p. 179).

In this vein and continuing Freire's legacy, the gathering in 2012 of the "Australian Council of Adult Literacy" must be mentioned. The issue of the campaign addressed there was explicitly inspired in Paulo Freire's ideas, bearing in mind previous experiences such as Cuba, Tanzania, Nicaragua, Guinea Bissau, India, and East Timor, which will be specifically expounded on in the next section. In the Tasmania campaign report, presented by Bob Boughton (2012), Freire's work is systematically referred to in diverse regions of the world as well as authors referencing the Brazilian educator.

\section{Liberation movements}

A third ambit of reception is composed of the liberation or independence movements, particularly in East Timor and New Caledonia, as well as, but less explicitly, in Vanuatu. These were spaces where the ideas of South American liberationist thinking were received and even reformed jointly with others, present in those intellectual ecosystems, contributing to inspire those movements. Certainly, in diverse places the types of struggles for independence were also diverse, besides successful o failed, and so were the ideas of liberationist thinking that made it to those places. In some cases, it was mainly Freirean educational thought, in other cases it was associated with theological thought.

In East Timor, the WCC, generally very influential in the circulation of liberationist ideas, and the agents of the main acting churches in the region did not play salient roles. The circulation of liberationist ideas involved other networks here. A very different model of eidetic circulation is produced by Timorese students matriculated in some universities from Portugal and committed to independence and what would later become the Democratic Republic of Timor-Leste. In this case, independence organizations and guerrillas assumed Paulo Freire's arguments as methods to promote literacy and politization of the masses, all this through "Casa dos Timores", the student organization that brought them together in Lisbon. There, the literacy handbook "Timor is our country" was printed, created by the Revolutionary Front for an Independent East Timor (FRETILIN) combining the pedagogical and independence drive. Antonio Carvarinho and Francisco Borja, da Costa, among others, worked on this document (Leach, 2017, p.63-64). Nevertheless, "to make a whole literacy campaign possible, Silva (2012, p.2) remarks that FRETILIN, in association with the Portuguese Decolonization Committee, established the 
The liberationist thinking in Oceania: cartography of circulation of Latin American ideas in the South Pacific

EDUARDO DEVÉS

"Grupo de Coordenaçao para Reformulaçao do Ensino em Timor" (Urban, 2017, p.86). According to Silva (2011, p.63), among those participating in this literacy commission was Portuguese Professor Judith Magalhaes who, alongside the students from "Casa dos Timores" in Lisbon, was one of the persons that brought Paulo Freire's ideas on awareness to the Timorese Student National Union (Silva, 2012, p.2; Urban, 2017, p.86). Samuel Urban (2017) underlines that it was precisely "through this Portuguese committee that Paulo Freire's Pedagogy of the Oppressed arrived to Timor, becoming the starting point of the literacy campaign" and, eventually, "members of Casa dos Timores would take part in FRETILIN, also becoming 'trainers' (in the literacy campaign), together with people from other groups such as the Timorese Student Union and some people from the Portuguese Committee of Decolonization" (p.87).

A different case was that of New Caledonia's independence or autonomy movement, where it was the case of theological libertarianism, in the context of a network connected to Fiji, Vanuatu, Papua and the WCC, rather than the Timorese formula. Although, the similarity is noticeable in the struggle for independence and the reception of South American thought among student groups in foreign countries. The New Caledonian Pothin Wete created his most relevant work to this end as a postgraduate thesis at Suva's Pacific Theological College, as in the case of J. Regenvanu a decade before. In 1987 he presented his work there on the possibility of a kanak liberation theology ${ }^{6}$. Charles W. Forman (2005, p.118) argues that Wata reviewed the historical base of the political, economic, and social current situation of the kanak people and the evangelical church, tracing the emergence of ecclesial instances in favour of independence, referring to liberation theologies in other parts of the world and aiming towards a kanak theology of liberation. According to Forman, Wete brought "the liberation theme to a more fundamental level. He believes Kanak liberation theology will enrich and deepen the liberation theologies of other lands" (p.117). Since "this [theology] expresses the cry of a people not just for political or economic liberation but for their very existence" (p.117). As stated by Wete, kanaks would be "in danger of losing their existence through the loss of traditional values and the adoption of foreign ways" (p.117). And this concern is based:

not simply on national identity, it has biblical roots as well. The demand for independence flows from all that Hebrew prophets have said about

\footnotetext{
${ }^{6}$ Wete, Pothin. The development of the political awareness of the Kanak Evangelical Church in New Caledonia and the Loyalty Islands from 1960 to 1987 and its theological implications possibility for a Kanak liberation theology, Thesis (B.D.), Pacific Theological College, 1988.
} 
The liberationist thinking in Oceania: cartography of circulation of Latin American ideas in the South Pacific

EDUARDO DEVÉS

justice and freedom. It is also related to the Christian for the new creation. That hope leads the Kanaks forward on the path toward independence. (Forman, 2005, p.117)

Wete continued (Forman, 2005) a line that had already been cultivated in the same institution by another kana, Djoubelly Wea, who worked on an education for the liberation of the kanak people. ${ }^{7}$ After their studies, Wea above all, but also Wete, became involved with New Caledonia's independence and identity movements. Pothin Wete later became professor at Pacific Theological College, which shows the presence of a line of thought clearly related to South American liberationist thinking. In several other places of the South Pacific, important figures of the independence movements, several of these belonging to the clergy of diverse denominations as in the case of New Caledonia, had very similar positions and specifically inspired by liberationist thinking, just as was mentioned above: John Momis, Walter Lini, Fred Timakata and Leslie Boseto.

\section{Indigenous people's organizations}

The fourth space is constituted by the organizations of indigenous peoples. In this ambit, the cognizance of otherness regarding the Caucasian ethnicity, predominant in New Zealand and Australia, has taken place through Paulo Freire's notions. In this endeavour the figure of Graham HingangaroaSmith, a leader of Maori movements and professor at Auckland University, stands out. His most important approach to the issue has been Maori education and the coordination of this people with other indigenous ones surrounding the Pacific, besides the Oceanics, in places such as Canada, Hawaii, mainland US, Taiwan and Chile, which has linked him to the "Tribal Universities" project. Hingangaroa-Smith (2003) argues that the "counter strategy to hegemony is that indigenous people need to critically 'conscientize' themselves about their needs, aspirations and preferences" (p.2-3). He justifies: "this call for a 'freeing-up' of the indigenous imagination and thinking" since:

one of the elements of colonization is the diminishment of the indigenous ability to actually imagine freedom or a utopic vision free of the oppressor. Thus, a critical element in the 'revolution' has to be the struggle for our minds, the freeing of the indigenous mind. (p. 3)

He is looking, however, to articulate the discourse coming from Paulo Freire with the trajectory of indigenous thinking, what he denominates "Kaupapa

\footnotetext{
${ }^{7}$ Published in 1977: An Education for the Kanak Liberation: A Project, Pacific Theological College.
}

Asia/ América Latina, vol. 6, no 11, (2021), pp. 38-56. DOI: 10.33177/11.3 
The liberationist thinking in Oceania: cartography of circulation of Latin American ideas in the South Pacific

EDUARDO DEVÉS

Maori approach". This pertains to the fact that a predominant term such as "decolonization" is a "reactive notion", whereas "in moving to transformative politics we need to understand the history of colonization but the bulk of our work and focus must be in the imagination of a future" (p.3). In that sense, he points out "the lesson of the Kaupapa Maori approach from New Zealand is that transformation involves two parts: a confrontation with the colonizer and a confrontation with 'ourselves', the inside-out model, that splices with Freire's notion of "first free ourselves before we can free others" (2003, p.3). Hingangaroa-Smith has continued working on the Maori thinking-resistancepraxis based on Paulo Freire, as his subsequent publications in 2005 and 2009 show, but above all 2017, in which he returns to the subjects relative to Freire and conscientization. Besides Hingangaroa-Smith, other people working on the same issues in New Zealand can be included, such as Tangiwai Kepa, who presented her PhD. thesis at Auckland University in 2001. In Language matters: The politics of teaching immigrants adolescents school English, where she gives account of the perspective employed in her investigation remarking that "this thesis was written from the perspective of a Maori indigenous professor", who in spite of being "trained technocratic approaches of practices", has been "looking for aspects of her intimate culture, the ways of representing the world of Tonga and Samoa and Paulo Freire's critical pedagogy, to transform contemporary education, which tends to exclude the teenager from learning in school" (2001).

\section{Conclusions}

A first cartography of the presence of South American liberationist ideas in various places of Oceania has been offered. These are not the only ones. The number of intellectual ecosystems could be expanded and the niches where these ideas arrived and prospered could be better specified. It is a first account, done with pragmatic criteria and one that allows for some conclusions that will now be detailed.

Concerning the type of intellectual environments where the ideas were received and cultivated. Four primary ambits have been determined (academic ambits in universities and seminars, liberation and national independence movements, adult education spaces and indigenous people's organizations) in 7 South Pacific states or territories (Australia, Fiji, New Caledonia, New Zealand, Papua NG, East Timor, and Vanuatu). Such ambits are not completely separate and interact or even overlap. Oceania alone has been chosen in the search of homogeneity among the types of intellectual ecosystems, although other cases 
The liberationist thinking in Oceania: cartography of circulation of Latin American ideas in the South Pacific

EDUARDO DEVÉS

in the South Pacific could have been addressed. There are studies that account for the reception of Paulo Freire's thinking, particularly in the Philippines (Cortez, 2013; 2014) and Indonesia (Nuryatno, 2006). The Indonesian case would have been especially different since Freire's reception operates in intellectual ecosystems with autochthonous languages and marked by Islam.

Regarding the channels through which South American ideas arrived at different Oceanic intellectual ecosystems and if these were exported or circulated from there and where to. It follows that, since these are intellectual ecosystems where the languages of the intelligentsia are almost exclusively English and French, it is clear that communication was not always directly between South America and Oceania, not even in the case of East Timor where the language of the intelligentsia is Portuguese. In all cases circulation was partially mediated by networks and publishing houses in Western Europe and the US, as can be seen from the translation, the institutions, the networks.

This certainly does not exclude the agency of South American figures that worked in different places of the Pacific, especially some cities of Australia or New Zealand, or participated in relevant positions of international networks such as the case of Paulo Freire himself, as well as José Miguez Bonino and Julio Santa-Ana (Devés 2016; Paredes y Escalante Gómez, 2010) at the WCC, and above all, the creation and management of the EATWOT, crucial to the circulation of liberationist ideas among diverse places of the periphery world. More precisely, answering the issue of the networks that connected those receiving and the energizers of the circulation, the difference between theologists from Australia and New Zealand and those operating in the ecosystems of the islands ought to be underlined.

The former had circulation in the first world, connected relatively early to the EATWOT, and from there to people from South America and other provenances with knowledge of liberationism. Regarding the latter, first the institution of Fiji's Pacific Theological College in Suva and the network that articulated those who taught and/or studied there with other former students and with numerous people participating from diverse Christian denominations must be considered. The Pacific Theological College presents itself as probably the most important institution where the ideas of South American liberationist thinking were received, cultivated y re-exported in the South Pacific region. It has been seen how students and teachers from different backgrounds converged there and how, at least in some cases, these ideas were exported to New Caledonia, for instance.

Now then, if the energizers that consciously or not sustained the circulation of ideas, have historically been very diverse agents: states or empires, 
The liberationist thinking in Oceania: cartography of circulation of Latin American ideas in the South Pacific

EDUARDO DEVÉS

diplomacy, educational institutions, missionaries, propagandists, it must be remarked that in this case it was primarily churches and other civil society agents, notwithstanding the fact that in many cases economic resources depended on the states and their financing to churches and NGOs. In any case, one must not only imagine grand energizers that made circulation a possibility, but also numerous cases of people linked to popular education, to indigenous organizations, to politics, to university teaching, to ecclesial practices, among other activities, that were enthusiastic of these ideas and decided to transform into diffusers and "adapters" such as the case of adult education in Australia or East Timor.

\section{References}

APPLE, M. (1999). Freire, neo-liberalism and education. Discourse: studies in the cultural politics of education, 20(1), pp. 5-20.

BAYLE, P.A. (2015). Conectando sures. La construcción de redes académicas entre América Latina y África. Íconos, 53, pp. 153-170. DOI: http://dx.doi.org/10.17141/iconos.53.2015.1445

BEIGEL, F. (2013). Centros y periferias en la circulación internacional del conocimiento. Nueva Sociedad, $\mathrm{n}^{\circ} 245$. https:// nuso.org/articulo/centros-y-periferias-en-la-circulacioninternacional-del-conocimiento/

Boughton, B. (2012). South-South Cooperation: Can it work in Australia? Keynote Presentation Australian Council of Adult Literacy Annual Conference Hobart, Tasmania. 19-21 September 2012. New England University.

Bundervoet, A. (1985). Liberation Theology in the Context of Papua New Guinea. Journal of Melanesian Association of Theological Schools, 1(2), pp. 182185. Goroka.

CERUTTI, H. (2007). La filosofía de la liberación. México: FCE.

Connelly, M. (1983). Influencia del pensamiento de Mao en América Latina. Estudios de Asia y África, 18(2), pp. 215-231.

https:/ / estudiosdeasiayafrica.colmex.mx/index.php/eaa/article/view/ 883

Cortez, F.G.F. (2013). The Philippine Engagement with Paulo Freire. KRITIKE, 7(2), pp. 50-70. http://www.kritike.org/journal/issue_13/cortez_december2013.pdf 
The liberationist thinking in Oceania: cartography of circulation of Latin American ideas in the South Pacific

EDUARDO DEVÉS

Cortez, F.G.F. (2014). The Prospect of Liberating Pedagogy in the Thoughts of Amable G. Tuibeo. Mabini Review, 3(1), pp. 16-69. Polytechnic University of the Philippines.

http://dx.doi.org/10.4067/S0718-23762017000100213

DEVÉs, E. (2016). La circulación de las ideas, una conceptualización: el caso de la teología latinoamericana en Corea del Sur. Estudios Avanzados, 25, pp. $20-41$.

DEvÉs, E. (2017). La teología asiática de la liberación, un caso de recepción, apropiación y reelaboración de ideas. Universum, 31(1), pp. 213-230.

DEVÉs, E. Y KOZEL, A. (2018). Estudios Eidéticos. Una conversación, desde el sur, sobre la vida de las ideas y la reconfiguración de un espacio disciplinar. Santiago de Chile: Ariadna.

Dussel, E. (1999). Teología da Libertação. Um panorama de seu desenvolvimento. Petrópolis: Vozes.

Forman, C.W. (2005). Finding Our Own Voice: The Reinterpreting of Christianity by Oceanian Theologians. International Bulletin of Missionary Research, 29(3).

GadotTi, M. (1996). Paulo Freire uma biobibliografía. Sao Paulo: Cortez Editora. Gardner, H. (2013). Praying for Independence. The Presbyterian Church in the Decolonisation of Vanuatu. The Journal of Pacific History, 48(2), pp. 122-143. DOI: https://doi.org/10.1080/00223344.2013.781761

GIBBS, P. (1998). The Religious Factor in Papua New Guinea Politics. Catalyst, 28(1), pp. 27-51.

GIBBS, P. (2005). Grassroots in Paradise: Contextual Theology for Papua New Guinea. Melanesian Journal of Theology, 21(1), pp. 37-62.

GiBBS, P. (2007). Narrative and Context in a Practical Theology for Papua New Guinea. Australian eJournal of Theology, 9.

Hassan, G. (1991). Church and state in Vanuatu 1945-1980: A "Pacific" contest for power. South Pacific Journal of Mission Studies.

KEPA, T. (2001). Language matters: The politics of teaching immigrant adolescents school English. PhD. Thesis, Auckland University.

LEACH, M. (2017). Nation-Building and National Identity in Timor-Leste. London and New York: Routledge.

LiBAnio, J.B. (1992). Panorama da teología da América Latina nos últimos 20 anos. Perspectiva Teológica, 24(63), pp. 147-192. 
The liberationist thinking in Oceania: cartography of circulation of Latin American ideas in the South Pacific

EDUARDO DEVÉS

MAGESA, L. (1985). Instruction on the "Theology of Liberation": A Comment. Journal of Melanesian Association of Theological Schools. 1(2), pp. 175-181. Goroka.

MAY, J.D. (1985a). Editorial: Introducing MJT. Journal of Melanesian Association of Theological Schools. 1(1), pp. 1-3. Goroka.

MAY, J.D. (1985b). Theologies of the "Third Church". Journal of Melanesian Association of Theological Schools. 1(1), pp. 65-70. Goroka.

McKeEver, M. (2004). Thirty years of liberation theology. Theology Digest, 51.

MEDLIN, J. (2017). The Australian literacy and numeracy workforce: a literature review. Occasional paper. Adelaide: NCVER.

Nuryatno, M.A. (2006). Education and Social Transformation: Investigating the Influence and Reception of Paulo Freire in Indonesia. Ph.D. Thesis Faculty of Education, McGill University.

Ollis, T.; Williams, J.; TOWNSEnd, R.; HARris, A.; JORQUERA, J. AND CAmpBeld, L. (2010). The Popular Education Network of Australia (PENA) and Twenty-First-Century Critical Education in Peters, M.A. and Besley, T. (Eds.), Paulo Freire. The global legacy (pp. 175-186). Berlin: Peter Lang Publishing Books.

OSMOND, P. (2016). What happened to our community of practice? The early development of adult basic education in NSW through the lens of professional practice theory. Literacy and Numeracy Studies, 24(2), pp. 3-

23. DOI: http://dx.doi.org/10.5130/lns.v24i2.4821

PAREDES, A. AND ESCALANTE GÓmEZ, E. (2010). La visualización de "colegios invisibles" en las publicaciones político-religiosas de editorial Tierra Nueva (década 1970) y su inserción en discursos de época. Theoria, 19(1), pp. 61-82. Universidad del Bío-Bío.

PARKER, E. AND KIKI, G. (2014). Is There a Better Way to Teach Theology to Non-Western Persons? Research from Papua New Guinea that Could Benefit the Wider Pacific. Australian eJournal of Theology, 21(2), pp. 108124.

Regenvanu, J. (2004). From Village to Nation: an Autobiography. Institute of Pacific Studies and Emaulus Campus. Suva: University of the South Pacific.

https://books.google.cl/books?id=0WEeYDxeE9gC\&printsec=frontcover\&h $\mathrm{l}=$ es\&source $=\mathrm{gbs}$ ge_summary_r\&cad $=0 \# \mathrm{v}=$ onepage $\& \mathrm{q} \& \mathrm{f}=$ false 
The liberationist thinking in Oceania: cartography of circulation of Latin American ideas in the South Pacific

EDUARDO DEVÉS

Richardson, P. (1985). Seeing Western Theology in Context. Journal of Melanesian Association of Theological Schools. Vol 1(2), pp. 61-65. Goroka.

Richard, P. (2002). La Iglesia y la Teología de la Liberación en América Latina y el Caribe: 1962-2002. Pasos 103.

Rothwell, M. (2012). Transpacific Revolutionaries: The Chinese Revolution in Latin America. Routledge.

Schugurensky, D. (2014). Paulo Freire. London: Bloomsbury.

SiLVA, S. (2009). La Teología de la Liberación. Teología y Vida, Vol. L, pp. 93116. DOI: http://dx.doi.org/10.4067/S0049-34492009000100008

SILVA, A.B. DA (2011). FRETILIN Popular Education 1973-1978 and its relevance to Timor-Leste today. PhD. Thesis, New England University.

SILVA, A.B. DA (2012). Literacy Model of the Maubere Pedagogy. Comunicação apresentada no Grupo de Estudos Brasil-Timor, Peace and Conflict Studies Institute.

SMITH, G.H. (2003). "Indigenous Struggle for the Transformation of Education and Schooling, Keynote Address to the Alaskan Federation of Natives Convention". Alaska: Anchorage.

SMITH, G.H. (2009). Mai i te maramatanga, ki te putanga mai o te tahuritanga: From Conscientisation to transformation in Andrzejewski, J.; Baltodano, M.P and Symcox, L. (Eds.) Social Justice, peace and environmental education: transformative standards (pp. 19-28). New York and London: Routledge.

Smith, G.H. (2015) "Equity as Critical Praxis: The Self-Development of Te Whare Wananga o Awanuiarangi” en Peters, M y T. Besley, Paulo Freire: The Global Legacy (Eds.) Peter Lang, New York.

SmitH, G.H. (2017). "Keynote address: 12 noon, Wednesday, July 26, University Theatre (ADM026) Academic Work as Transforming Praxis: From Discourse to Enactment (Show me the blisters on your hands!)". http:/ /rmooc.ca/news/july-26-keynote-130-pm-graham-hingangaroasmith/

TuZA, E. (1985). Instances of "God-talks" in Melanesia. Journal of Melanesian Association of Theological Schools. 1(1), pp. 47-60. Goroka.

Urban, S. (2017). Paulo Freire e a educação popular em Timor-Leste: uma história de libertação. Educação e Emancipação, 10(1), pp. 76.

DOI:10.18764/2358-4319.v10n1p76-100 
The liberationist thinking in Oceania: cartography of circulation of Latin American ideas in the South Pacific

EDUARDO DEVÉS

Asia

Anerica

Latina

56

Vervoorn, A. (2005). Intelectuales públicos en Asia y el Pacífico. Anuario Asia Pacífico, n¹, pp. 461-470.

WETE, P. (1988). The development of the political awareness of the Kanak Evangelical Church in New Caledonia and the Loyalty Islands from 1960 to 1987 and its theological implications possibility for a Kanak liberation theology. Thesis (B.D.), Pacific Theological College.

ZEA, L. (1988). "Prólogo" a Rizal, José Noli me Tangere, Biblioteca Ayacucho, Caracas. 
WORK IN

PROGRESS 


\section{ASEAN: ¿REGLA O EXCEPCIÓN?}

ASEAN: ¿NORM OR RARITY?

\section{Catalina Mas}

Universidad de Buenos Aires

catalina.mas22@gmail.com

RESUMEN: El presente trabajo tiene como objetivo explorar la aplicabilidad de dos de las teorías de la integración regional más relevantes (neofuncionalismo e intergubernamentalismo) a la Asociación de Naciones del Sudeste Asiático (ASEAN, por sus siglas en inglés). En este sentido, se buscará encontrar, a través de fuentes primarias y secundarias, las características más relevantes de ambas corrientes. Se les prestará especial atención a los acuerdos plasmados en forma de instrumentos legales, ya que se constituyen como la materialización de estos. De este modo, es posible medir la frecuencia, eje temático y nivel de especialización de cada acuerdo para testear si se trata de instrumentos de naturaleza intergubernamental o, por el contrario, se puede observar algún nivel de spillover con el correr de los años.

Palabras clave: ASEAN, integración regional, cooperación, neofuncionalismo, intergubernamentalismo.

ABSTRACT: The following article seeks to explore the applicability of two of the most relevant regional integration theories (neofunctionalism and intergovernmentalism) regarding the Association of Southeast Asian Nations (ASEAN). To do so, it will try and find the key elements of each theory present in its institutional functioning through primary and secondary sources. Special attention will be paid to the agreements between the parties in the form of legal instruments since they are the materialized form. In this manner, it is possible to monitor and measure the frequency, topic, and level of specialization of each agreement, to test whether they have an intergovernmental nature, or, on the contrary, there is a spillover effect over the years.

Key Words: ASEAN, regional integration, cooperation, neofunctionalism, intergovernmentalism. 


\section{Introducción}

La Asociación de Naciones del Sudeste Asiático (ASEAN, por sus siglas en inglés) ha pasado por diversos procesos de profundización en materia de cooperación. En este sentido, la agenda fue mutando desde los objetivos securitarios para hacerle frente a Vietnam y posteriormente China, hasta la profundización en la cooperación económica y social. El pasaje desde 1967, con la firma del primer tratado que instauró un trato preferencial entre sus miembros, hasta la cumbre de Singapur en 1993, que definió las bases para una zona de libre comercio, demostrarían la importancia creciente que supuso la integración regional para sus miembros (Laursen, 2010). Actualmente, la organización posee principios plasmados en tratados, una organización tripartita y un organigrama que parecería apuntar hacia una mayor cooperación en áreas más abarcativas de la política regional (Laursen, 2010; Min-hyung, 2011).

En la actualidad, la ASEAN está posicionada como un actor estratégico en la arena internacional, abriendo la posibilidad de dialogar con otros actores de forma conjunta e inaugurando foros ampliados como ASEAN+3. Dependiendo de la perspectiva de análisis con la que se decida analizar a ASEAN se lo podría considerar -desde la perspectiva securitaria- como un elemento de balancing regional mostrando un contrapeso con China, o bien -desde el punto de vista económico- como un bloque que permite posicionar mejor a la región en términos económicos y comerciales (Börzel, 2015; Min-hyung, 2011).

Sin embargo, el hecho de mostrar una mayor cohesión no eclipsa lo que los académicos han denominado el "ASEAN way", una forma de diálogo y prevención de conflictos entre los integrantes que salvaguarda la autonomía nacional de cada uno de los Estados parte. Tanto su relevancia en la región y a nivel sistémico como su particularidad generan la necesidad de entender más y mejor el fenómeno del "ASEAN way". En este sentido, es interesante revisitar las teorías de la integración regional a la luz de este caso para así testear su capacidad explicativa.

\section{Metodología}

$\mathrm{Al}$ momento de analizar las experiencias de integración regional, no es menor el hecho de que las teorías clásicas hayan surgido a la luz de la experiencia europea. Se trata de teorías que pretenden ser de rango entre medio y alto, siendo altamente generalizables (Malamud, 2011). Asimismo, han surgido varias críticas y teorías alternativas como la de gobernanza (Börzel, 2015). Si bien estas no son incompatibles con ciertas corrientes de las teorías clásicas, generan aportes significativos que nos pueden ayudar a comprender mejor las dinámicas de interacción entre los actores. 


\section{ASEAN: ¿regla o excepción? \\ CATALINA MAS}

El fin del presente trabajo será explorar el nivel de aplicabilidad de las principales teorías clásicas de la integración (neofuncionalismo e intergubernamentalismo) para tratar de responder cuál se adecúa más al caso de ASEAN. A tal fin se revisarán, en primer lugar, los principios generales de los dos grandes cuerpos de teorías de la integración regional y los aportes de la perspectiva de gobernanza (Börzel, 2015). En segundo lugar, se intentará aplicar los elementos esenciales de cada cuerpo teórico al caso de ASEAN siguiendo las particularidades organizativas, los acuerdos logrados y las experiencias históricas.

En este sentido, se utilizará una metodología mixta cuali y cuantitativa. Por un lado, se revisarán fuentes primarias publicadas por ASEAN en su página oficial, por ejemplo, el organigrama y los tratados y principios explicitados en su tratado de conformación. A su vez, se consultarán fuentes secundarias con respecto a los "valores asiáticos" -orden y disciplina- de la región (Del Río Martínez, 2018), la historia y el funcionamiento de ASEAN. Finalmente, se realizará un análisis cuantitativo del desarrollo de instrumentos legales y acuerdos teniendo como eje la temporalidad a fin de distinguir si hubo mutación en los temas más salientes y testear la posibilidad de encontrar un fenómeno de spillover (Schimmelfennig y Rittberger, 2006).

El presente trabajo es una primera aproximación que deberá ser complementada con otros monitoreos a futuro. Se tomarán como fuente el listado de acuerdos e instrumentos legales ASEAN ya clasificados en las tres comunidades (económica, político-securitaria y sociocultural). Se le asignará un eje temático y, posteriormente, se operacionalizarán en cuanto a su grado de especificidad en dos tipos: 1. referidos a los marcos organizacionales de la ASEAN; 2. referidos a la resolución sustancial de una temática específica.

\section{Aproximaciones teóricas clásicas y aportes de Gobernanza}

\section{III.1. Neofuncionalismo}

El neofuncionalismo se considerará a la luz de las contribuciones de varios autores supranacionalistas (especialmente institucionalistas sociales y legales), ya que es posible pensar en estas teorías como las sucesoras directas de la teoría neofuncionalista clásica fundada por Haas (Stroby Jensen, 2016). El neofuncionalismo asume que el mismo mecanismo de la integración produce una mayor integración a través de, al menos, cuatro mecanismos: spillover funcional, spillover político, spillover institucional, y la sociabilización de elites. Considera como premisa básica que "la cooperación en un área de la política crea presión en otras áreas, posicionándolas en la agenda política" (Schimmelfennig y Ritterberg, 2005, p. 84). Al contrario de los realistas e intergubernamentalistas, consideran que el proceso de integración no debería ser considerado como un juego de suma cero bajo el cual los Estados pierden frente 
al fortalecimiento de otros. Adicionalmente, interpreta que este proceso es semiautomático (o path-dependent), donde los grupos de interés, actores no gubernamentales y lobbies juegan un rol sumamente importante.

La noción de "semiautomático" o path-dependent es mejor entendida a través del concepto de spillover. Como se ha mencionado anteriormente, "refiere al proceso mediante el cual los miembros de un proyecto de integración (...) intentan resolver cuestiones insatisfechas recurriendo a la colaboración en otro sector relacionado" (Schmitter, 1969, p. 162). Estos procesos de spillover pueden ser clasificados en tres tipos. El primero es el spillover funcional, que refiere al mecanismo mediante el cual cada paso en la cooperación lleva a otro. Un ejemplo de esto es la cooperación en el área económica (Stroby Jensen, 2016). El segundo es el spillover político, en este caso son las elites nacionales y lobbies quienes impulsan la cooperación con la excusa de que es necesaria para resolver problemas específicos.

El tercer tipo es el spillover institucional, según el cual existen instituciones supranacionales que habilitan -o no- el espacio para el spillover político a partir de externalidades positivas o negativas generando incentivos para extender y profundizar la integración dando cuenta de sus intereses comunes (Schimmelfennig y Rittberger, 2006). Sumado a los tres mecanismos de spillover hay un cuarto elemento que facilita la cooperación: la socialización de la elite. Esta está sumamente relacionada con el spillover político y refiere a los cambios en las alianzas y lealtades de actores claves del plano nacional al supranacional. Esto llevaría la conformación de grupos leales a las instituciones supranacionales (Stroby Jensen. 2016).

\section{III.2. Intergubernamentalismo}

El intergubernamentalismo nació como teoría a mediados de la década de 1960 como respuesta a la teoría neofuncionalista. Algunos de los aportes dentro de esta línea son el enfoque de política doméstica, el locking-in de los Estados y el intergubernamentalismo liberal (Cini, 2016). Los académicos que suscriben esta teoría están mayormente relacionados con la escuela neorrealista de relaciones internacionales, con presupuestos e hipótesis similares exceptuando el intergubernamentalismo liberal. En primer lugar, consideran que la política internacional, incluyendo los proyectos de integración regional, son un juego de suma cero con ganadores y perdedores. En segundo lugar, creen en la lógica de actuación de los Estados bajo los principios de autoayuda en la que cada Estado buscará maximizar su posición en una arena internacional anárquica (Cini, 2016; Morgenthau, 1985; Pollack, 2012).

Sin embargo, los teóricos neorrealistas, en contraste con los realistas clásicos, creen que la cooperación entre Estados puede surgir en momentos en los que es conveniente para los intereses de los Estado miembro, ayudando a 


\section{ASEAN: ¿regla o excepción? \\ CATALINA MAS}

reducir los niveles de anarquía y los costos de cooperación a largo plazo. "La cooperación es esencialmente conservadora y pragmática. Descansa en las premisas de que para resolver problemas en común son necesarias soluciones en común" (Cini, 2016, p. 67). El intergubernamentalismo cree que cada Estado negocia y sopesa pros y contras en cada paso hacia la profundización del proceso de integración. Como menciona Cini (2016), los Estados no transfieren soberanía como lo consideran los neofuncionalistas, sino que la aúnan o crean un pool de soberanía en distintas áreas de políticas públicas.

Si bien el intergubernamentalismo sigue siendo una teoría relevante, ha sido criticado por varios académicos. El mayor de los cuestionamientos refiere a que la mayoría de las corrientes desestiman el plano doméstico que puede tener grandes consecuencias en términos de agenda-setting y decisión de las elites de cada Nación. Es decir, que este componente es otro de los cálculos que debería tener en cuenta la teoría. El enfoque de política doméstica y el intergubernamentalismo liberal miran más en profundidad este asunto. Analizan indicadores sobresalientes en el contexto doméstico al momento en que se producen las grandes oleadas de integración (expansión y profundización), intentando explicar las decisiones tomadas de acuerdo con el plano internacional y los incentivos nacionales.

Adicionalmente, el enfoque de locking-in de los Estados ayuda a analizar el efecto bola de nieve de cooperación presente en las teorías neofuncionalistas. Consideran que los factores institucionales son importantes y que, pasado un punto, los Estados se ven "encerrados" dentro de una estructura de cooperación institucional por fuera de la cual no pueden o no tienen incentivo para actuar. Este enfoque, a diferencia de los neofuncionalistas, considera que los Estados siguen siendo el principal actor que decide continuar con el proceso de pooling de soberanía basado en la racionalidad instrumental de un gobierno ya que termina generando externalidades positivas. En este enfoque la cooperación sigue siendo racional y pragmática. Finalmente, el intergubernamentalismo cree, a diferencia del neofuncionalismo, que es una teoría ontológicamente reproductiva, cree que los grandes eventos son los responsables en el cambio en las instituciones. No hay un costado transformativo y evolutivo en las instituciones, no son pathdependent, los Estados tienen que promover los cambios institucionales basados en cambios en el equilibrio y los incentivos pragmáticos.

\section{III.3. Gobernanza}

El enfoque de gobernanza les da igual importancia a los actores estatales como no estatales. Esto implica tener en cuenta no solo las redes institucionales formales, sino también las informales (Börzel, 2015). Este enfoque prioriza tanto a los actores como al proceso y progreso en la relación de los actores. En este sentido, este nuevo aporte sigue las directrices de los principios comprendidos 
en el neofuncionalismo. El enfoque de gobernanza generalmente distingue tres tipos de reglas institucionalizadas: jerárquicas, competitivas (mercados) y de negociación (redes de contactos) (Börzel, 2015). Las últimas dos son no jerárquicas y son de aplicación voluntaria; esto implica que los conflictos de interés son resueltos mediante negociaciones y no a través del enforcement de leyes previamente establecidas.

Este aporte se centra en el impacto que tiene el estilo de gobernanza sobre las instituciones y sus formas de comportarse, coordinar, expandir y/o profundizar los procesos de integración regional y cooperación. En este sentido, el enfoque comparte puntos en común con las teorías más racionalistas, como el cálculo racional de las teorías neorrealistas e intergubernamentalistas sobre los incentivos para cooperar. Asimismo, comparte el enfoque bipartido entre los actores estatales y no estatales como las teorías neofuncionalistas. Sin embargo, no solo tiene puntos en común con los enfoques racionalistas, sino que también es compatible con las perspectivas constructivistas al tener en cuenta las percepciones e interpretaciones de los actores involucrados.

De esta manera, este enfoque se nutre de las críticas y avances que cada cuerpo de teorías de la integración regional fue experimentando en el recorrido histórico de la construcción y testeo de conceptos. Llega a ser una teoría, en cierto sentido, integradora. Reconcilia distintos conceptos de los dos cuerpos de teorías racionalistas predominantes en la literatura de la integración regional, sumándole elementos del constructivismo que ha sido relegado por parte de la mayoría de los académicos de este fenómeno.

\section{Particularidad asiática}

Como se mencionó anteriormente, la ASEAN es un proyecto de integración regional que surgió a la luz de dilemas securitarios en la zona con el fin de servir de balance frente a la preponderancia de Indonesia, y posteriormente de mantenerse neutros frente a las vicisitudes de la Guerra Fría siendo el Sudeste Asiático una zona álgida en la disputa entre los dos hegemones (Estados Unidos y la Unión Soviética) (Börzel, 2015). Actualmente, a su vez, el hecho de que todos los países del Sudeste Asiático ${ }^{1}$ se hayan unido les permite negociar y posicionarse de mejor manera frente a China y los mercados internacionales. En este sentido, más allá de la declaración de neutralidad, se utilizó el fortalecimiento de la industria y la economía para lograr ser un pivot de negociación y fortalecer sus posiciones (Laursen, 2010).

En términos de funcionamiento, la misma ASEAN se autodenomina intergubernamentalista. Esto se refleja en un liderazgo débil sin preponderancia

\footnotetext{
1 Timor Oriental está actualmente negociando su incorporación a la ASEAN.
} 


\section{ASEAN: ¿regla o excepción? \\ CATALINA MAS}

de un líder político (Laursen, 2010), mecanismos de resolución de disputas a través de la negociación, respetando la soberanía de cada una de las partes. Esto se observa en la declaración de principios comprendida en el Tratado de Amistad y Cooperación de 1976:

Respeto mutuo por la independencia, soberanía, igualdad, integridad territorial e identidad nacional de todos los miembros; El derecho de cada estado a guiar su existencia nacional libre de cualquier coerción, interferencia o subversión exterior; No-interferencia en los asuntos internos de otro país.; Solución de las diferencias o disputas por medios pacíficos; Renuncia a la amenaza o uso de la fuerza; Cooperación efectiva entre los países miembros. (Association of Southeast Asian Nations, 1976)

Todo esto en su conjunto conforma lo que la mayoría de los académicos han bautizado como la $A S E A N$ way. A simple vista, esta organización debería ser analizada bajo el lente del intergubernamentalismo, ya que se trata de un foro institucionalizado de negociación donde son los mismos mandatarios estatales los que se ponen de acuerdo en seguir líneas similares de políticas en distintas áreas a su vez que aplican una tarifa interna entre ellos. Sin embargo, a su vez, a lo largo de los años se han abierto canales de comunicación que le permiten un rol mayor a actores y grupos de interés no estatales como lo son las cámaras de comercio (ASEAN Chambers of Commerce and Industry), las Iniciativas Interministeriales de cooperación (ASEAN University Network) la asociación portuaria o los centros de estudios estratégicos (ASEAN Center for Energy) y otras organizaciones no gubernamentales que han establecido relación (ASEAN, 2015).

Asimismo, el hecho de que resolvieran las disputas a través de la negociación podría ser un símbolo de los denominados "valores asiáticos" (Lee, 1998) y no un diagnóstico con respecto a la mecánica de interacción de ASEAN mismo, esto escaparía al objeto de estudio de una teoría racionalista como lo es el intergubernamentalismo. Esto indicaría la importancia de intentar analizar el fenómeno bajo el lente del neofuncionalismo para entender la interacción con actores no estatales y conjugarlo con teorías con un enfoque más constructivista para comprender si se debe a la percepción y construcción identitaria de los actores. Los "valores asiáticos" integrarían el desarrollo económico y la disciplina social, esto indica que los asiáticos poseen un espíritu de equipo que les permite cooperar. Esto se ve plasmado en los conceptos de musjawarah (consulta) y mufakat (consenso), que definen al respeto por la soberanía y la no interferencia en asuntos internos (Min-hyung, 2011).

La responsabilidad social y el deber de los mandatarios con sus pueblos de acuerdo con el contrato social asiático permitiría confiar en la negociación y a su vez podría poner una traba a la posibilidad de delegar soberanía en un órgano supranacional, ya que violaría este contrato. Sin embargo, Lee (1998) 
desmitifica este concepto de los "valores asiáticos" definiéndolo como un artificio ex post a fin de justificar políticas represivas y como modo de contraposición ética frente a occidente.

En términos neofuncionalistas, la característica que más llama la atención es la convivencia de tres comunidades distintas: la comunidad económica, político-securitaria y sociocultural. Esto podría ser un síntoma del efecto spillover que introducen los neofuncionalistas, ya que para poder seguir cooperando en un área económica es necesario profundizar la cooperación en otra área como la política. Tal y como lo indica Laursen (2010), la Declaración de Bali de 2003 establece los tres pilares o comunidades como mutuamente interdependientes y reforzantes. Esto implicaría una distribución creciente en la cantidad de acuerdos de un área con respecto a otras. Al analizar la distribución temporal de los acuerdos, sin embargo, este fenómeno no se verifica. La dimensión económica tiene una preponderancia del $84 \%$ con respecto al resto de las comunidades (12\% comunidad política y $3 \%$ la comunidad sociocultural). No se encuentra un crecimiento orgánico debido al efecto del spillover, sino que los acuerdos políticos se generan en oleadas al igual que los culturales y económicos.

Con respecto a los económicos, hay tres picos en los acuerdos en 1998, 2005 y 2010. Tanto en 1998 como 2010 coinciden con los dos años inmediatamente posteriores a estallidos de crisis económicas regionales (1997) y globales (2008). Esto coincidiría con la hipótesis intergubernamental de oleadas de voluntad política por cooperar a fin de mejorar la posición a nivel sistémico de los países. Es cierto que la frecuencia de cumbres realizadas se ha incrementado (Min-hyung, 2011), por lo que se verifica un aumento en la interacción de las partes, lo cual podría indicar una creciente socialización de las elites. Esto podría deberse, sin embargo, a los efectos de la globalización que genera incentivos racionales a cooperar, y no necesariamente a un efecto neofuncionalista de socialización. A su vez, ASEAN es una organización internacional que ya lleva más de 52 años en la arena política y que cuenta con precedentes de interacción en foros de cooperación como el Foro de Cooperación Económica Asia-Pacífico (APEC por sus siglas en inglés), donde las elites -no solo estatales-interactúan. A pesar de esto, no se habilitó una gran profundización en la integración regional, por lo que este mecanismo que llevaría a la profundización de esta no sería explicativo en el caso de ASEAN.

En lo que respecta al tratamiento específico de cada una de las comunidades, se puede observar que la preponderancia de la comunidad económica no es solamente cuantitativa, sino también cualitativa. Mientras que en la comunidad política la mayoría de los acuerdos son a fines de crear la estructura organizativa de ASEAN, en la comunidad económica se llegan a consensos sustanciales con respecto a temas específicos y muy sensibles. En la cuestión sociocultural, también hay una prevalencia del $62 \%$ en lo que respecta a consensos sobre temas específicos, sin embargo, tan solo se han logrado firmar 


\section{ASEAN: ¿regla o excepción? \\ CATALINA MAS}

8 instrumentos dentro de esta comunidad ( $3 \%$ del total). A su vez, se puede observar que la comunidad económica tiene una gran fragmentación en cuanto a ejes temáticos sobre los que se han acordado cuestiones, siendo los más salientes el comercio, seguido por la provisión de servicios y transporte. La comunidad política, por su parte, tiene una preponderancia en cuestiones referentes a las formalidades, principios y fondos de cooperación del ASEAN mismo. Paralelamente, la comunidad sociocultural tiene como prioridad cuestiones referentes a la educación, la ecología y la cooperación humanitaria. De esta forma, se podría concluir que las teorías neofuncionalistas no son las más indicadas para comprender la totalidad del proceso de integración de ASEAN. Sin embargo, nos aportan otro enfoque que no habría que perder de vista frente a la preminencia de las teorías intergubernamentalistas.

Finalmente, podemos considerar la teoría de la gobernanza como la síntesis que mejor se puede llegar a explicar el caso de ASEAN. La misma logra incluir tanto la perspectiva racionalista como la constructivista. A su vez, entiende la mecánica orgánica de más y mayor integración como derivado de las instituciones y actores (estatales y no estatales) propios de las teorías neofuncionalistas. Esto mismo se verifica en el entendimiento de la prevalencia de las formas de toma de decisiones entre actores estatales y las características predominantemente intergubernamentalistas. Comprende, por un lado, que para poder cooperar no es necesario solo una balanza de beneficios mayor a los peligros, sino también las expectativas de los actores con respecto al resto de los estados parte. Esto se verifica con las oleadas de ingresos a países que coincide con la pacificación o finalización de conflictos domésticos de parte de estos, lo cual permite una expectativa mayormente enfocada en la negociación y la confianza. A su vez comprende que, si bien los actores formalmente de veto son los Estados, también hay foros paralelos donde se conforman grupos de interés no estatales.

Asimismo, agrega la noción de los tres tipos de reglas institucionalizadas. ASEAN no posee un mecanismo de enforcement donde se prevea un tribunal o penalidades fijas por el no cumplimiento de los pactos o disputas, sino que elige la vía de la negociación entre partes respetando la soberanía de cada uno de los Estados por igual. De esta forma, se trataría de un tipo de regla no jerárquico con arreglo a negociar en el caso de disputas.

A su vez, la mayoría de los temas en agenda corresponden a la economía. De esta forma también habría cierta injerencia del tipo de regla de competencia u orientada al mercado. En este sentido, es posible pensar el aumento en la cooperación como consecuencia de la globalización, diversificando el tipo de actores internacionales, habilitando nuevos canales de comunicación y generando incentivos positivos para la cooperación regional frente a una mayor competencia internacional. Esto sigue las directrices que la teoría de la gobernanza indica (Börzel, 2015). 


\section{Conclusión}

Derivado de lo anterior, podemos concluir que el caso de ASEAN podría llegar a considerarse como uno de los más complejos hasta el momento. Conjuga elementos que se encuentran dispersos en distintas teorías desarrolladas hasta el momento. Debido a que el compendio teórico en lo que refiere a teorías de la integración de rango medio está mayormente inspirado en la experiencia europea, no hay una única teoría que refleje la plétora de elementos únicos que están presentes en el sudeste asiático. Es necesario avanzar hacia teorías más abarcativas y holísticas. El enfoque de gobernanza es, entonces, un ejemplo de las posibilidades teóricas que se encuentran más allá de los horizontes que dividen a racionalistas, liberales y constructivistas, a la vez que dividen a aquellos que ven a las organizaciones supranacionales como neofuncionalistas $o$ intergubernamentalistas.

Siguiendo los paradigmas clásicos, deberíamos descartar las teorías neofuncionalistas debido a que no se verifica la mayoría de sus premisas en la práctica ni habría indicadores de una profundización organizacional que lleva a pensar que en un futuro este sería el camino. Pero a su vez, tampoco se puede tomar a la teoría intergubernamental en su totalidad, ya que hay elementos únicos al caso del Sudeste Asiático que no son comprendidos por sus desarrollos teóricos, mayormente las cuestiones de mayor integración entre actores no estatales y las expectativas de los actores involucrados desde la perspectiva constructivista.

ASEAN es un caso en el que se encuentran distintos niveles de cooperación, momentos coyunturales y pragmáticos de expansión y profundización de la integración. Es una organización que posee un plan de desarrollo semineofuncionalista frente a las disputas, sin terminar de funcionar de esta manera ni siquiera de manera nominal. Este artículo ha buscado introducir la aplicación de algunas de las teorías básicas en la literatura de integración regional. Se deberá ahondar a futuro con más y mejores herramientas metodológicas, teóricas e información acerca del desarrollo efectivo del proceso de integración a medida que avance el desarrollo de la organización y los nuevos aportes teóricos sobre integración regional.

\section{Referencias bibliográficas}

Association of Southeast Asian Nations (1976). Treaty of Amity and Cooperation in Southeast Asia (TACSE). https://asean.org/treatyamity-cooperation-southeast-asia-indonesia-24-february-1976/ 
BÖRZEL, T. (2015). Theorizing Regionalism: Cooperation, Integration, and Governance. En Börzel, T.A. y Risse, T. (Eds.), Oxford Handbook of Comparative Regionalism (41-63). Oxford University Press.

CINI, M. (2016). Intergovernmentalism. En Cini, M. y Pérez-Solórzano Borragán, N. (Eds.), European Union Politics (65-78). Oxford University Press.

Del Río MARTíneZ, A. (2007). "La tercera ola democrática en Asia: explicación política para un fenómeno político". Actas del XII Congreso Internacional de ALADAA. Benemérita Universidad de Puebla, México.

JENSEN, C. S. (2000). Neofunctionalist theories and the development of the European social and labour market policy. Journal of Common Market Studies, Vol, 38/1, pp. 21-92

LAURSEN, F. (2010). Comparative Regional Integration: Europe and beyond. Ashgate: Farnham, Reino Unido.

LEAL-ARCAS, R. (2007). Theories of Supranationalism in the EU. Journal of Law in Society, Vol. 8, No. 1, pp. 83-113.

LEE, E. J. (1998). ¿Valores asiáticos como ideal de civilización? Nueva sociedad No. 155 (Mayo-Junio): 111-125.

Malamud, A. (2011). Conceptos, teorías y debates sobre la integración regional. Norteamérica, 6(2), 219-249.

MiN-HYUNG KIM (2011). Theorizing ASEAN Integration. Asian Perspective, Vol. 35, No. 3: 407-435.

Morgenthau, H. (1985). Politics among nations: The struggle for power and peace. New York: Knopf.

POLlack, M. A. (2012). Theorizing the European Union: realists, intergovernmentallist and institutionalist approaches. En Jones, E., Menon, A. y Weatherill, S. (eds), European Integration Theory. Oxford: Oxford University Press.

SCHIMMELFENNING F. y RITTBERGER B. (2006). Theories of European integration: assumptions and hypotheses. En Richardson, J. (Ed.), European Union. Power and policy-making (73-95). London: Routledge.

SCHMITTER, P. (1969). Three neofunctional hypotheses about international integration. International Organization, 23/1: 161-6.

Stroby Jensen, C. (2016). Neo-functionalism. En Cini, M. y Pérez-Solórzano Borragán, N. (Eds.), European Union Politics (53-64). Oxford University Press.

SwEET, A. S. (2012). Neofunctionalism and Supranational Governance (unabridged version). Faculty Scholarship Series. Paper 4628.

WeILER. J. (1981). The Community System: the Dual Character of Supranationalism. Yearbook of European Law, 1/1. 267-306 
ENTREVISTAS 


\section{LA DIFÍCIL TAREA DE LLEVAR LA DEMOCRACIA A ASIA: UNA ENTREVISTA A ALBERTINA PITERBARG}

\section{THE DIFFICULT TASK OF INTRODUCING DEMOCRACY IN ASIA: AN INTERVIEW OF ALBERTINA PITERBARG}

En el año 2008, la experta electoral Albertina Piterbarg se mudó junto con su familia a Timor Oriental para trabajar en la misión de Cascos Azules de Naciones Unidas. Este pequeño país, ubicado en el extremo meridional del archipiélago indonesio y en la parte oriental de la isla de Timor, es una de las naciones más jóvenes del mundo. Tras siglos como colonia portuguesa, seguidos por años de anexión forzosa a Indonesia, los timorenses alcanzaron la independencia en 2002.

Timor Oriental emergió como nación independiente siendo el país más pobre de Asia y con una sociedad devastada por la violencia que marcó la retirada indonesia. Naciones Unidas intervino en el proceso de transición, haciéndose cargo de todas las funciones de gobierno y la pacificación del territorio hasta que un gobierno civil pudiera hacerse cargo. En 2006, el retorno de la violencia llevó al establecimiento de la Misión Integrada de las Naciones Unidas en Timor Oriental (o UNMIT por sus siglas en inglés) para el restablecimiento y mantenimiento de la paz.

Fue en el contexto de esta misión, que Albertina llegó para trabajar en la preparación de las primeras elecciones de sucos (aldeas) de 2009. En sus cuatro años en el país, trabajó junto a múltiples actores involucrados en la preparación, realización y supervisión de procesos electorales como funcionarios, organizaciones de la sociedad civil, organizaciones internacionales, iglesias y jefes tribales. Charlamos con ella sobre su experiencia profesional y personal en un país tan remoto y en proceso de crear sus instituciones democráticas.

\section{¿Cómo fue la vida en Timor Oriental? Vos fuiste con tu familia, con dos hijas.}

Maravillosa, fue un verano dorado. Fueron cuatro años de vivir en un lugar increíble, dificilísimo porque fue muy jugado lo nuestro ya que no hay salud ni agua potable y todo eso. Pero fue una experiencia genial, porque es una sociedad a la que le encanta los chicos, porque los chicos son riqueza, los chicos son alegría. Entonces para ellos, para mis colegas de la comisión electoral, que yo haya ido con mis hijas era una muestra de respeto. Aunque me preguntaban: 
“¿cuántas hijas tiene usted?”, y cuando les decía que tenía dos, ellos me decían: “¡No, más más más! Más tiene que traer”. Dos hijas para ellos es nada. Pero bueno, el hecho de que yo estaba con mis hijas y mis hijas estaban ahí era una muestra de mi respeto hacia ellos y para ellos yo era respetable por estar con mis hijas. O sea, para ellos, alguien que no tiene hijos no es bien visto.

En largo plazo esto debe ser todo un problema demográfico. En especial, en un país con poco territorio. Problemas como la deforestación.

Bueno ya hay deforestación. De todos modos, bajó la cantidad de hijos por mujer. Pero no es algo planificado, es riqueza porque cada hija después representa una dote. Además, en Timor hay otra cosa muy interesante: el concepto de amistad no existe. Vos no tenés amigos, vos no haces amigos; sos de un clan y tenés otro clan del cual formas parte porque casaste a uno de tus hijos o porque se casó tu hija. Es una sociedad tan pobre que no puede sustentar amistades, porque tal vez a ese amigo no lo puedas alimentar y vos tenés que asegurar la permanencia de tu clan. No se puede perder el tiempo con amigos, de la misma manera que no tienen mascotas. La mascota se come, el perro se come. Cuando fui hace diez años, la idea de mascotas era totalmente insólita para ellos. A lo sumo, la mascota era el gallo de riña.

\section{O sea que no hay bares, no hay lugares donde la gente va a tomar un café con alguien.}

Hay bares para los malae. Los malae son los extranjeros, había mucho bar para ellos. Hay algunos bares para nacionales, pero no es la idea de la amistad. Y otra cosa que no existe en Timor: la queja. Nadie se queja. No está bien visto quejarte; la cultura asiática en general lo condena.

En Argentina, la queja es una forma habitual de encarar lo cotidiano. Esto incluso ante la mirada incrédula de personas que vienen de lugares con problemas "más graves". ¿ $\mathrm{Ni}$ siquiera con todos los problemas que enfrenta Timor se permite la queja?

Nunca, la queja no es bien vista. Vos decís "no, no sabes lo que me pasó, vino y me dijo y yo le dije y después me dijo y yo le dije" o como acá: "esto es un desastre". Eso no está bien en Timor, aunque se estén muriendo de hambre la queja no existe. A mí lo que más me pasaba viviendo en Timor es que volvía a la Argentina y me chocaba la gente quejándose. 
Te estableciste junto con tu familia en Timor en calidad de experta electoral de Naciones Unidas, supervisando la organización de elecciones tras años de conflicto violento. ¿Cómo era el trabajo intelectual y organizativo previo a tu tarea en el campo?

Primero, siempre hay lo que se llama un National Mission Assessment (NAM). Es una misión que va al país y hace una evaluación de la situación electoral. Yo llegué en 2008 para preparar la primera elección municipal de sucos de 2009. Pero mi llegada tuvo que ver con un assessment hecho por la United Nations Electoral Assistance Division (UNEAD). Ellos hacen un informe del que resulta un proyecto a ser homologado por el gobierno. Con la firma del gobierno se obtiene el mandato de la misión y el mandato en tanto misión electoral. No todas las misiones electorales hacen lo mismo. En el caso de Timor para el año 2009, las elecciones las iban a llevar adelante las autoridades nacionales y nosotros íbamos a trabajar como advisers, o sea, como asesores dentro de las instituciones gubernamentales

Después hay un plan del que se parte y tenés un jefe de equipo obviamente. Uno hace propuestas con la contraparte y la contraparte te dice si le gustan o no. Cuando yo llegué, lo que también tenía que hacer era preparar el presupuesto de las elecciones de 2009 para que cubriese todas las campañas de educación pública necesarias. Básicamente, que todos los ciudadanos estuvieran informados y preparados para votar. Entonces, primero que hay que trabajar en la institucionalidad del proceso. Esto lleva a la descentralización, ya que la comisión electoral tenía a su vez sus oficinas y comisarios en cada uno de los quince distritos. Por esto yo trabajaba a nivel local en lugares diferentes como Baucau, Oecusse o Ataúro. Se trabaja en que las personas se inscriban, en poder llegar a los lugares remotos de difícil acceso y que las personas estén empadronadas. Todas cuestiones de la preparación de las elecciones Otra parte del trabajo era hacia el interior de la Comisión Electoral. Preparando a todos los grupos de la sociedad civil para que puedan hacer observación electoral. En eso, la iglesia de Timor tiene un rol muy particular. Las observaciones electorales eran manejadas en gran medida por la iglesia católica.

\section{¿Qué escenario de organizaciones de la sociedad civil encontraste en Timor? ¿Cómo fue trabajar con ellas?}

La sociedad civil es un componente necesario, pero a la vez complicado. Nunca es un componente fácil. Dependiendo del país puede tener diferentes 
perfiles. En el caso de Timor, tenías organizaciones internacionales religiosas dedicadas a cuestiones de maternidad u organizaciones dedicadas a asuntos electorales como International IDEA. Tenés todos los players internacionales que cumplen un rol y no siempre son amigos. A veces son competidores dependiendo de su posición.

Después tenés la sociedad civil local. Era una sociedad civil, en el momento que yo llegué y probablemente esto cambió, incipiente y con muy poquitos años de vida. La mayoría de las organizaciones locales se habían fundado en 2001 y 2002. Algunas de ellas hacían muy buenos trabajos cuando lo hacían en partnership con organizaciones internacionales. Después tenés, como todo, muchas organizaciones que son creadas ad hoc con lindos nombres, lindas ideas, pero están más a la pesca de fondos internacionales. Debo decir que algunas de las organizaciones más efectivas y mejor organizadas eran de la sociedad civil femenina. También eran efectivas las organizaciones dedicadas a cuestiones de acceso al agua e higiene y a temas humanitarios como los desplazados.

A pesar de esto, era difícil porque la mayoría eran muy débiles institucionalmente. Con el asesor del Primer Ministro para la Sociedad Civil, lo que hicimos básicamente fue un assessment de cuáles eran las organizaciones que ya estaban trabajando en cuestiones de educación cívica: en qué partes del país, con qué programas, con qué financiación, en qué idiomas. Entonces organicé un comité al interior de Naciones Unidas de trabajo en educación cívica donde nos juntábamos todas las agencias -UNICEF, UNESCO, UNDP, DPKO, UNFPA, ACNUR-e invitábamos a las organizaciones internacionales. Con esto veíamos quien estaba financiando a qué ONG en lo que respecta a educación cívica.

Esto es muy interesante, en tanto la cuestión de la construcción electoral es cuestión de la construcción de la democracia. Hablar de estas cuestiones con gente local debe ser impresionante porque quizás no pasaron por experiencias democráticas y liberales. ¿Cómo fue hablar de esto con ellos?

Una de las sorpresas que tuve -no solo en Timor sino también en otros países de Asia- es que se trata de una sociedad tribal, entonces hay otra interpretación de lo comunitario. Ya hay una mentalidad que es la mentalidad de la comunidad y tiene toda una impronta. Y lo que tiene el sistema de sucos y aldeias -había 442 sucos y más de mil aldeias en un territorio relativamente pequeño- es que ya hay un entramado del ejercicio del poder civil sin intervención del poder militar, y si bien no es democrático en sí mismo, ya es un ejercicio de civilidad. 
Ahora cuando el sistema democrático se imprime sobre Timor lo hace sobre ese sistema, integrando los sucos y las aldeias. Entonces cuando son las elecciones municipales de sucos y aldeias, que son cargos honoríficos, genera un choque con la municipalidad que sí tiene presupuesto. Entonces hay roces entre los dos niveles de gobernabilidad.

Respecto al tema de la mentalidad, yo diría que me sorprendió un poco lo sofisticado del pensamiento político y la comprensión de la importancia de la participación y la toma de decisiones a nivel local, porque realmente las mentalidades tribales - por lo menos las que yo conozco- tienen esa impronta muy fuerte de culturas locales con redes de ejercicio del poder civil. Por supuesto, cómo se eligen los grupos de poder dentro de las tribus y las aldeias no es lo mismo que en la democracia representativa. Lo que quiero decir es que ya hay cierto espíritu cívico que es interesante.

\section{¿Algo que quizás nos hace pensar más en una democracia directa que en una democracia republicana?}

Totalmente, tienen algo de democracias directas. Ellos no lo llamarían así, pero era una democracia directa en un sentido muy puro te diría porque no es democracia directa impuesta.

\section{Por lo que decís, pareciera que ya había cierto lenguaje de participación cívica y tenías que traducirlo a un sistema electoral. ¿Cuáles fueron los desafíos de a la educación cívica?}

Los desafíos tienen que ver con la geografía de Timor, tanto la geográfica física como la geografía cultural. Por ejemplo, el problema de las diferencias de género que son muy atávicas. Es una sociedad machista y tribal donde la educación es percibida como algo un poco ajeno a la cultura de la comunidad, donde se necesita ante todo que la gente sea mano de obra para la agricultura en una economía de subsistencia. Además, otro problema es la cultura del trabajo: trabaja el que tiene menor escala social. El chefe no trabaja porque un gran jefe no va a trabajar. De hecho, en las familias, el hermano mayor trabaja mucho menos porque el menor trabaja para él. La comida se reparte de la misma manera. Primero come el marido después el hijo más grande y así hasta el más chiquito. Todas estas cuestiones de supervivencia afectan obviamente la educación cívica. El gran desafío es cómo acercar la cultura cívica a la vida de todos los días cuando ésta es tan ruda, cuando la preocupación es si tenés o no tenés arroz, si tenés agua, si en el parto tuviste al bebé o no. 
A esto se suma la cuestión de género. Las reuniones de suco y las de aldeia se hacen en un espacio común donde solo están los hombres. Entonces hay muchos desafíos para superar y cosas por explicar: la necesidad de participar políticamente, de informarse, de saber quiénes van a ser los candidatos, de saber que te podés candidatear, de saber que no tenés por qué votar a alguien si su propuesta no te interesa, de saber que necesitás tener tu tarjeta de identificación, etc. También está el analfabetismo y la pluralidad lingüística. No todo el mundo habla lo mismo, se habla bahasa, tetum, variantes del tetum y otras lenguas. Entonces, teníamos que trabajar con las radios locales, ya que en aquella época el celular no estaba en todos lados. Todos estos son desafíos en un país muy pobre y con muy pocos recursos. ¡Y muy aislado, muy aislado! Aislado del mundo por su geografía y su pasado como colonia de Indonesia.

Por otra parte, están las cuestiones políticas al interior de la Comisión Electoral. Los intereses de las quince personas que eran los comisarios y que por suerte ahora son siete. Por lo general, las comisiones electorales son bastante ineficientes, pero son necesarias en situaciones de posconflicto. Porque la comisión electoral refleja un acuerdo de paz en un país luego de una situación de conflicto. Estas comisiones con tanta gente, a diferencia de países con comisiones más sofisticadas, representan ese acuerdo.

Otro gran desafío es la corrupción. Que los fondos recibidos de la comunidad internacional sean bien gastados. Esto afecta porque los fondos destinados a educación cívica o a tener un manual o charlas pueden irse al caño. Obviamente lo primero que se recorta son los fondos para educación cívica.

¿Qué desafíos tiene la estructuración de una oferta electoral comprensible y accesible para culturas tribales como las de Timor? En Sudáfrica tuvieron que poner fotos en lugar nombres de candidatos y en Brasil números porque había una cultura vinculada a la lotería de quiniela. ¿Cuál fue la vuelta que le encontraron en Timor para engarzar una oferta electoral comprensible con el universo simbólico de la cultura local?

En Timor es muy fácil. A través de los jefes de sucos y los jefes de aldeias llegás a toda la población. Si el jefe es quien te explica cómo votar -era fácil, con boletas sencillas-, el desafío no era el acto de votar, sino que todos estuvieran informados. Es una sociedad que no tiene acceso a grandes medios de comunicación y que vive muy aislada, porque en Timor las distancias son cortas, pero nadie tiene auto y las carreteras eran pésimas. Transporte común casi no existía. 
La estructura electoral más importante era la Iglesia, los sucos y las aldeias. Aquí se daba una interrelación entre estas estructuras y los órganos electorales del gobierno. Por ejemplo, el jefe del Secretariado Técnico Da Administração Eleitoral (STAE) era también un jefe religioso. En Timor, las elecciones no son organizadas por la Comisión Electoral sino por el STAE. Es un organismo técnico que depende del Ministerio del Interior y del Primer Ministro. En cambio, la Comisión Electoral era independiente y estaba bajo la órbita del presidente. Entonces la comisión podía hacer un seguimiento técnico del STAE con independencia.

Entonces el jefe del STAE era también jefe religioso y como tal tenía un nivel social dentro la lógica tribal muy importante. Él iba a las aldeias y los sucos y hacía reuniones con los jefes para lograr consensos sobre la participación electoral a través de las reglas consuetudinarias de gobierno tradicional. Eso era muy útil en Timor.

Hablar de democracia moderna es hablar de partidos políticos. Mencionabas el rol de los jefes en el proceso electoral a nivel local en los sucos y aldeias. ¿Qué llegada tenían los partidos políticos a esas localidades? ¿Partidos como FRETILIN o CNRT tenían presencia en esos territorios?

Yo en este momento no lo recuerdo. Lo que recuerdo es que el FRETILIN, obviamente, era súper popular. Y había como quince o veinte partidos políticos que eran grupúsculos que andaban dando vueltas por ahí. Pero no, ellos se apoyaban sobre lo que ya estaba. Obviamente que el FRETILIN era muy popular, realmente tenía un alto grado de aceptación en todo el país. Xanana era muy popular, Ramos Horta era muy popular en ese momento.

Llegas a Timor como experta electoral para una misión de paz de Cascos Azules. Para una misión integrada con fuerzas armadas internacionales con el objetivo de poner fin a la violencia desatada en 2006 y fortalecer al gobierno civil. Ya desde la retirada de las fuerzas indonesias luego del referéndum, la vida política de Timor se vio interrumpida por la violencia. ¿Las elecciones también fueron violentas?

Las dos elecciones que yo viví en Timor no fueron elecciones a las que yo catalogaría como violentas o en donde primó la violencia como parte del conflicto electoral. De hecho, en las elecciones 2012 hicimos el "Pacto de Eleição Pacífica" y donde estuvieron todos los partidos políticos en todas las 
reuniones. No quiere decir que no hubiera violencia en la sociedad, me refiero a que no fueron necesariamente campañas electorales donde murieron candidatos, o donde hubiese atentados en los actos de campaña o donde las autoridades electorales eran atacadas, o donde los centros de los partidos políticos también fuesen atacados, o donde hubiese un enorme vandalismo de los materiales de campaña, o donde los centros electorales fueran atacados. No había un clima de violencia política en torno a lo que era el proceso electoral. Ahora, desde ya no era una sociedad pacífica. De hecho, a la noche la ciudad era patrullada y había toque de queda cuando yo llegué. Habían prendido fuego a media ciudad.

Respecto a esto que estás diciendo parece haber, a nivel de la élite política, de la élite dirigencial de todos los niveles, como un acuerdo en que estaba bien hacer las elecciones ¿Eso se vinculaba con la Independencia de algún modo?

Desde una mirada personal, porque como te digo, yo no estaba en la rosca política, yo creo que sí. Tal vez los de Polítical Affairs lo tienen más claro. Me parece que, a nivel de la clase política, y te lo digo yo que trabajé con Xanana, del lado de la elites había un consenso más allá de las diferencias ideológicas. Se sentían cómodos con la idea de la continuidad política, con la continuidad democrática. No veo dónde pudiera estar la conveniencia para ellos, que estaban en puestos ya de poder, de desestabilizar la democracia; no era necesario. Podían simplemente llegar a pactos, y en ese sentido me parece que la oposición al FRETILIN estaba también interesada en llegar a pactos. Pero esto es mi opinión personal, cuando yo estuve allá no vi intención de desestabilizar, ellos comenzaban a sentir los beneficios de la estabilidad, y sobre todo los beneficios de ser la élite gobernante.

\section{¿Cómo fue su experiencia con Xanana Gusmão? ¿Cómo lo describiría?}

No se puede negar que él fue una figura enormemente carismática. Ahora, ¿como primer ministro? No sé, era un líder, con un liderazgo más informal. Que vos puedas llevar adelante una resistencia armada no quiere decir que después te den un gobierno y sepas qué hacer con eso; son cosas distintas. Después tomaron decisiones por cuestiones nacionalistas con las que yo estaba profundamente en desacuerdo. Por ejemplo, una decisión que a mí me pareció muy equivocada fue la decisión de que no se enseñara más en lengua bahasa, y el tetun es un idioma muy limitado. Le falta vocabulario porque justamente es un idioma que está vinculado con la supervivencia. Entonces hicieron del 
portugués y del tetun lenguas nacionales, y la educación pasó a ser en portugués y tetun de un día para el otro. Entonces, ¿qué pasó? Los que hablaban bahasa, no hablaban ni tetun ni portugués y los que sí hablaban tetun lo hacían en sus casas.

¿Sentiste la presencia, de alguna forma, de Indonesia tratando de inmiscuirse en el proceso?

No, lo que sentí muy fuertemente fue la presencia de Australia y de China más que Indonesia. En ese momento yo creo que las relaciones con Indonesia estaban muy enfriadas, incluso amistosas en términos generales. Pero, lo que sentí fue una enorme presencia de China y de Australia.

\section{¿Y personificadas en qué? ¿En prensa, pensiones?}

No, en dádivas al gobierno. El ministerio de defensa fue construido con donaciones, como un regalo de China. O sea, todos los ministerios los construía China como un regalo. No sé qué pedían a cambio. Y después, yo me enteraba de mucha presión sobre todo con el problema del agua. China quería construir represas en el país. Por otra parte, estaba el petróleo. Ahí veías lo que era el tema de El Fondo del Petróleo del lado también de Australia y Estados Unidos.

\section{¿Te parece que desde América Latina hay alguna lección que podamos aprender de Timor? ¿Errores y aciertos que debiéramos estar mirando para mejorar en América Latina o Argentina?}

Algo que personalmente me impactó y que después lo volví a ver repetido en muchos lugares es que cuando uno se enfrenta a situaciones en donde están estos problemas de posconflicto hay que saber que hay potencias en juego. Nunca tenés conflictos de este tipo sin tener fuerzas extranjeras que también están interesadas en que las cosas se muevan para un lado o para el otro.

\section{Muchas gracias, Albertina. No es frecuente hablar sobre Timor con personas con experiencia directa. Eso es muy valioso.}

Gracias a ustedes. No saben lo lindo que es poder hablar con gente a la que le interesa Timor. Porque una de las grandes frustraciones que yo tenía era que a nadie le importaba Timor. Cuando yo volvía a Buenos Aires para ver a mi 
familia me preguntaban "¿Y qué tal allá?". A la gente le cuesta tener empatía con lo que no pueden imaginar. Es un país desconocido pero maravilloso.

Cierro con una anécdota. Desde que pasé por Timor me encantan los cocodrilos. Aparecían en la playa: cocodrilos de rio, de manglar y de mar. Y para ellos, que son animistas, los cocodrilos son los antepasados, entonces no se los mata porque vos no matas a tus antepasados, quedás maldito si hacés eso. Pero si te come un cocodrilo es tu culpa, quiere decir que vos no eras muy buena persona. Si el cocodrilo te come es porque había algo mal con vos, sino el cocodrilo no te va a comer porque es tu ancestro. Entonces recuerdo que una vez cuando estaba yendo a la oficina del PNUD que daba a la comisión electoral estaba justo frente a la playa. De repente veo que por la costanera hay como un malecón y está toda la gente así asomada mirando un cocodrilo enorme pero tranquilo. Nadie gritando ni tirando piedras ni nada en pleno centro de la ciudad. Y son esas anécdotas que personalmente a mí me marcan tanto porque es en lo cotidiano del día a día donde ves esas diferencias. No son diferencias irreconciliables, pero te abren la cabeza. 


\section{ACOPIANDO FÓSILES EN MANTAS: UNA ENTREVISTA A PATRICIA EUSTAQUIO PÉREZ \\ HOARDING FOSSILS IN BLANKETS: AN INTERVIEW TO PATRICIA EUSTAQUIO PÉREZ}

Durante el año de la pandemia, 2020, la artista plástica filipina Patricia Eustaquio Pérez expuso Hoarding Fossils in Blankets (Acopiando Fósiles en Mantas, en español). La exhibición estuvo formada por seis piezas, seis grandes tapices, los primeros de una serie en la que la artista ha estado trabajando en los últimos tiempos. Las obras retoman, según las propias palabras de la artista, la tradición femenina de la tapicería para realizar un acto de traducción entre las obras maestras del arte filipino en reinterpretaciones femeninas y colectivas. De esta forma, cada pieza además reteje, desarma y vuelve a ensamblar, la memoria, o más precisamente las marcas que el paso del tiempo construye sobre los objetos, capa sobre capa.

Patricia Eustaquio Pérez nació en Filipinas en 1977 y reside y trabaja en Manila. Su obra se caracteriza por explorar diferentes técnicas y disciplinas. Desde las más tradicionales como pintura, escultura y dibujo hasta campos que incluyen la decoración, la artesanía y en estas obras, el arte tapiz. Su obra ha explorado cuestiones como el paso del tiempo, la construcción de la memoria y las marcas, las ausencias y las reinterpretaciones constantes que produce la memoria. Charlamos con ella sobre el arte, sobre su nueva exhibición.

En su exhibición, el tapiz adquiere una dimensión social que parece dialogar con el carácter íntimo, laborioso y manual de su creación. ¿Cuál fue el camino que la condujo a esta reevaluación del arte tapiz en su trabajo?

He trabajado frecuentemente con textiles en mi práctica artística, junto con otros materiales y medios diversos. Siempre consideré a los materiales como portadores de aspectos sociales y políticos, ya que su utilidad es un indicador de las preferencias innatas y los gustos adquiridos de las personas. Al emplearlos en la creación de objetos, estos materiales adquieren más y más de esos sentidos sociales en términos de cómo se utilizan esos objetos. Quería orientar discusión para incluir esos procesos de transformación del material en objeto y sus implicancias. 


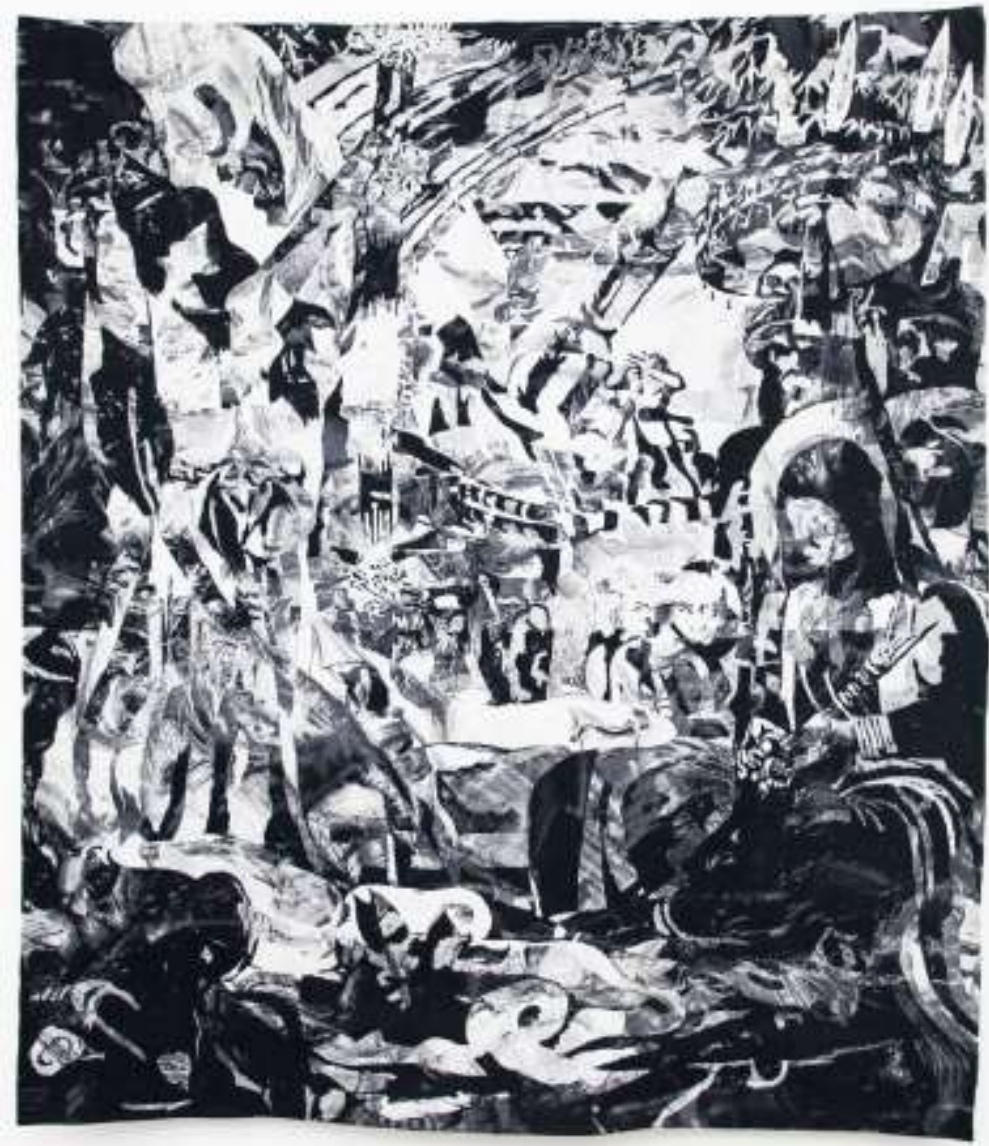

Figura 1: An Unraveling (Conversation Among Ruins, After Francisco), 2019.

Tapiz tejido digitalmente con algodón y lana, 290h x 244w

Las texturas, el lugar que se le da a lo sensorial y la combinación versátil de elementos plásticos en sus obras denotan un profundo sentido de la experimentación. ¿Cómo es que el uso de medios y técnicas digitales contribuyeron a expandir sus posibilidades de acción con los materiales y enriquecieron sus inquietudes estéticas?

Toda esta tecnología me ha permitido atribuir cierta plasticidad a la fotografía que exhibe aspectos muy digitales, pero también muy táctiles que de otro modo no habría sido capaz. Las máquinas están programadas para hacer cosas específicas, pero lo que introducimos en esas máquinas les permite generar más permutaciones del producto y esto es lo que me resulta emocionante al trabajar digitalmente con un telar o con una tableta y computadora. Mi trabajo en la computadora solo se está limitado por cuanto 
pinto y cuanto fotografío esas pinturas. En función de solo estas dos cosas, mis opciones son infinitas.

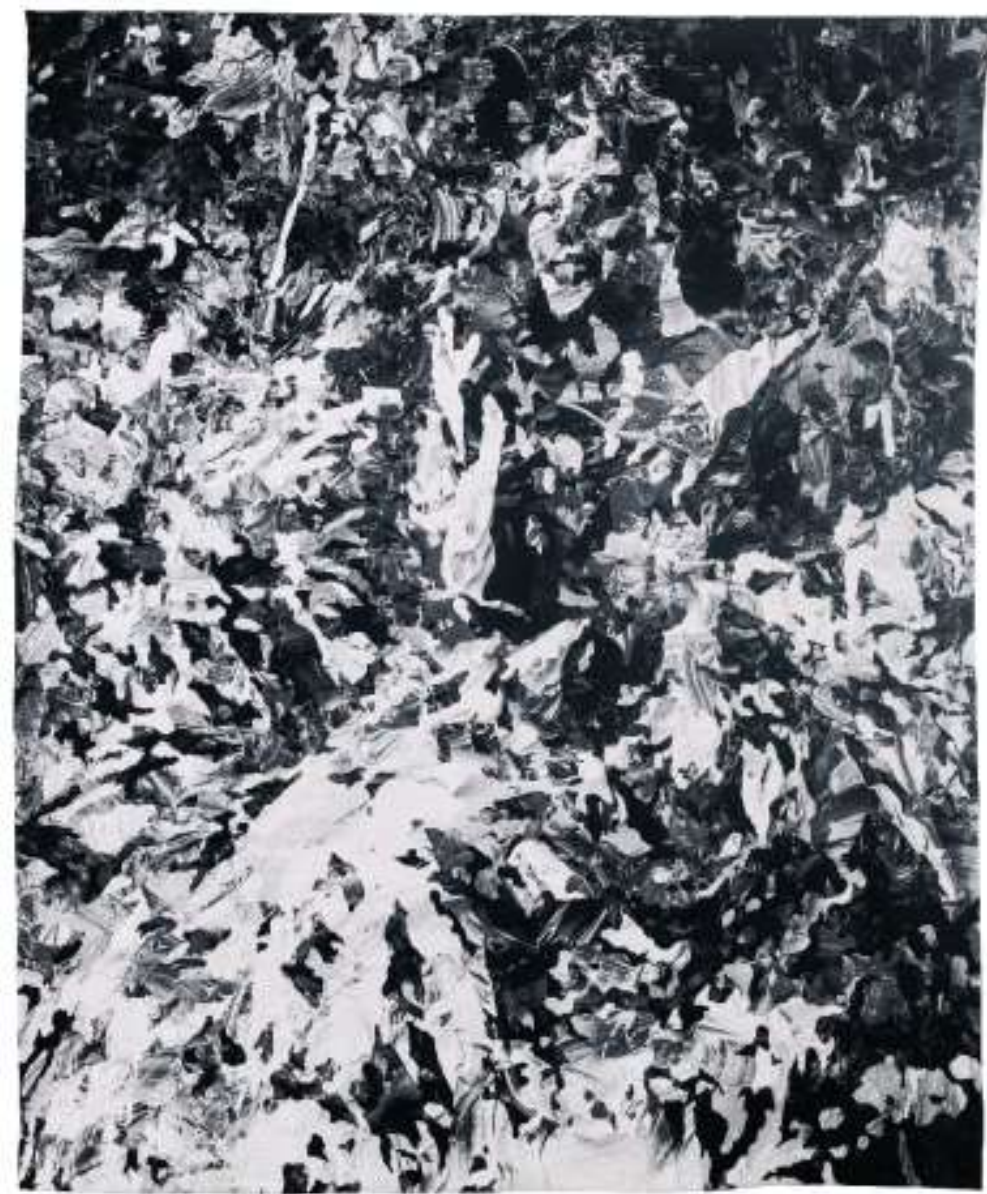

Figura 2: An Unraveling (Conversation Among Ruins, After Amorsolo), 2019.

Tapiz tejido digitalmente con algodón y lana, $114.17 \mathrm{~h}$ x $91.34 \mathrm{w}$

Usted hace referencia a lo femenino, destacando el lugar marginal del tapiz en la historia del arte occidental como aquel que parecería débil ante la fuerza vehemente de lo masculino que usted asocia a la pintura. ¿Cuál considera que ha sido el rol asumido por el arte realizado por mujeres en Filipinas? ¿En la actualidad, hay desafíos inherentes en ser una artista mujer en un ambiente tradicionalmente dominado por hombres? 
Sorprendentemente, hay muchas mujeres artistas en ejercicio en Filipinas. Digo sorprendentemente, pero tal vez esto no debería ser una sorpresa. La sociedad filipina es compleja en tanto las mujeres son muy visibles en la mano de obra y en todas las áreas de la sociedad. Hemos tenido a dos presidentas, mucho más que en otras naciones. Pero al mismo tiempo la misoginia y el machismo siguen siendo dominantes y comportamientos "aceptados". Mujeres con una voz, especialmente en la arena política, son vistas como histéricas o desestimadas como radicales fanáticas. Últimamente, es común que las mujeres en la industria creativa sean etiquetadas como radicales izquierdistas por parte de los militares y como resultado sean puestas bajo vigilancia. Yo participo activamente en actividades feministas, pero no soy parte de ningún grupo de artistas organizados.

Sus obras tienen un anclaje visual que nos remite al lenguaje dinámico del expresionismo abstracto. ¿Qué influencias diría que convergen en su obra y su concepción del arte?

Es difícil decirlo, realmente nunca consideré mi trabajo como parte de un tipo de género, aunque reconozco las muchas referencias a las que mi trabajo remite. Pienso que también hay muchas referencias surrealistas, en tanto me gusta juntar cuadros de cosas aparentemente no relacionadas, pintadas en conjunto por mitos o cadenas de pensamiento. Pienso que cuando se escribe en imágenes, la poesía y sus cadencias se juntan para referirse mutuamente. Tal vez al trabajar ahora, en este siglo, llevo conmigo todo el bagaje de todos los que me antecedieron y tendría que considerar muchas cosas.

Crear, sin embargo, siempre ha sido central. Creo objetos; esto es lo más importante en mi trabajo. Así que supongo que las ideas de la artesanía y diseño, tal como se han desarrollado en los márgenes de las Bellas Artes, es donde me hallo.

En el acto de acumular fósiles (fragmentos, sombras y memorias recolectadas) en mantas tejidas por muchas manos, usted alude en cambio al acto de traducir, asociando ambos gestos al valor intrínseco de la artesanía. ¿Cómo se traduce el valor del trabajo manual y la historia de su país en sus obras?

Últimamente (y aquí me refiero a los últimos años) he estado muy interesada en los períodos precoloniales y coloniales de Filipinas, y he estado mirando las cosas que comerciábamos con otros países. Ha sido interesante porque hemos estado comerciando recursos naturales y nuestra propia mano 
de obra durante siglos. Los objetos manufacturados precoloniales fueron utilizados tan intensamente por las personas que los fabricaron que su producción comercial nunca fue proseguida. Mientras que, en tiempos coloniales, los españoles y americanos estaban interesados ante todo en nuestra madera y otros recursos naturales así que no se le dio mucha importancia a la educación o a las manufacturas. Esto nos brinda una imagen del tipo de participación que teníamos en el comercio global.

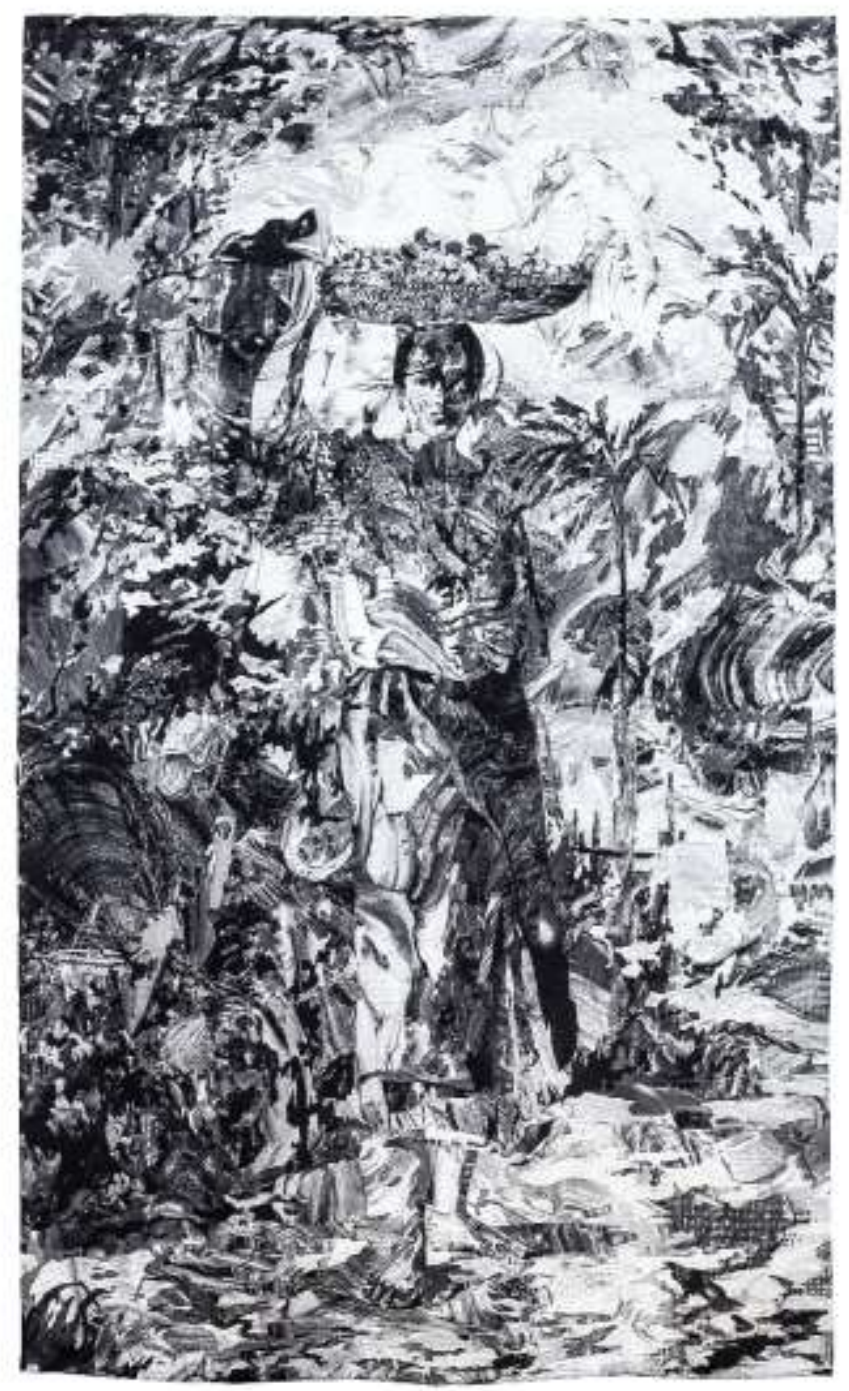

Figura 3: La Vendedora de Lanzones, 2020.

Tapiz tejido digitalmente en algodón y lana, $92.13 \mathrm{~h}$ x 54.33w 
Cuando finalmente algunos filipinos se abrieron paso a través de estos límites impuestos, nuestra participación en el comercio global se expandió hacia la educación e ideas y mis obras remiten a la traducción de esa educación e ideas. La idea del arte occidental fue traducida e introducida en la sociedad filipina y utilizada en la propaganda en contra del colonialismo. Esto es muy evidente en las obras de Juan Luna y Félix Resurrección Hidalgo, cuyos trabajos interpreté mediante el tapiz.

En la propuesta estética de las seis piezas textiles que componen esta muestra hay un reconocimiento notable a algunos de los grandes maestros del arte filipino como Fernando Amorsolo y Félix Hidalgo y Padilla. Ellos dieron testimonios vibrantes de la vida cotidiana de las personas en su país. ¿Cuál diría que es la actual resonancia de estos maestros en los jóvenes artistas filipinos y qué la llevó a elegir sus obras como matriz para componer sus propias piezas artísticas?

Supongo que los maestros siempre serán maestros en tanto siempre se les atribuirá algo de respeto ya sea ahora o en el futuro. Elijo las obras de estos artistas porque eran un indicador de las penurias identitarias de Filipinas colonial y postcolonial. Las obras de Hidalgo y Amorsolo sugieren un esfuerzo de su parte por definir una identidad e idilio filipinos. Me resulta irónico que sus ideas sobre esas cosas son retratos de mujeres filipinas, que las Filipinas, la nación, el ideal sea una mujer. También que su trabajo sea ampliamente elogiado porque ellos eran hombres. Ninguna de las mujeres pintoras filipinas durante este período alcanzó la fama de esos artistas masculinos. Esta es una de las cuestiones cruciales que me llevaron a explorar el trabajo con las obras de estos maestros.

Sus trabajos ya han pasado por varias instancias de exhibición y reconocimiento a nivel nacional e internacional. ¿Cómo describe el estado actual del arte contemporáneo filipino y cuál es su proyección internacional? ¿Hay un modo específico por el cual el arte filipino reclama su propia singularidad en un mundo cada vez más globalizado?

Pienso que ha habido muchos preconceptos que han distorsionado como otros perciben el arte filipino, o a las Filipinas. Somo un "otro" a pesar del reconocimiento internacional. Por una parte, vivimos junto al océano pacífico y se espera que como asiáticos mostremos cierta forma de exotismo. Por otra parte, las Filipinas han tenido una historia colonial tan agitada que nuestra propia cultura evolucionó con esa historia. Es por esto que nuestra educación se orienta hacia los sistemas educativos de los Estados Unidos. 
Asimismo, somos la única nación predominantemente católica en Asia y en ese sentido somos más parecidos a países en América Central y del Sur. Pero claramente también somo indo-malayos con nuestra propia cultura diferente y firmemente arraigada.

Últimamente, la mayoría de las personas ve a las Filipinas como una fuente primaria de mano obra de servicios, y esto agrega otra capa a lo que las personas tienden a esperar del arte y los artistas filipinos. Pero como usted decía, las cosas están cambiando lentamente y espero que esta pausa pandémica contribuya a mejores cambios en los términos por los cuales las personas se vinculan con el arte de los "otros". 
RESEÑAS 
Gasquet, Axel and Gorica Majstorovic Ed. Cultural and Literary Dialogues Between Asia

and Latin America

CHISU TERESA KO

\section{GASQUET, AXEL AND GORICA MAJSTOROVIC ED. CULTURAL AND LITERARY DIALOGUES BETWEEN ASIA AND LATIN AMERICA}

Palgrave Macmillan, 2021. 274 pp.

\section{Chisu Teresa Ko}

Ursinus College

The edited volume Cultural and Literary Dialogues Between Asia and Latin America edited by Axel Gasquet and Gorica Majstorovic is an important addition to the growing fields of Asian Latin American and Transpacific Studies. While the connections between these regions have been understudied, their historical contacts run deep. In their informative and succinct introduction, Gasquet and Majstorovic frame these contacts within the broader context of the "first globalization on a planetary scale and the first prefiguration of the subsequent modernity" that initiated "prolonged intra-colonial connections between Asia, America, and Europe." The volume attempts to reflect the vast historical, geographic, and cultural diversity encompassed within these regions and their histories of contact. The contributions are from scholars based in Asia, Europe, the United States, and Chile and address an impressive range of gazes, exchanges, expressions, movements, historical periods, and geographic regions, from Hispanic-Filipino intellectual Trinidad Hermenegildo Pardo de Tavera's travel writings about Argentina in the early twentieth century to contemporary literature on hybrid Asian and Latin America identities, the reception of Chilean literature in twentieth-century South Korea and diasporic Nikkei experiences in the Americas, among others. The volume, published in English, is divided into four parts each consisting of three or four chapters.

The three chapters included in the first section titled "Asian Hybrid Identities and Latin American Transnational Narratives" analyze the works of contemporary Latin American writers who explore, through fiction and nonfiction, complex hybrid identities: Chinese and Argentine in Federico Jeanmarie's Tacos altos (2016); Chilean and Palestinian in Lina Meruane's Volverse palestina; Mexican, Syrian, and Lebanese in Memoria de Libano (2003) by Carlos Martínez Assad and Casa Damasco (2013) by Maura Soto Antaki. The contributors-María Montt Strabucchi, Lila McDowell Carlsen, and Verónica Torres - trace perceptively how these complex hybrid identities and expressions are shaped by physical and cultural transnational comings and goings. Torres's assertion that Memoria de Líbano and Casa Damasco "showcase a different conception of Mexican identity" or Montt Strabucchi's observation that Tacos 
Gasquet, Axel and Gorica Majstorovic Ed. Cultural and Literary Dialogues Between Asia

and Latin America

CHISU TERESA KO

altos "interrupts discourses of homogeneity in Latin America" hold true for the other works examined in this section, all of which push the boundaries of national, diasporic, and individual identities through transnational experiences and imaginaries.

Part II, "Reception and Translations of Latin American Writers in Asia," offers important critical contributions and innovative persepctives. Ignacio M. Sánchez Prado focuses on the essay-memoir La casa del dolor ajeno (2015) by Mexican writer Julián Herbert to address the historical "erasure of Asia" that correlates to the structures of Mexican capitalism and Hong Kong director Wong Kar-Wai's film Happy Together (1997) to consider the "joint historical experience of the neoliberal condition" that Asia and Latin America share. Sánchez Prado proposes that in order to avoid practices of continued historical erasure, scholarship on Asia-Latin America should revise theoretical tools such as Orientalism "to break them away from their grounding in the epistemological practices of the European imperial enterprise" and to examine, instead, direct contacts and mutual readings between the peripheries.

Woo Suk-kyun's enlightening chapter on the reception of Latin American literature in twentieth century South Korea does just that. Woo traces in fascinating detail the historical, ideological, intellectual, and commercial contexts in South Korea and beyond that led to the dissemination of contemporary Latin American literature in South Korea, and in particular, the popularity of literary works that portray the Chilean coup. While the unique importance of the Chilean coup in the South Korean cultural imaginary can be explained by parallel late-twentieth century histories of military regimes, coups, and massacres, Woo traces a complex web of genealogies of intellectual influences and literary translations. These include the first translations of Pablo Neruda's poems in the 1960s and 70s, translations of books on liberation theology and dependency theory in the 1970s, and the emergence of antiAmericanism and Third World consciousness. Puo-An Wu Fu concludes this section with a chapter on the novel Mongolia (2015) by Peruvian Tusán writer Julia Wong and the short story "El testigo chino" by Anna Kazumi Stahl, a Japanese American author who writes mostly in Spanish and has resided in Argentina for almost three decades. The chapter examines the literary strategies of the two works-focused on cultural and linguistic translations and "real-life bilinguaging"- that help construct "a readable world."

The chapters in Part III entitled "Diffraction Worlds of Nikkei Identities" reveal the heterogeneity of Asian experiences and identities as well as the cultural imaginary produced around them. Sigeko Mato analyzes Peruvian author of Japanese descent Carlos Yuhsimito del Valle's short story "Ciudad de Cristal" about a Japanese Peruvian boy in an internment camp in Texas. Seth Jacobowitz examines the crisis and eventual emergence of a "new diasporic consciousness" within the Japanese communities in Brazil during World War II. The chapter 
Gasquet, Axel and Gorica Majstorovic Ed. Cultural and Literary Dialogues Between Asia

and Latin America

CHISU TERESA KO

brings into light the short story "Revenge" by Japanese immigrant writer Sugi Takeo which, according to Jacobowitz, has remained in "near-total obscurity." This story, published in 1938 in a Japanese-language literary journal based in Sao Paolo, is put in conversation with contemporary Brazilian film Dirty Hearts (2011). Ignacio López-Calvo examines the "monstrifying" of Japanese immigrants in Peru in Jorge Salazar's novel La medianoche del japonés (1991) and of Chinese Mexicans in Juan José Rodríguez's Asesinato en una lavandería china (1996). By reading these novels together, this chapter highlights not only the differing historical circumstances and experiences of Japanese and Chinese immigrants in Latin America but also the entanglements of Sinophobia, Nipponophobia, and the "national (mestizo) projects."

The first two chapters of Part IV, "Crossroads of Asia-Latin American Narratives and Travel Writing," focus on the connections between the Philippines and Latin America. Jorge Mojarro compares José Rizal's canonical novel Noli me tangere (1887) to key Latin American foundational fictions. Axel Gasquet's chapter illuminates readers on one among "very rare" travelogues of Latin America by Filipino intellectuals. This chapter focuses on Trinidad Hermenegildo Pardo de Tavera's "Argentine Memories," published in Spanish two years after his visit to Argentina in 1914. Gasquet shows how Pardo de Tavera's observations-on Argentina's social life, political and social structures, and predictions about the future-were informed by his status from a distinguished Hispanic-Filipino family, an acritical vision of Argentina's "path to modernity," as well as other testimonials about Argentina's 1910 centennial celebration that focused on this nation's liberal "successes."

This section also includes Everton V. Machado's chapter on Brazilian poet Cecília Meireles's testimony to her visit to India in 1953 and Estefanía Bournot's examination of Colombian writer Hector Abad Faciolince's Oriente empiza en el Cairo (2001) and Brazilian Bernardo Carvalho's Mongolia (2003). These last two chapters return to the question of the possibility of a south-south epistemology raised throughout the volume. Bournot detects in Abad and Carvalho's contemporary novels the persistence of colonial and Orientalist images of the East as a "static object, deprived of subjectivity and declared incapable of possessing any prospective or retrospective dimensions." By contrast, for Machado, even if Meireles's south-south dialogue was inscribed within the European Orientalist tradition and was limited by a unilateral direction from West to East, the poet's attempts to connect the peripheries and integrate "the voice of the Other" should not be overlooked.

As titles rarely do, some of the titles of the four sections do not entirely reflect the contents of their chapters. But rather than a shortcoming, this only underscores the breadth, scale, and reach of this volume that includes scholarship of multiple and layered interests, subjects, and perspectives that cannot be reduced to a title or deservedly summarized in a brief book review. 


\section{ÓSCAR HAHN. IMÁGENES NUCLEARES Y OTROS POEMAS}

Cartonera del Escorpión Azul, 2021. 47 pp.

\section{Rebeca Higuera Vidal}

Universidad Autónoma de Madrid.

rebeca.higuera@uam.es

La radioactividad causada por el armamento nuclear tarda unos veinte mil años en desaparecer, aproximadamente. Por este motivo, el bombardeo de las ciudades de Hiroshima y Nagasaki en 1945, durante la Segunda Guerra Mundial, se considera una de las mayores tragedias que han tenido lugar en la historia moderna. Los acontecimientos se encuentran documentados en muchas fotografías, vídeos y testimonios. Además, el sufrimiento de los supervivientes y las consecuencias medioambientales las tenemos ante nuestros propios ojos. Pero, a pesar de todo, parece que la humanidad no ha aprendido nada, y se dirige irremediablemente hacia su extinción a causa de la fisión del átomo de uranio.

Muchos artistas latinoamericanos han reflexionado en su obra sobre lo ocurrido en Japón y las posibles implicaciones que puede tener para el futuro. Entre ellos, despunta el chileno Óscar Hahn (1938), quien ha trabajado la literatura hispanoamericana desde distintas perspectivas: como profesor en la Universidad de Iowa durante más de treinta años; como ensayista y crítico, cuya labor se encuentra recogida en distintos libros, véase Vicente Huidobro o el atentado celeste (1998), Magias de la escritura (2001) o Palabras sin fronteras (2018); y, sobre todo, como poeta. Hahn ha sido distinguido con varios laureles a lo largo de toda su trayectoria, por ejemplo, con el Premio Casa de América de Poesía por En un abrir y cerrar de ojos en el 2006, con el Premio Nacional de Literatura en Chile en el 2012 o con el XXVII Premio Loewe en el 2014 por Los espejos comunicantes, entre otros galardones. La amenaza nuclear es una constante en toda su obra, desde que apareció entre sus primeras composiciones de Esta rosa negra (1961), hace ya sesenta años. Y con el paso del tiempo, se ha convertido en una de sus mayores obsesiones.

Imágenes nucleares y otros poemas (2021) recoge algunas de las creaciones de Hahn dedicadas a la guerra, al armamento nuclear y a sus secuelas para el planeta y para la civilización. Esta edición de Cartonera del Escorpión Azul otorga a sus poemas un soporte en consonancia con el mensaje de sus versos, cuidando todos los detalles. Por un lado, los libros son fabricados a mano y con materiales reciclados, lo que hace cada ejemplar único. Además, los poemas están acompañados por las ilustraciones de Manolo Mareos; y, por otro lado, la selección y la introducción están a cargo de Sergio Laignelet. Gracias a su trabajo, 
el volumen le permite al lector transitar por toda la obra de Hahn. En primer lugar, se encuentran los poemas reunidos con el título de «Imágenes nucleares», que corresponden a sus comienzos poéticos. Estas composiciones pueden leerse de manera independiente o como un poema extenso, cuya disposición por números de tres cifras describe los horrores vividos en Hiroshima («444. Visión de Hiroshima») y Nagasaki («555. El muerto en Nagasaki») como un descenso a los infiernos, provocado por el apocalipsis nuclear, que finaliza en una indolente partida de azar entre los dioses («666. Reencarnación de los carniceros»). Y después se halla la sección «Otros poemas», formada por las composiciones seleccionadas entre los libros más recientes de Hahn, como Pena de vida del 2008 («Mar y cielo» o «Retrato de una Familia Iraquí»), La primera oscuridad del 2011 («El incendio» $\mathrm{O}$ «Revelación») o el ya mencionado Los espejos comunicantes («Vals de Santiago» o «Guerra sucia»). El volumen incluye también un poema inédito, cedido por el autor para esta edición («Canción del sin con qué»), y un autógrafo de Hahn («En la tumba del soldado desconocido»).

Cartonera del Escorpión Azul acerca así a España a uno de los poetas más importantes del panorama iberoamericano actual. Su iniciativa cuenta con otros títulos, como Voces de un cuerpo de Giovanni Collazos (con nota de Cristina Elena Pardo y fotografías de Jorge Coco Serrano), y los más recientemente publicados: Din don y más hortensias azuis de Luz Pichel (ilustrado por Anxo Pastor) y 999 palabras de Víktor Gómez (con nota de Lola Andrés y Benito del Pliego e ilustraciones de Enrique Cabezón).

La guerra es un tema de la literatura universal. Todas las culturas poseen un modelo que forma parte de su tradición. En Occidente, por ejemplo, la poesía épica mitifica conflictos bélicos, a grandes rasgos, desde La Ilíada, donde las deidades desencadenan un conflicto gracias al que sus protagonistas se convierten en héroes conocidos hasta la actualidad. Para Hahn, las deidades juegan cruelmente con el destino, al margen de los acontecimientos: «Y vi los carniceros al tercer día; / rojos como una sangre avergonzada, / jugaban con siete dados hechos de fuego, / pétreos como los dientes del silencio» (p. 15); y la guerra nunca es una hazaña que concede la inmortalidad, sino todo lo contrario. Sus poemas están poblados por los fantasmas de las víctimas, obligados a vagar entre escombros. Aunque la tragedia sea colectiva, la muerte es una experiencia individual: «Cada una de las víctimas / que se desintegraron en Hiroshima / murió su propia muerte» (p. 28). Nunca se desvelan nombres propios y su recuerdo se pierde, al igual que sus objetos personales: «Todos ellos sonriendo/ desde una foto a medio chamuscar / hallada entre los escombros / de su casa / después del bombardeo» (p. 27).

La búsqueda de saber y trascendencia es inherente también al ser humano. Las buenas intenciones y los descubrimientos científicos pueden acabar malográndose por su propia naturaleza. Así ocurre con la energía nuclear, esa piedra filosofal moderna, que una vez encontrada en el cráneo trepanado de su 
creador, muestra grandes propiedades benéficas, pero también revela su inmenso peligro contaminante, impidiendo la vida: «transmuta el plomo en oro y los metales / preciosos en uranio radiactivo / Lo que viene después es la diabólica / reacción en cadena de sus átomos / Ya desató el infierno de Hiroshima / ya arrasó la ciudad de Nagasaki / si se activa otra vez devastará / al fuego al agua al aire y a la tierra» (p. 39).

Una vez los humanos se hayan extinguido, quizá nazca una nueva civilización, marcada en su cuerpo por la radiactividad. Sus antepasados, entre los que se identifica Hahn, son los profetas de un nuevo Ares: «Los mutantes me mirarán con asombro / y entrarán de nuevo en la caverna / para adorar la imagen de su dios / que es un hongo atómico (p. 35). Y la naturaleza también renacerá. La falta de luz solar provocará que las plantas hagan cálculos matemáticos, resuelvan teoremas e invadan las ciudades, acabando con los mutantes: «Si los despojos de los dormidos /pudieran pensar / sabrían que fueron devorados / por manadas de plantas inteligentes» (p. 32).

En conclusión, la cuidada edición de Imágenes nucleares y otros poemas que publica Cartonera del Escorpión Azul potencia el mensaje ético de los versos de Óscar Hahn ofrece un recorrido por toda la obra del poeta chileno y alberga en sus páginas una de las miradas más lúcidas que puedan encontrarse en la poesía hispanoamericana actual. Al pronunciarse sobre la guerra y lo nuclear y al imaginar ese nuevo mundo poblado por mutantes, Hahn anticipa las probables consecuencias de la radiactividad a la vez que consigue dar una voz sumamente original a sus víctimas. 
Mato, Shigeko. Las voces que entrecruqan el Perú y Japón.

Alba de Diego Pérez DE LA TORRE

\title{
MATO, SHIGEKO. LAS VOCES QUE ENTRECRUZAN EL PERÚ Y JAPÓN.
}

Murrup Ediciones, 2021. 105 pp.

\author{
Alba de Diego Pérez de la Torre \\ Universidad de Waseda
}

La literatura no es solo uno de los caudales del arte, también es esbozo de la identidad y la memoria del ser humano y reflejo de los devenires culturales que marcan la historia de los diferentes países del mundo. A principios del siglo veinte sucesivas oleadas de migrantes japoneses viajaron a varios países de América Latina en busca de un futuro mejor. Años después, en la década de los noventa, los descendientes de los primeros migrantes recorrían la ruta inversa movidos, de nuevo, por un mismo sueño de prosperidad. Hoy, este cruce de destinos, de experiencias, de vidas, ha acabado por cristalizar en un fenómeno de estudio reciente que se puede definir como literatura nikkei o, en otras palabras, el compendio de testimonios literarios que son herederos de una historia de intercambio cultural entre Japón y Perú que comenzó hace casi un siglo atrás.

He utilizado este preámbulo con objeto de resaltar dos rasgos del libro de Shigeko Mato que lo convierten precisamente en una referencia fundamental para entender la complejidad que entraña la literatura nikekei. Así, si en el párrafo que abre esta reseña se hablaba de esa vertiente testimonial que existe en la literatura, en el libro que nos ocupa predomina un enfoque multidisciplinar que incluye reflexiones relacionadas con la antropología, la filosofía o la historia. De esta suerte, el análisis literario que nos ofrece Mato adquiere una nueva profundidad que nos plantea, a su vez, cuestiones muy interesantes sobre la esencia del ser humano, su identidad y sus recuerdos. Por otro lado, en lo que concierne a la explicación de la literatura nikkei como fenómeno literario, habría que destacar, además de una cuidada labor de documentación por parte de la autora, la selección de los contenidos tratados, que consiguen transmitir al lector un esbozo clarividente de la esencia de este movimiento.

Las voces que entrecruzan el Perú y Japón empieza con una sección introductoria en la que Mato expone las dificultades de definición que implica el término de literatura nikekei (que, por cierto, también ha inspirado otras de sus investigaciones) y comparte el proceso creativo e investigador que ha ido dando forma al volumen. Considero que la elección del título, Las voces que entrecruzan el Perú y Japón, constituye todo un acierto, ya que muestra en efecto esta naturaleza migrante que caracteriza a la literatura nikekei, pero también se halla en perfecta 
consonancia con los contenidos de su libro, que se articula en un análisis polifónico de cuatro obras muy diferentes entre sí.

En el primer capítulo se analiza Chambala era un camino de la poeta peruano-okinawense Doris Moromisato, que medita acerca de la niñez, la identidad y la familia. Mato en concreto se va a centrar en la noción de la "memoria migratoria", que aparece ya apuntada en el título del poemario, pues Chambala es el nombre de la localidad (hoy integrada en el complejo urbanístico de Lima) en el que nació la escritora. Tomando, por lo tanto, a Chambala como punto de partida se inicia una suerte de "viaje a través de la escritura", en el que, según nos explica Mato, la búsqueda de identidad se realiza por medio de la interconexión de distintos tiempos: el de los padres, que abandonan Okinawa en pos de nuevas oportunidades, el de la infancia de la propia Doris Moromisato en Perú, y, por último, el de la hermana, que regresa a Japón con objeto de proporcionar un futuro mejor a su hijo en Perú.

En la segunda sección se trata la novela Merameyo to ningyo wa utau (traducida por Mato como Despiértate, canta la sirena) del autor japonés Tomoyuki Hoshino. De acuerdo con la investigadora, el estudio de esta obra, que además fue galardonada en Japón, resulta especialmente valioso, ya que aborda el tema de los descendientes de japoneses en Perú desde la perspectiva japonesa. Asimismo, se pone de relieve un término, la "multiplicidad de la identidad", que se halla en consonancia con la heterogeneidad cultural que caracteriza a las distintas sociedades de hoy. De hecho, es muy significativo que el protagonista de la novela, que se ha criado en Japón, rechace de forma tajante sus orígenes peruanos y que solo cuando acaba reconciliándose con los diversos planos que comprende su identidad, puede realmente enfrentarse a los dilemas y obstáculos que le depara el porvenir.

El siguiente capítulo está dedicado al relato "Lolo" de Luis Fernando Arriola Ayala. De nuevo la elección tanto de la obra como del autor añade otra pincelada distintiva al entramado de voces y testimonios que engloba la literatura nikekei, ya que desvela una práctica sorprendente que se dio sobre todo en Perú durante la contratación masiva de descendientes de japoneses para que trabajaran en Japón: la venta de apellidos y la circulación de pasaportes falsificados. Mato observa que el propio Arriola Ayala logró entrar en Japón sirviéndose de uno de estos pasaportes para trabajar como obrero en una fábrica. Esta experiencia va a acabar cristalizando en su trayectoria literaria, y concretamente en el cuento "Lolo", protagonizado por un joven inmigrante peruano y por otro filipino de avanzada edad (de ahí el título, ya que lolo significa "abuelo" en chabacano), que están empleados en una planta incineradora de basuras. En contraste con las obras anteriores, se incide aquí en un concepto de naturaleza menos amable: la repugnancia que inspira el extranjero indocumentado, ligada a su vez a problemas como el acoso laboral, la subcontratación de mano de obra barata y la explotación. 
Mato, Shigeko. Las voces que entrecruzan el Perúy Japón. Alba de Diego Pérez de LA Torre

El libro se cierra con el relato "El japonés Fukuhara" del escritor peruano Selenco Vega Jácome, que se puede considerar el reflejo inverso al poemario de Doris Moromisato analizado en el primer capítulo. En efecto, vuelven a tratarse temas como la infancia, la familia...es decir, el bagaje de recuerdos que acompaña a todo ser humano, sin embargo, Mato añade ahora un nuevo matiz que contribuye a alterar levemente su significado: "memoria silenciada". A medida que se profundiza en la lectura del capítulo se comprende que este tipo de memoria operaría a un doble nivel. Por un lado, en lo que respecta al plano individual, haría alusión a los recuerdos traumáticos; y, por otro, en lo que concierne al plano colectivo o social, se vincularía con la represión política (en este caso, con la que tuvo lugar durante el mandato del presidente Alberto Fujimori). Nos hallaríamos ante una nueva dimensión de lo nikkeei que sirve para revisar además ciertos acontecimientos políticos que han condicionado la historia de Perú en los últimos años.

Considero que las cuatro obras que vertebran Las voces que entrecruzan el Perú y Japón están muy bien escogidas, ya que constituyen las coordenadas que nos permiten percibir la complejidad, y también la riqueza, que engloba la literatura nikkei, la cual daría cabida a distintos perfiles de autores y también a diversas cuestiones como la memoria migratoria, la multiplicidad de la identidad, la repugnancia o el rechazo en las distintas sociedades de acogida, las fricciones entre distintos grupos culturales... El estudio de Mato nos proporciona, por lo tanto, una interesante materia de reflexión no solo sobre literatura (en particular sobre un movimiento que puede adquirir especial notoriedad en los próximos años), sino también sobre muchas de las preguntas que se plantean las sociedades actuales acerca de la identidad, la memoria o incluso, la inmigración. Al fin y al cabo, no hay que olvidar que la literatura es, igual que se afirmaba al comienzo de esta reseña, el conjunto de testimonios o "voces" que dan coherencia y sentido a nuestra propia historia. 

